Pacific Northwest National Laboratory

Operated by Battelle for the

U.S. Department of Energy

Under Contract DE-AC-05-76RLO-1830
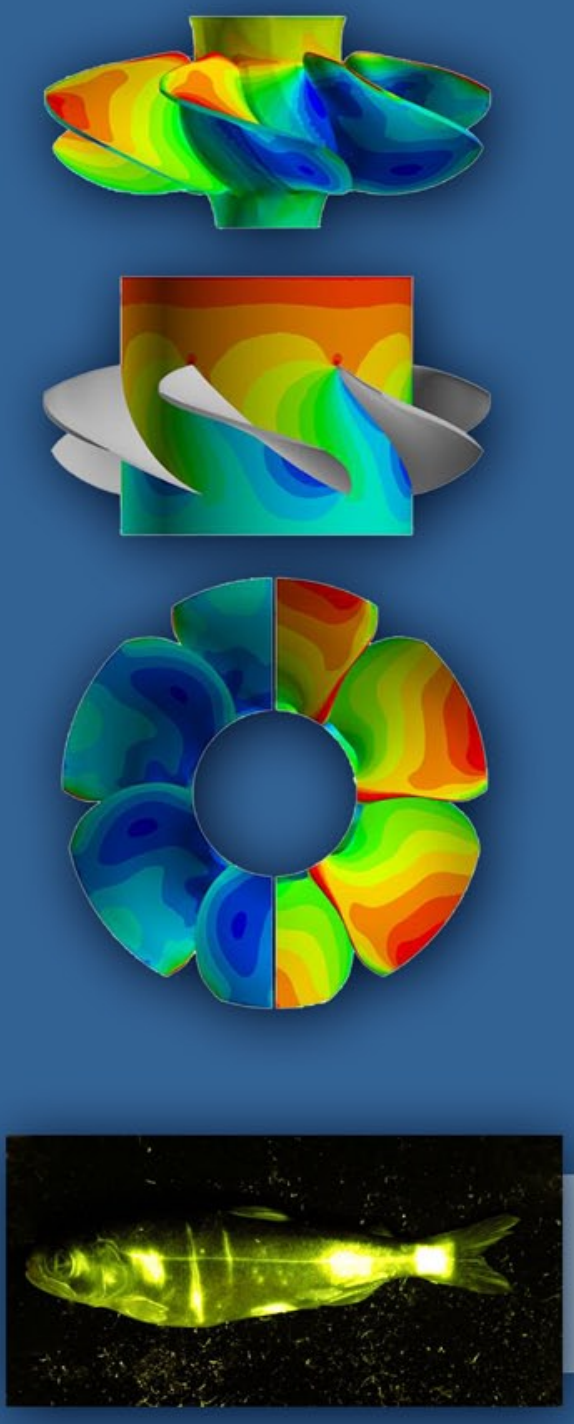

\section{Biological Assessment of the Advanced Turbine Design at Wanapum Dam, 2005}

\author{
DD Dauble \\ ZD Deng \\ MC Richmond \\ RA Moursund \\ TJ Carlson \\ CL Rakowski \\ JP Duncan
}

Final Report

August 2007

\section{U.S, Deparsinsent of Energy \\ Esjergy Efficjency and Renewable Energy}

Wind and Hydropower Technologies

Bringing you a prosperous future where energy is clean, abundant, reliable, and affordable 


\title{
DISCLAIMER
}

This report was prepared as an account of work sponsored by an agency of the United States Government. Neither the United States Government nor any agency thereof, nor Battelle Memorial Institute, nor any of their employees, makes any warranty, express or implied, or assumes any legal liability or responsibility for the accuracy, completeness, or usefulness of any information, apparatus, product, or process disclosed, or represents that its use would not infringe privately owned rights. Reference herein to any specific commercial product, process, or service by trade name, trademark, manufacturer, or otherwise does not necessarily constitute or imply its endorsement, recommendation, or favoring by the United States Government or any agency thereof, or Battelle Memorial Institute. The views and opinions of authors expressed herein do not necessarily state or reflect those of the United States Government or any agency thereof.

\author{
PACIFIC NORTHWEST NATIONAL LABORATORY \\ operated by \\ BATTELLE \\ for the \\ UNITED STATES DEPARTMENT OF ENERGY \\ under Contract DE-AC05-76RL01830
}

Printed in the United States of America

\author{
Available to DOE and DOE contactors from the \\ Office of Scientific and Technical Information, \\ P.O. Box 62, Oak Ridge, TN 37831-0062; \\ ph: (865) 576-8401 \\ fax: (865) 576-5728 \\ email: reports@adonis.osti.gov
}

\begin{abstract}
Available to the public from the National Technical Information Service, U.S. Department of Commerce, 5285 Port Royal Rd., Springfield, VA 22161 ph: (800) 553-6847 fax: (703) 605-6900 email: orders@ntis.fedworld.gov online ordering: http://www.ntis.gov/ordering.htm
\end{abstract}




\title{
Biological Assessment of the Advanced Turbine Design at Wanapum Dam, 2005
}

\author{
D.D. Dauble \\ Z. Deng \\ M.C. Richmond \\ R.A. Moursund \\ T.J. Carlson \\ C.L. Rakowski \\ J.P. Duncan
}

Final Report

August 2007

Prepared for the U.S. Department of Energy

Office of Energy Efficiency and Renewable Energy

Wind and Hydropower Technologies

Under Contract DE-AC05-76RL01830

Pacific Northwest National Laboratory

Richland, Washington 99352 



\section{Executive Summary}

This report summarizes the results of studies sponsored by the U.S. Department of Energy and conducted by Pacific Northwest National Laboratory (PNNL) to evaluate the biological performance of an advanced design turbine installed at Unit 8 of Wanapum Dam on the Columbia River in 2005. In all studies, paired comparisons were made between Unit 8 and a conventional Kaplan turbine, Unit 9. PNNL studies included an evaluation of blade-strike using deterministic and probabilistic models, integrated analysis of the response of the Sensor Fish to severe hydraulic events within the turbine system, and a novel dye technique to measure injury to juvenile salmonids in the field.

The first study involved applying deterministic and stochastic blade-strike models to the advanced and existing turbine designs. Modeled probabilities were compared to results of Sensor Fish releases and injury/mortality of balloon-tagged fish under the same operational parameters. The new advanced design turbine had slightly higher modeled injury rates than the existing turbine design; however, there was no statistical evidence that suggested significant differences in blade-strike probabilities. Overall, injury rates predicted by the deterministic model were higher than experimental rates of injury while those predicted by the stochastic model were in close agreement. Fish orientation at the time of entry into the plane of the leading edges of the turbine runner blades is an important factor contributing to uncertainty in modeled results.

A second study focused on expanded analysis of Sensor Fish data through the use of computational fluid dynamics (CFD) simulations and other analytical techniques. The Sensor Fish data was collected in conjunction with balloon tag tests involving juvenile Chinook salmon. Sensor Fish pressure and acceleration measurements were analyzed to identify characteristic signatures in each passage time history. These signatures were used, together with CFD and streamline plots, to identify the frequency and location of significant acceleration events such as collisions and shear. The Sensor Fish data were divided into four regions for each release condition (i.e., turbine, discharge, release pipe depth, and intake bay). Events were classified as either collision or shear and by severity level. The majority (80\%) of severe acceleration events were due to collision. When all four regions were pooled, the two turbine units had similar probability of severe collisions (i.e., 20\%). Unit 8 (advanced turbine) had fewer severe shear events $(1.1 \%)$ than unit $9(3.4 \%)$, but Unit 8 had more slight shear events $(29.3 \%)$ than Unit $9(19.7 \%)$. Although mean pressure nadirs recorded by Sensor Fish were consistently higher for Unit 8, values were highly variable. Thus, there was no overall evidence of correlation with Sensor Fish collision events and measured pressure nadir. The overall predicted shear injury rates were 3.1\% for Unit 8 and $4.4 \%$ for Unit 9. This compared to observed injury rates of $1.1 \%$ and $0.9 \%$ for Units 8 and 9 , respectively, determined using balloon tags. Most predicted shear injury occurred in the stay-vane/wicket gate and runner regions with 30 -ft releases showing higher rates.

A third study involved a dye technique developed to determine external fish injuries difficult to detect visually. Juvenile Chinook salmon were balloon-tagged and released through the advanced design and existing turbines during paired tests. Upon recapture, they were coated with a fluorescein dye and exposed to ultraviolet light, which helped to make the scrapes, cuts, descaling, and other injuries visible. The dye-exposed juvenile salmon were photographed and the images were analyzed by a computer 
software program to assess if statistical differences in injury could be correlated to turbine type and operating condition. The advanced turbine (Unit 8) yielded different results than the conventional turbine (Unit 9) in only four instances: lower incidence of eye, dorsal fin, anal fin, and dispersed ventral damage at $15 \mathrm{kcfs}$. For other injury categories, there was no significant difference between the two types of turbines. Based on these data, we focused on head region injuries due to the potential to affect fish survival. The most pronounced difference between turbine types was eye injury. Eye damage occurred in nearly $30 \%$ of fish passing Unit 9 , but $<10 \%$ of those passing through Unit 8 at $15 \mathrm{kcfs}$. Eye injury was $<5 \%$ for test fish passing either unit at $17 \mathrm{kcfs}$.

Collectively, our studies indicated the advanced turbine design met desired fish passage design goals for Wanapum Dam. There was a lower predicted rate of shear injury in Unit 8 compared to Unit 9. Both rates of pressure changes and minimum pressure as measured by the Sensor Fish were also less severe in Unit 8. The addition of more wicket gates to Unit 8 (i.e., 32 compared to 20 for Unit 9) and changes to their geometry and alignment had mixed results. For example, this design creates a greater opportunity for collision and an increase in slight shear in the wakes of the gates. Although Unit 8 had a 6-blade runner, the rate of severe collisions was half that of the 5-blade turbine in Unit 9. No difference in shear events or collisions was found following modifications to the draft tube in Unit 8. Results of our field tests and mathematical models were in close agreement with injury/mortality studies conducted with balloontagged fish. 


\section{Acknowledgments}

This project was supported by the U.S. Department of Energy's Office of Energy Efficiency and Renewable Energy Wind and Hydropower Technologies Program. Jim Ahlgrimm was the contracting office technical representative. The authors wish to thank the Public Utility District No. 2 of Grant County for assisting with this research effort.

We would like to thank the following PNNL staff:

- Matthew Bleich for technical assistance with dye injury studies

- John Serkowski for graphical support to CFD modeling

- Craig McKinstry for statistical analysis

- Bill Perkins for technical assistance with integrated Sensor Fish analysis

- Terri Gilbride for editorial assistance.

The project also would like to thank the following:

- Richard Fisher and Michael Graf, Voith-Siemens Hydropower, for providing data on advanced turbine modeling.

- John Skalski and Rich Townsend, University of Washington, for data analysis in support of Sensor Fish studies.

- Normandeau Associates, Inc., for field support. 
Biological Assessment of the Advanced Turbine Design at Wanapum Dam, 2005 


\section{Abbreviations and Acronyms}

\begin{tabular}{|c|c|}
\hline AHTS & advanced hydropower turbine systems \\
\hline ASI & arbitrary sliding interface \\
\hline CFD & computational fluid dynamics \\
\hline $\mathrm{cfs}$ & cubic feet per second \\
\hline DOE EE/RE & U.S. Department of Energy Office of Energy Efficiency and Renewable Energy \\
\hline ESBS & extended length submerged bar screens \\
\hline FERC & Federal Energy Regulatory Commission \\
\hline $\mathrm{hp}$ & horse power \\
\hline $\mathrm{kcfs}$ & thousand cubic feet per second \\
\hline $\mathrm{mg} / \mathrm{L}$ & milligrams per liter \\
\hline MGR & minimum gap runner \\
\hline MR & mutilation rate \\
\hline MS-222 & Tricaine Methanesulfonate \\
\hline MW & megawatt \\
\hline ORNL & Oak Ridge National Laboratory \\
\hline PNNL & Pacific Northwest National Laboratory \\
\hline PUD & public utility district \\
\hline Q & discharge \\
\hline RPM & revolutions per minute \\
\hline SV & stay vane \\
\hline USACE & U.S. Army Corps of Engineers \\
\hline WG & wicket gate \\
\hline WGA & wicket gate angle \\
\hline WGO & wicket gate opening \\
\hline
\end{tabular}


Biological Assessment of the Advanced Turbine Design at Wanapum Dam, 2005 


\section{Contents}

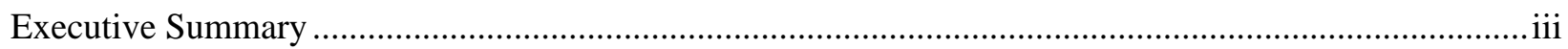

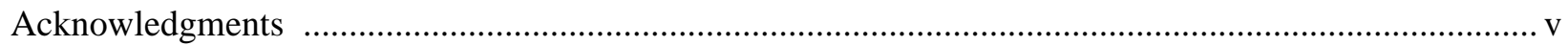

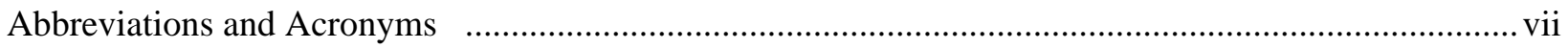

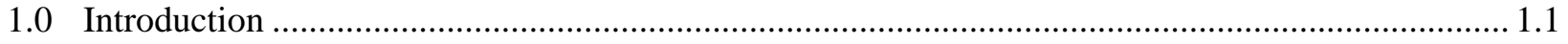

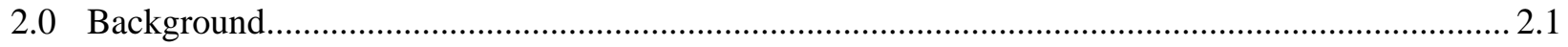

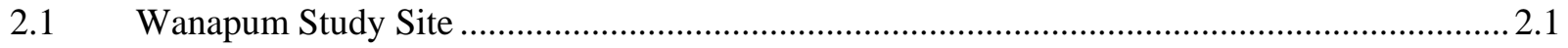

2.2 Wanapum Dam Existing and Advanced Turbine Designs ................................................... 2.2

3.0 Blade Strike Modeling for the Wanapum Original and Advanced Turbine Design Runners............ 3.1

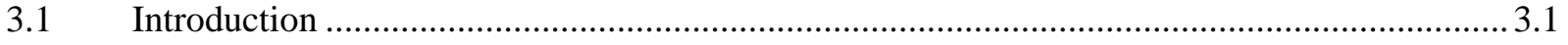

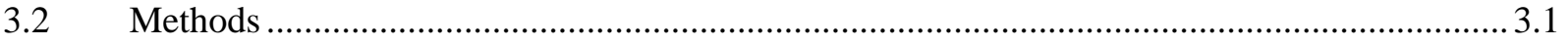

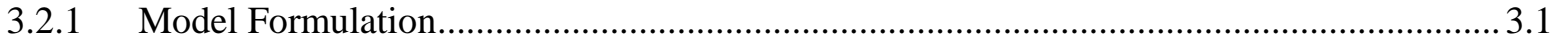

3.2.2 Application to Wanapum Dam Turbines ......................................................................... 3.3

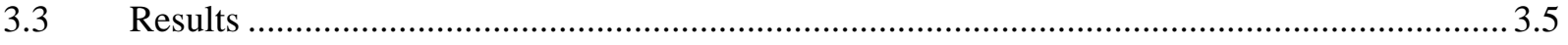

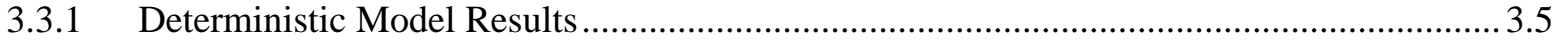

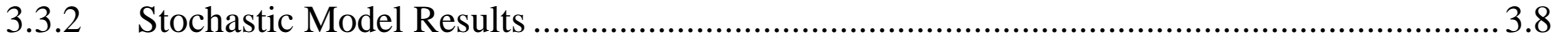

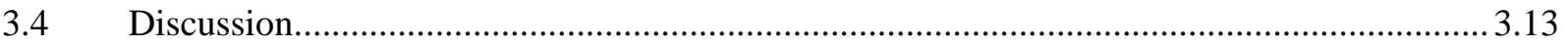

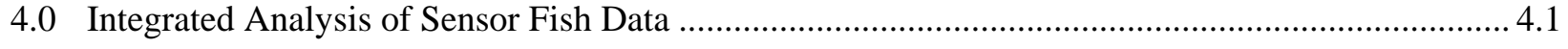

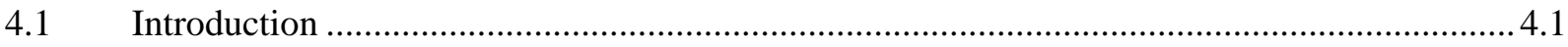

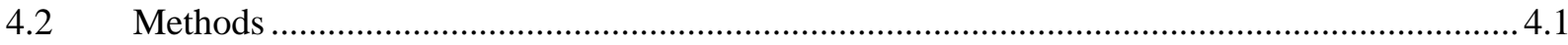

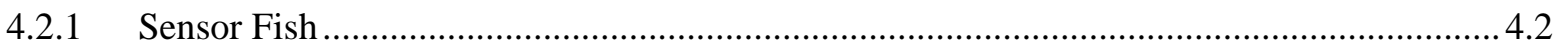

4.2.2 Computational Fluid Dynamics Modeling ....................................................................... 4.3

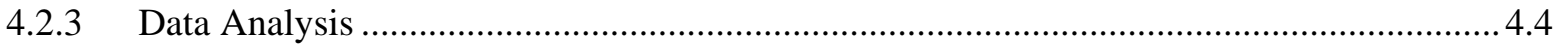

4.2.4 Shear Injury Response Relationship ................................................................................ 4.10

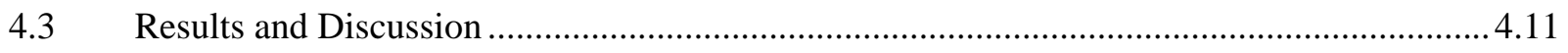

4.3.1 Sensor Fish Collision and Shear Events.....................................................................11

4.3.2 Correlation Between Sensor Fish Pressure Nadir and Collision Events .......................... 4.19

4.4 Comparison of Live Fish Survival and Sensor Fish Data.................................................. 4.21

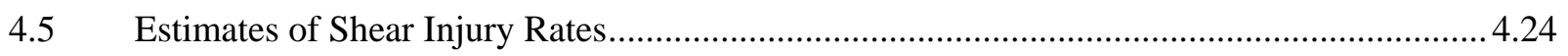

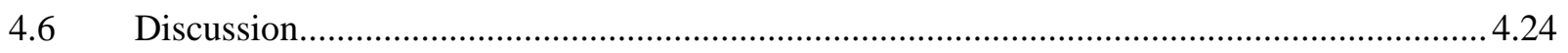

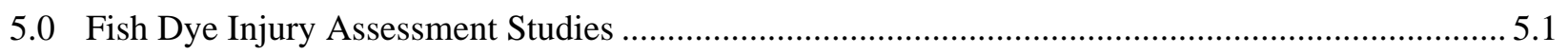

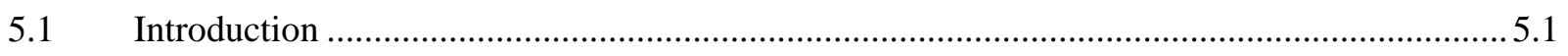

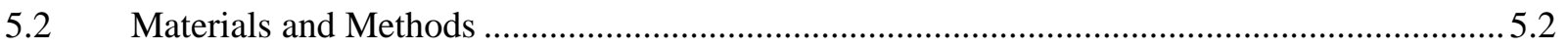

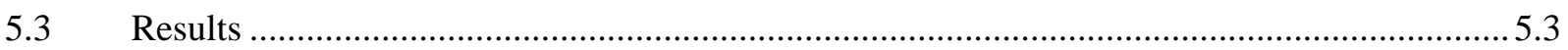




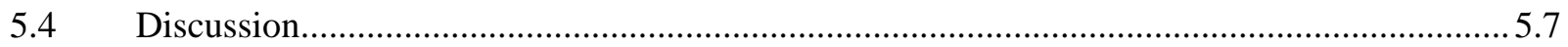

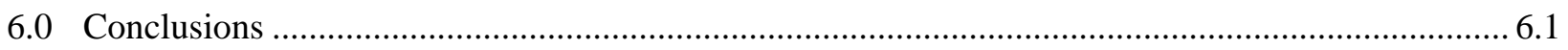

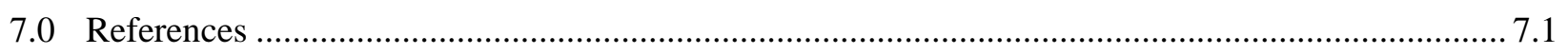

Appendix A - Tabulated Results of Sensor Fish Studies at Wanapum Dam 2005 ............................... A.1 


\section{Figures}

2.1 Location of Wanapum Dam on the Columbia River in Central Washington State .................... 2.1

$2.2 \quad$ Wanapum Dam on the Columbia River, Washington.............................................................2.2

2.3 Conventional Unit 9 showing the Stay Vanes, Wicket Gates, and Runner ................................ 2.3

2.4 Unit 9 (conventional) Stay Vanes, Wicket Gates, and Runner ................................................. 2.4

2.5 Unit 9 (conventional) Stay Vanes, Wicket Gates, and Runner ................................................ 2.4

2.6 Unit 8 (AHT) showing the Stay Vanes, Wicket Gates, and Runner .......................................... 2.5

$2.7 \quad$ Unit 8 (AHT) Runner and Spherical Hub ......................................................................... 2.5

2.8 Unit 8 (AHT) Detailed View of Hub Showing the Reduced Gap between the Runner and

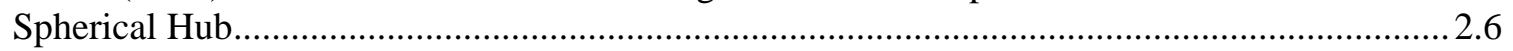

2.9 Unit 8 (AHT) Stay Vanes, Wicket Gates, and Runner .......................................................... 2.6

2.10 Unit 8 (AHT) Wicket Gate Overhang Has Been Removed .................................................... 2.7

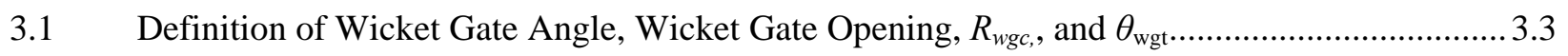

3.2 Water Velocity Vectors at the Runner Blade............................................................................ 3.3

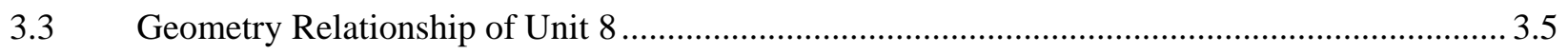

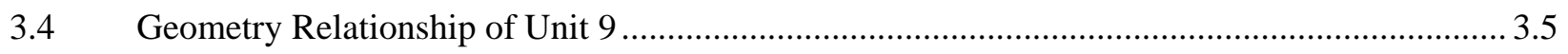

3.5 Prediction of Blade Strike by the Deterministic Model as a Function of Discharge and Comparison with Sensor Fish Results, AHTS Unit (Unit 8) ..................................................... 3.6

3.6 Prediction of Blade Strike by the Deterministic Model as a Function of Discharge and Comparison with Sensor Fish Results, Existing Unit ............................................................... 3.6

3.7 Comparison of the Predictions of Blade Strike by the Deterministic Model for Both Units ........ 3.7

3.8 Average of the Predicted Injury Rate by the Deterministic Model as a Function of Discharge and Comparison with Different Injury Types and Injury Rates for Juvenile Chinook Salmon.

3.9 Comparing Average Injury Rate Predicted by the Deterministic Model with Empirical Estimates of Visible Injury, 48-hr Mortality, Shear Injury, and Mechanical Injury

3.10 Predictions of Blade Strike by the Stochastic Model as a Function of Discharge and Comparison with Sensor Fish Results

3.11 Distribution of Assumed Relative Sensor Fish Length (left) and Standardized Regression Coefficients (right) Indicating the Sensitivity of Stochastic Blade Strike Predictions to Relative Fish Length, Discharge, and Fish-Passage Radius (R_fish)

3.12 Predictions of Blade Strike Injury Rate by the Stochastic Model as a Function of Discharge and Comparison with Different Injury Types and Injury Rates for Juvenile Chinook Salmon.

3.13 Comparing Average Injury Rate Predicted by the Stochastic Model with Empirical Estimates of Visible Injury, 48-hr Mortality, Shear, and Mechanical Injury..... 
3.14 Distribution of Assumed Relative Fish Length and Standardized Regression Coefficients....... 3.13

4.1 Location of Live Fish and Sensor Fish Release Pipes in Wanapum Turbine Intake for

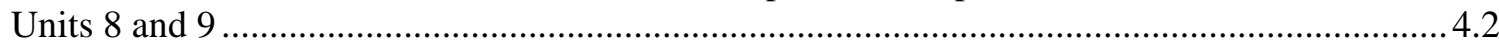

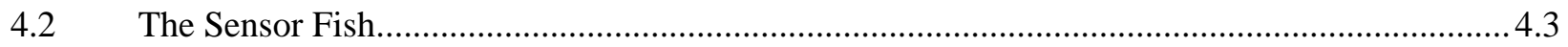

4.3 Overall Computational Domain Used for the Unit 9 (conventional) Turbine

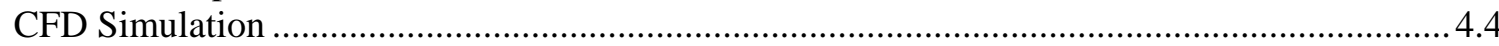

4.4 Example of Turbine Passage Measurements using the Sensor Fish ......................................... 4.5

4.5 Particle Paths in CFD Output along which Typical Pressure Change Profiles

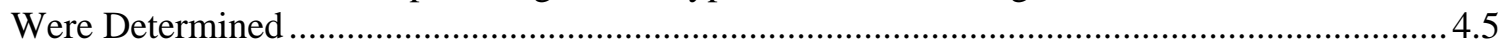

4.6 Profiles of Pressure along the Trajectories shown in Figure 4.5.............................................. 4.6

4.7 Typical Pressure Distribution Used for Estimating when the Sensor Fish

Exited the Runner Region..................................................................................................... 4.7

4.8 Side and Top Views of Turbine Intake, Scrollcase, and Draft Tube ........................................ 4.8

4.9 Duration of Acceleration within $70 \%$ of the Peak Value is (a) $<0.0075$ second for a Collision Event; (b) > 0.0075 second for a Shear Event............................................................. 4.9

4.10 Fitted Probability of Minor and Major Injuries as a Function of Sensor Fish Acceleration as Derived from Binary Logistic Regression..................................................... 4.11

4.11 Comparison of Probabilities of Collision and Shear Events for the Two Units ...................... 4.12

4.12 Comparison of Probabilities of Significant Events for the Two Units ................................... 4.13

4.13 Comparison of Probabilities of Significant Events by Different Release Pipe Elevations ........ 4.13

4.14 Comparison of Probabilities of Severe Collision or Shear Events in Different

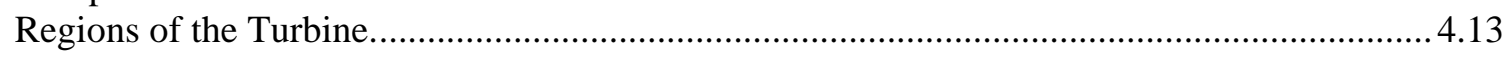

4.15 Probability of Severe Collision and Shear Events for the Wicket Gate/Stay Vane Region...... 4.14

4.16 Probability of Severe Collision and Shear Events for the Runner Region............................... 4.14

4.17 Probability of Severe Collision and Shear Events for the Draft Tube Region........................ 4.15

4.18 Probability of Severe Collision and Shear Events for all Regions and Intake

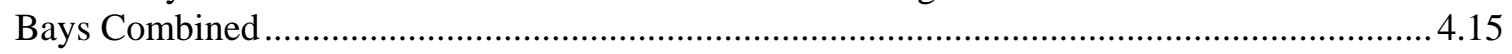

4.19 Pressure Time History from Sensor Fish Data and CFD Particles Released in Wanapum Unit 9 Bay B operating at 17 kcfs ........................................................................ 4.20

4.20 Comparison of Sensor Fish Severe Event and Live Fish Survival Rates for Unit 9

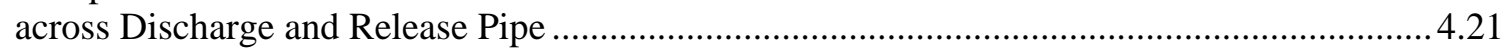

4.21 Comparison of Sensor Fish Severe Event and Live Fish Survival Rates for Unit 8 across Discharge and Release Pipe.....

4.22 Comparison of Sensor Fish Severe Event and Live Fish Injury-Free Rates for Unit 9 across Discharge, Release Pipe, and Intake Bay.

4.23 Comparison of Sensor Fish Severe Event and Live Fish Injury-Free Rates for Unit 8 across Discharge, Release Pipe, and Intake Bay..

4.24 Median and Range of Lowest Pressure Recorded by Sensor Fish in Units 8 and 9 ................. 4.25

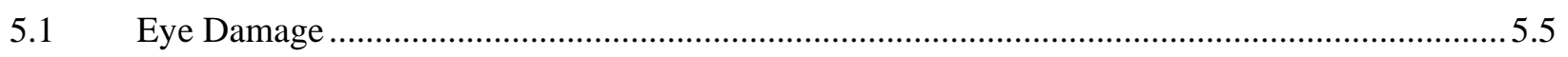


5.2 Damage to Isthmus.

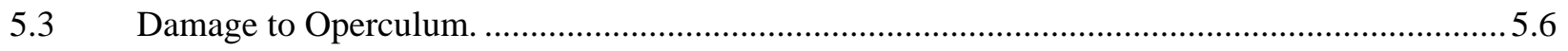

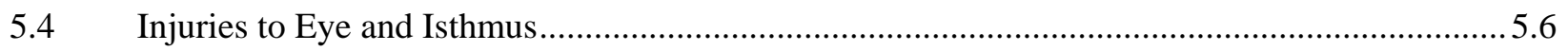

5.5 Frequency of Eye Injury Versus Turbine Discharge showing Interaction of Discharge

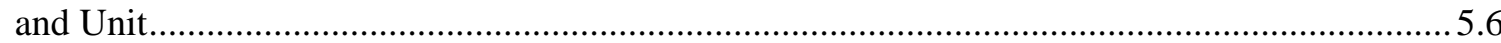

5.6 Frequency of Eye Injury Versus Unit Type Showing a Different View of the Interaction of Main Effects 


\section{Tables}

2.1 Characteristics of Conventional and Advanced Hydro Turbines at Wanapum Dam

3.1 Comparison of Blade-Strike Injury Rates Predicted by the Deterministic Model with Injury Types and Rates Observed for Juvenile Chinook Salmon after Passage through the AHT Unit 8 Turbine

3.2 Comparison of Blade-Strike Injury Rates Predicted by the Deterministic Model with Injury Types and Rates Observed for Juvenile Chinook Salmon after Passage through the Conventional Unit 9 Turbine....

4.1 Classification of Sensor Fish Significant Acceleration Events .................................................. 4.9

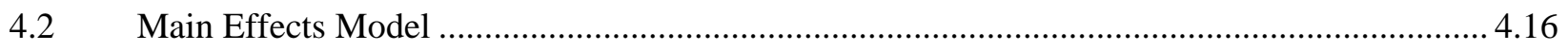

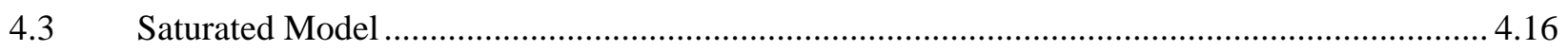

4.4 Final Model with Three Main Effects and Three-Way Interaction........................................ 4.17

4.5 Least Squares Means and Differences in Model Predicted Mean Event Rates between Units 8 and 9 by Discharge Level (Q) and Release Pipe .......................................................17

4.6 Least Squares Means and Differences in Mean Event Rates between Units 8 and 9 by Turbine Region.

4.7 Correlation between Sensor Fish Pressure Nadir and Occurrence of Collision in the Intake, Wicket Gate, and Blade Regions

4.8 Correlation between Sensor Fish Pressure Nadir and Occurrence of Strike in the Blade Region.

4.9 Comparison of Sensor Fish Severe Event and Live Fish Survival Rates for Each Turbine ...... 4.21

4.10 Predicted Major Shear Injury Rates from Sensor Fish Measurements .................................... 4.24

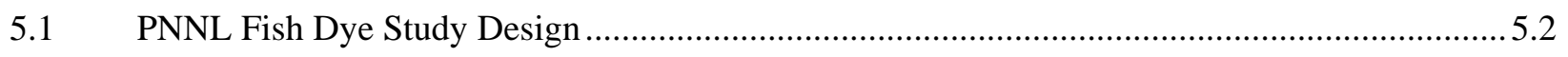

5.2 Summary of All Injury Occurrences for Advanced and Conventional Turbines......................... 5.4 


\subsection{Introduction}

In May 2003, Public Utility District No. 2 of Grant County (Grant PUD) requested authorization from the Federal Energy Regulatory Commission (FERC) to replace the 10 turbines at Wanapum Dam (Grant PUD 2003). Wanapum Dam is within the Priest Rapids Project and is located on the Columbia River at river kilometer (rkm) 668 in southeastern Washington State. The existing Kaplan-type turbines have been in place for over 40 years and were reaching the end of their useful machine life. Grant PUD proposed to replace the turbines with an advanced turbine design that would improve power output, increase efficiency, and include features to improve survival for fish passing through the turbines.

Specific features for increasing development output from 895 megawatts (MW) to 1,118 MW included a larger runner diameter, greater hydraulic capacity, and increased number of wicket gates. Design features believed to reduce adverse impacts to fish during turbine passage included reshaping the stay vanes, improved alignment and reduced size of wicket gates, and a spherical runner and discharge ring to eliminate gaps at the hub and discharge ring. In addition, the draft tube would be reshaped to improve hydraulic conditions and reduce re-circulation and turbulence. One of these advanced turbines was installed at Wanapum Dam turbine unit 8 in February 2005.

The first step in performance testing for the advanced turbine was to compare fish passage and survival estimates and hydraulic conditions between the advanced and conventional turbine designs. Based on this information, a decision would be made on whether to proceed with installation of the remaining nine advanced turbines.

Injuries and mortality of fish that pass through hydroelectric turbines and other downstream passage routes can result from several mechanisms, such as rapid and extreme pressure changes, shear stress, turbulence, strike, cavitation, and grinding (Cada 2001). Improvements in survival and reductions in the injury rate for fish passing through turbines is being sought through changes in hydroturbine design and operation (Odeh and Sommers 2000).

Four general approaches are currently being applied in the development of safer turbines and spillways: 1) direct evaluation of turbine passage injury and mortality rates and other aspects of risk of injury (biological response) in field studies utilizing balloon-tagged fish and Sensor Fish (Mathur et al. 1996, 2000; Carlson et al. 2003); 2) laboratory studies to establish the biological criteria for fish injury and mortality by quantifying the hydraulic forces required to produce biological responses observed in field studies (Turnpenny 1998; Johnson et al. 2003; Neitzel et al. 2004; Deng et al. 2005b); 3) application of reduced-scale physical models (Hecker and Cook 2005); and 4) computational fluid dynamics (CFD) modeling techniques to explore and evaluate turbine design and operation alternatives (Rakowski et al. 2005; Cada et al. 2006b).

The U.S. Department of Energy, Office of Energy Efficiency and Renewable Energy (EE/RE), provided co-funding to Grant PUD for aspects of performance testing that supported the FERC application. The primary measure of biological performance for the new advanced turbine was direct injury/mortality of juvenile Chinook salmon (Oncorhynchus tshawytscha) as determined by balloon tagrecapture methodology. A randomized block experiment was conducted that included the two turbine types (new and conventional), three intake bays for each turbine, two entrainment locations within each 
turbine intake bay, and four turbine discharges (Skalski et al. 2005). Passage conditions, i.e., hydraulics, for the test fish were also characterized simultaneously using a Sensor Fish (Duncan et al. 2005). The field studies were conducted from February through April 2005.

In addition to the FERC license studies, the U.S. DOE EE/RE provided funding to Oak Ridge National Laboratory (ORNL) and Pacific Northwest National Laboratory (PNNL) to conduct an expanded set of studies that would broaden the biological performance testing of the new turbine design. ORNL studies in support of the Wanapum test focused on assessing the potential for indirect mortality (Cada et al. 2006a) and evaluating biochemical measures of fish response (Sale et al. 2006). PNNL studies included an evaluation of blade-strike using both deterministic and stochastic models, an extended analysis of the response of the Sensor Fish to strike, pressure, and turbulence within the turbine system, and a novel dye technique to measure injury to juvenile fish in the field,.

This report summarizes the results of these three studies conducted by PNNL in 2005 in support of the Wanapum advanced turbine test. Each study is described in a separate section that includes objectives, methods, results, and discussion. Chapter 3 describes the blade strike deterministic and stochastic modeling studies. Chapter 4 provides results of the Sensor Fish analysis. Chapter 5 describes results of fish injury evaluations at Wanapum Dam using the PNNL-developed dye technique. Chapter 6 addresses how the collective studies relate to the overall objective of assessing improved environmental performance for the advanced turbine. Chapter 7 is references. Appendix A provides detailed data collected during Sensor Fish shear and turbulence testing and live fish survival, and injury testing at Units 8 and 9 . 


\subsection{Background}

\subsection{Wanapum Study Site}

Wanapum Dam is owned and operated by Public Utility District No. 2 of Grant County (Grant PUD). The dam is located in central Washington State on the Columbia River at river km 668

(Figure 2.1). Average Columbia River discharge at this location is approximately 120,000 cubic feet per second (cfs). The dam consists of a reinforced concrete powerhouse and spillway and a non-overflow earth fill section (Figure 2.2). Construction began in 1959 and power was first generated in 1963. The 1000-foot-long powerhouse contains 10 Kaplan turbine units. The spillway is 830 feet long with 12 Tainter-type radial gates.

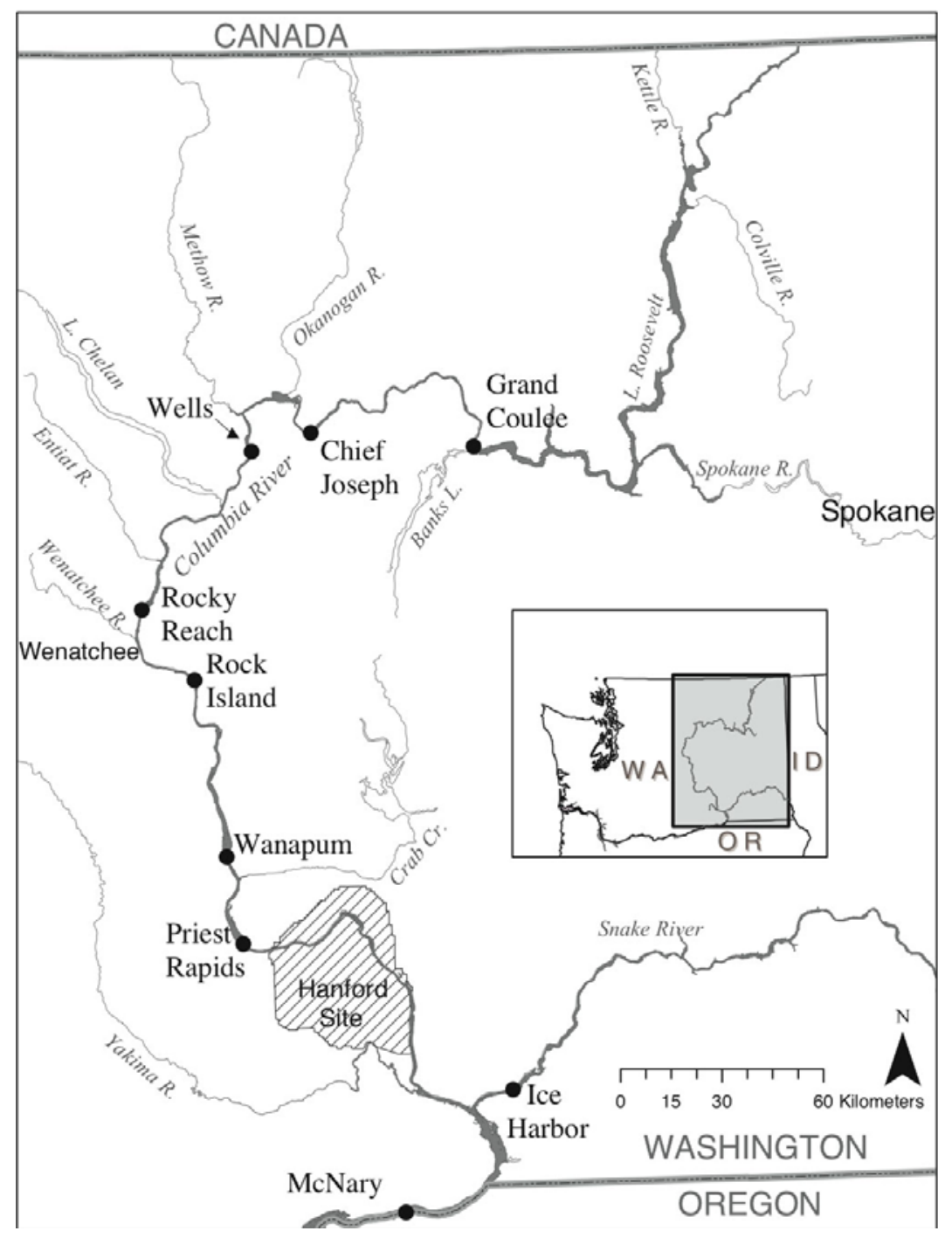

Figure 2.1. Location of Wanapum Dam on the Columbia River in Central Washington State 


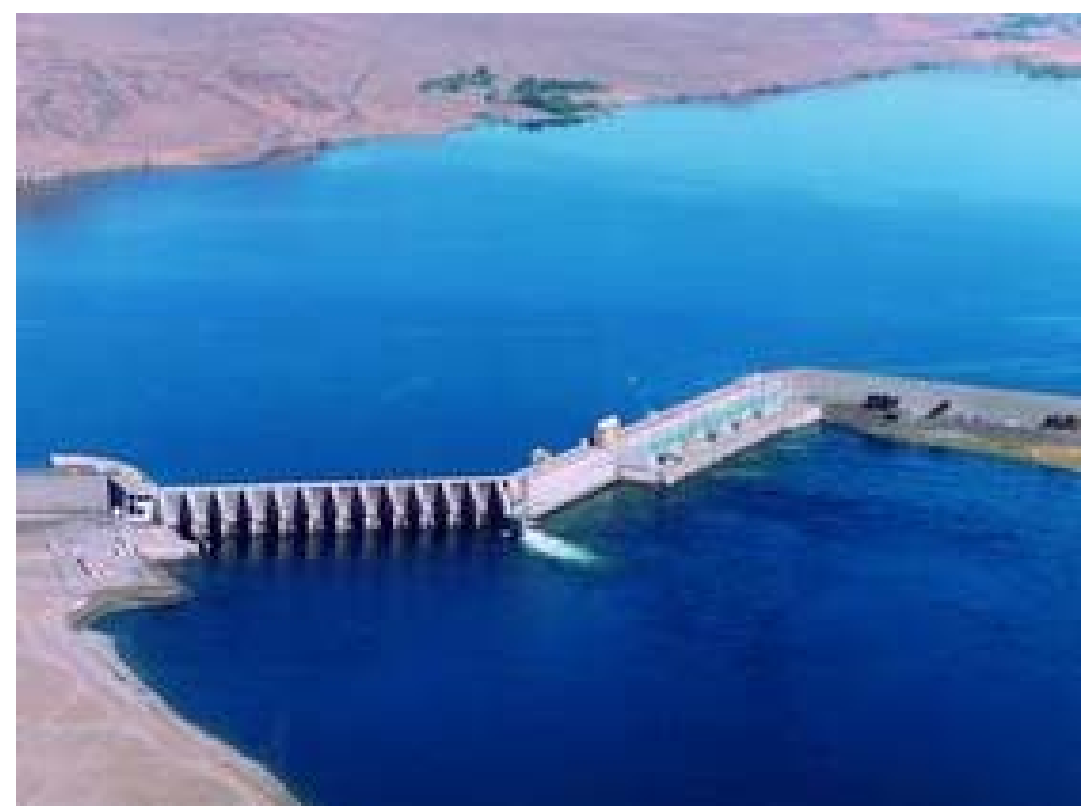

Figure 2.2. Wanapum Dam on the Columbia River, Washington. The spillway is on the left, the powerhouse is in the center, and the earth fill section is on the right.

\subsection{Wanapum Dam Existing and Advanced Turbine Designs}

In the early 1990s, Grant County initiated a comprehensive program to replace existing turbines with new units that would produce more power and improve survival of turbine-passed fish. Unit 8 was the first of these advanced hydropower turbines (AHT) to be installed. It began operation in February 2005. Table 2.1 compares the general features of the conventional and the new AHT unit.

All turbines were conventional Kaplan units consisting of a 285-inch-diameter runner with 5 blades, 16 stay vanes (SV), and 20 wicket gates (WG). The stay vanes are not shaped (Figure 2.3 and 2.4) and the wicket gate tails overhang the discharge ring (Figure 2.5). Depending on operating conditions, the hub and blade tip gaps are significant and potential sources of fish injury.

In contrast to the conventional units, the AHT design includes several key features to increase power generation and improve fish survival. Increased power generation $(150,000 \mathrm{hp})$ is achieved through a larger runner diameter of 305 inches. The AHT runner (Figure 2.6) has six blades and a spherical hub and discharge ring to virtually eliminate gaps at the hub and blade tips (Figures 2.7 and 2.8). The stay vanes are shaped to reduce turbulent flow and the number of wicket gates is increased from 20 to 32 in order to align them with the stay vanes (Figure 2.9). The wicket gate overhang was also eliminated (Figure 2.10). The AHT design reduces velocity gradients (shear) and the rate of change of pressure, both of which have been related to fish injury (Cada 2001 and Cada et al. 2006). The draft tube was also modified to reduce flow recirculation and associated turbulence. 
Table 2.1. Characteristics of Conventional and Advanced Hydro Turbines at Wanapum Dam

\begin{tabular}{|c|c|c|}
\hline & $\begin{array}{c}\text { Conventional Turbine } \\
\text { (Unit 9) }\end{array}$ & $\begin{array}{l}\text { Advanced Hydropower Turbine } \\
\text { (Unit 8) }\end{array}$ \\
\hline Manufacturer & Dominion Engineering & Voith Siemens Hydropower \\
\hline Hydraulic capacity (cfs) & 14,200 & 17,800 \\
\hline $\begin{array}{l}\text { Rated power output (hp) } \\
\text { at } 80 \mathrm{ft} \text {. net head }\end{array}$ & 120,000 & 150,000 \\
\hline Number of blades & 5 & 6 \\
\hline Runner diameter (inches) & 285 & 305 \\
\hline Number of stay vanes & 16 & $\begin{array}{l}16 \\
\text { shaped for improved flow }\end{array}$ \\
\hline Number of wicket gates & 20 & $\begin{array}{l}32 \\
\text { in line with stay vanes and no } \\
\text { discharge ring overhang }\end{array}$ \\
\hline $\begin{array}{l}\text { Wicket gate spacing } \\
\text { (inches) }\end{array}$ & 33.5 & 21.5 \\
\hline Runner rotation (RPM) & 85.7 & 85.7 \\
\hline Runner features & $\begin{array}{l}\text { Original design with } \\
\text { modifications to reduce hub } \\
\text { gaps }\end{array}$ & Spherical runner and discharge ring \\
\hline \multicolumn{3}{|l|}{ Hub gaps (inches) } \\
\hline Leading edge & 0.12 to 4.89 & 0.10 \\
\hline Trailing edge & 0.12 & \\
\hline \multicolumn{3}{|l|}{ Blade tip gaps (inches) } \\
\hline Leading edge & 0.76 to 3.82 & 0.31 \\
\hline Trailing edge & 0.76 to 12.19 & 0.31 \\
\hline Draft tube & Original design & Modified to improve flow \\
\hline
\end{tabular}

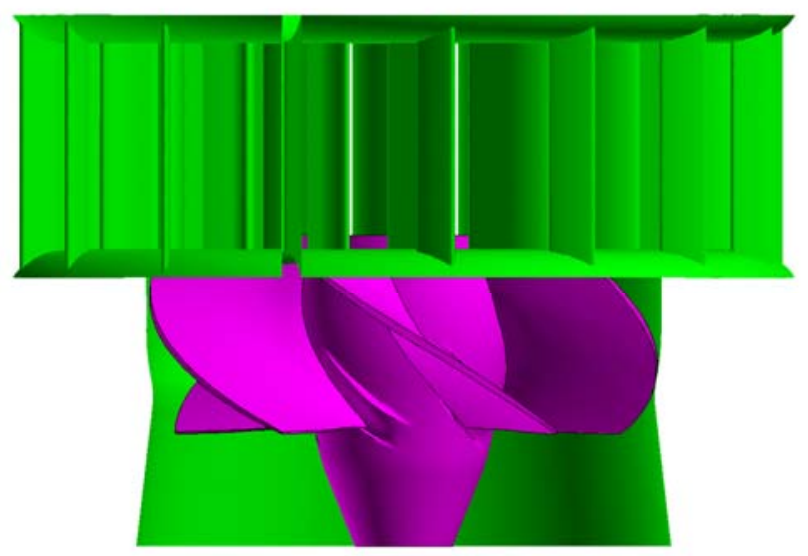

Figure 2.3. Conventional Unit 9 showing the Stay Vanes, Wicket Gates, and Runner 


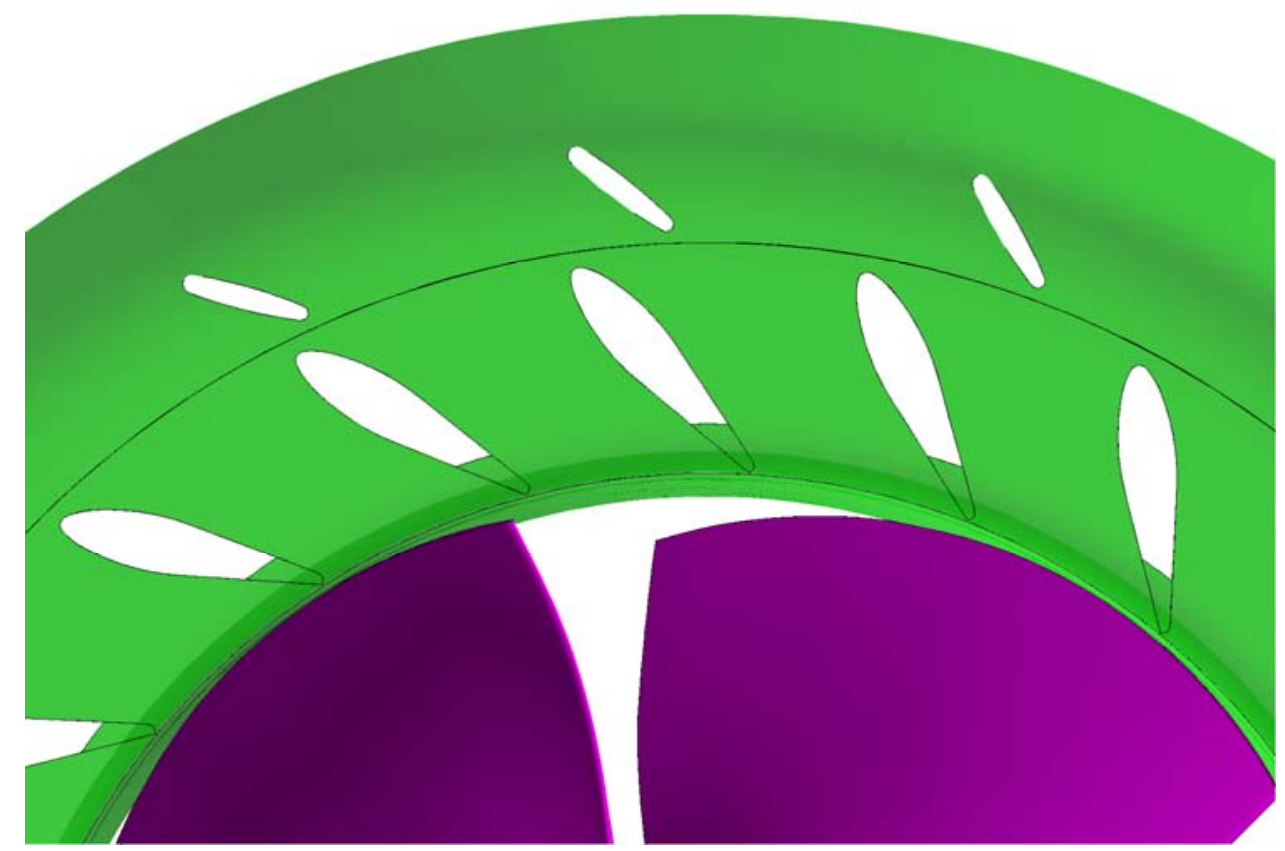

Figure 2.4. Unit 9 (conventional) Stay Vanes, Wicket Gates, and Runner. Note the wicket gates are not aligned with the stay vanes.

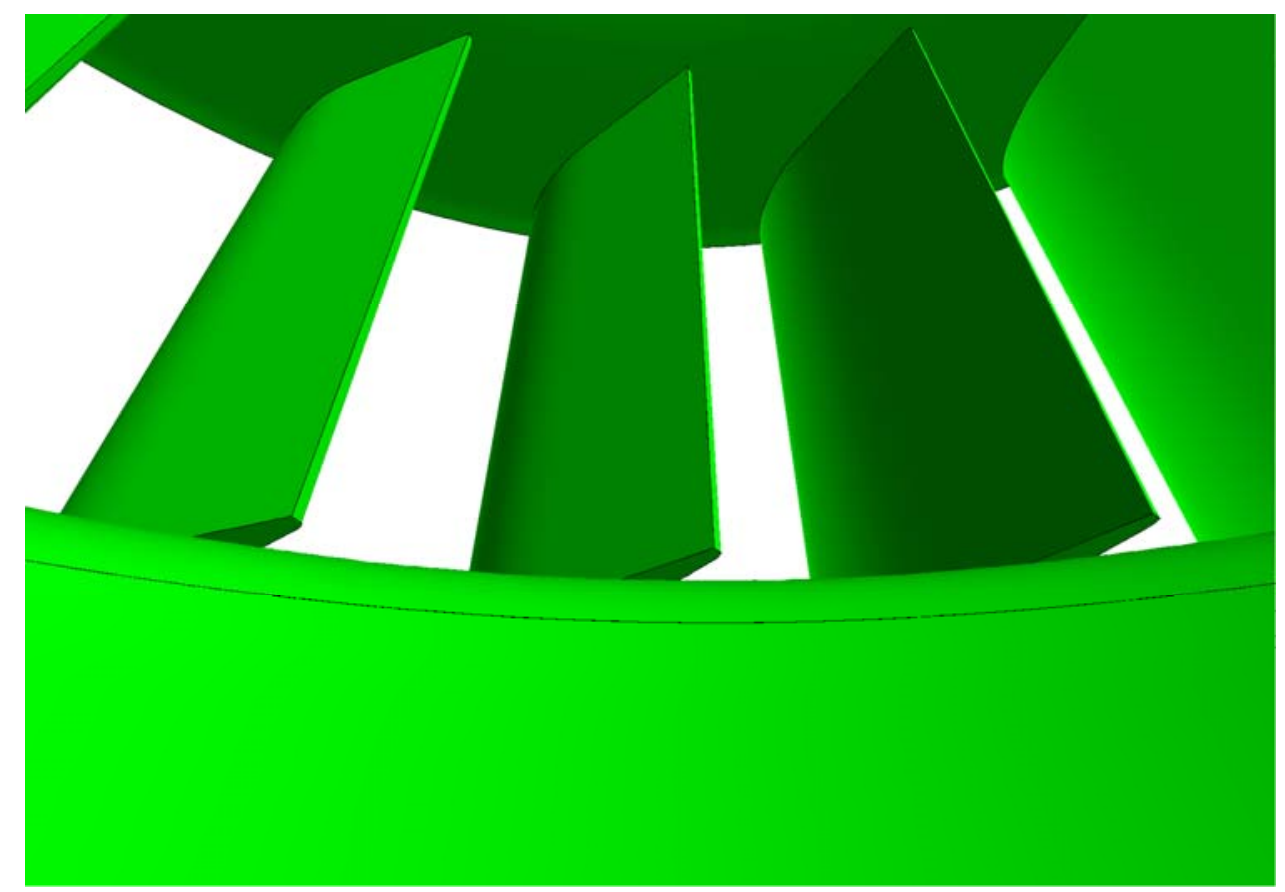

Figure 2.5. Unit 9 (conventional) Wicket Gate Overhang 


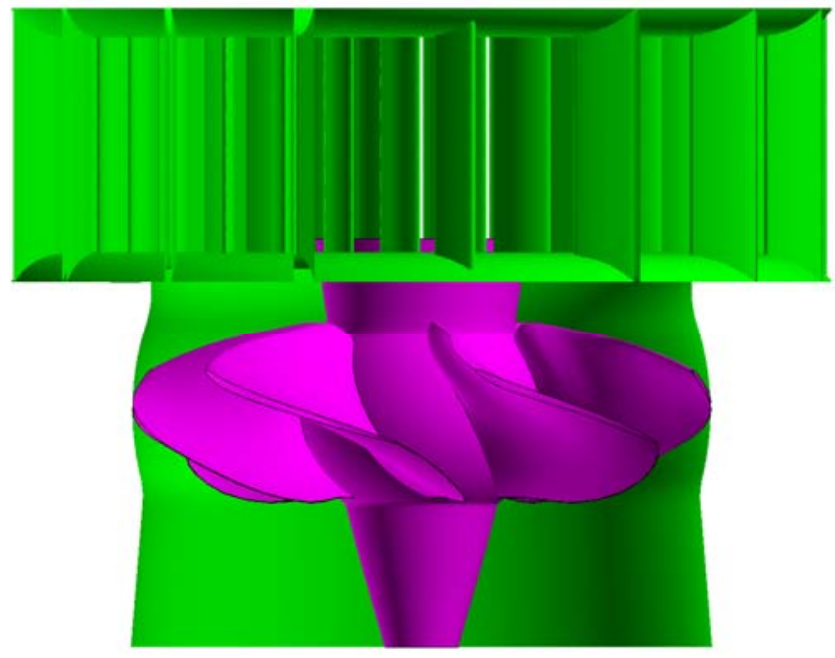

Figure 2.6. Unit 8 (AHT) showing the Stay Vanes, Wicket Gates, and Runner. Note the shaped runner and spherical hub.

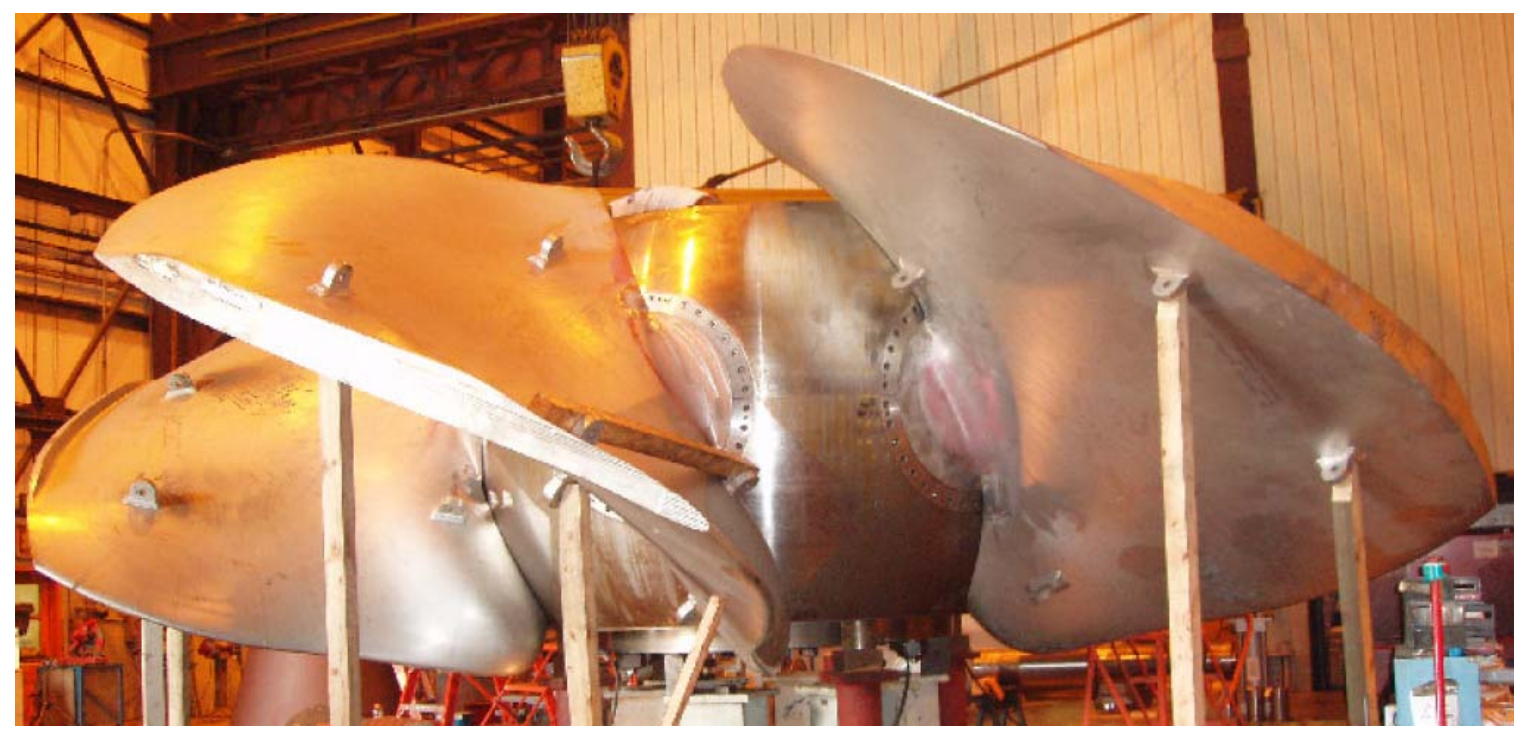

Figure 2.7. Unit 8 (AHT) Runner and Spherical Hub (photo provided by Voith Siemens Hydropower) 


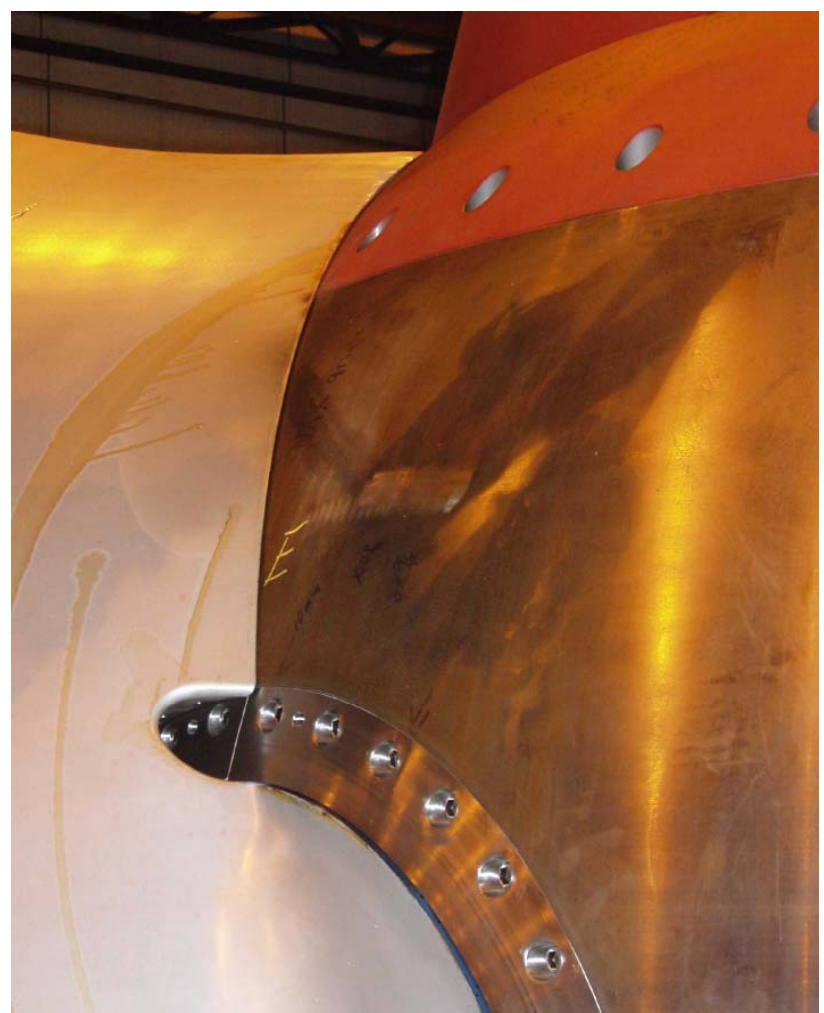

Figure 2.8. Unit 8 (AHT) Detailed View of Hub Showing the Reduced Gap between the Runner and Spherical Hub (photo provided by Voith Siemens Hydropower)

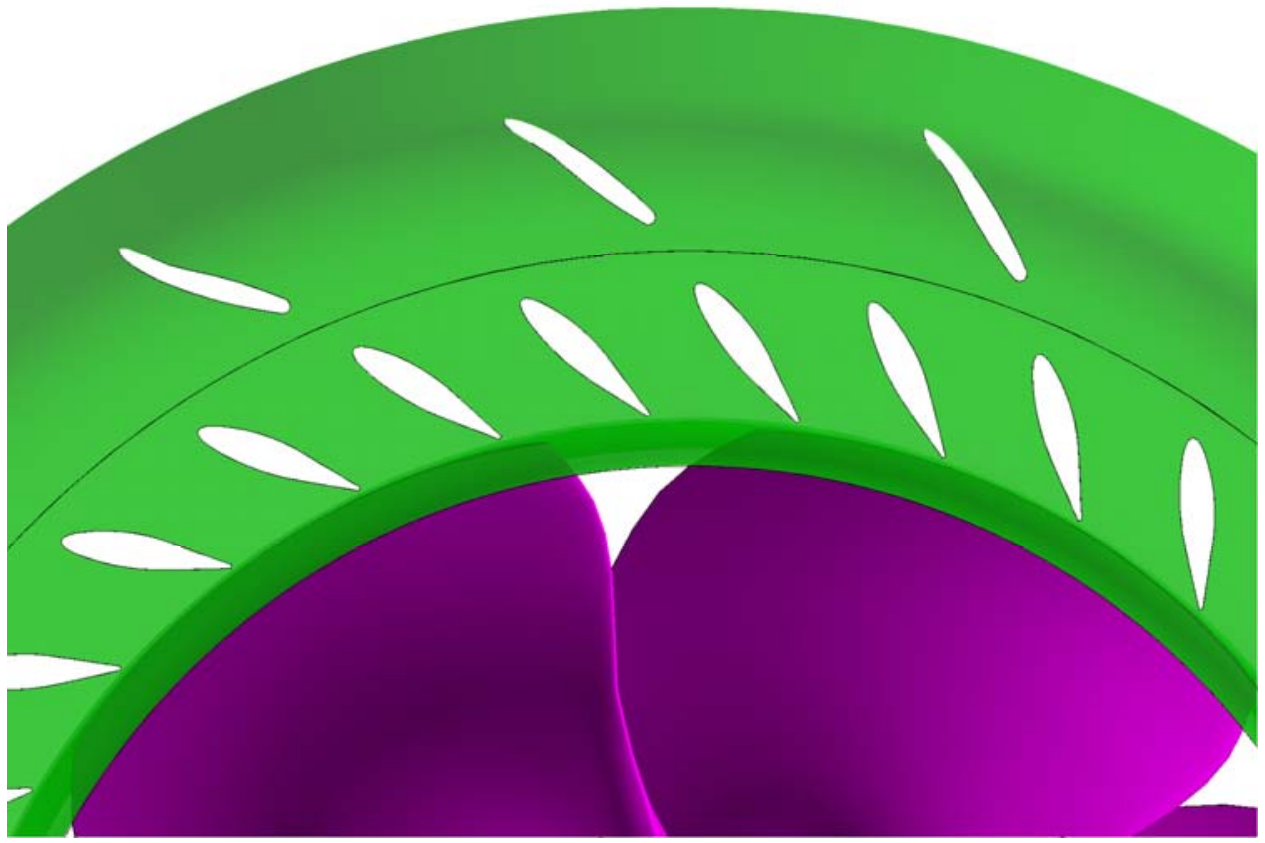

Figure 2.9. Unit 8 (AHT) Stay Vanes, Wicket Gates, and Runner. Note the number of wicket gates was increased and the gates were lined up with the stay vanes which were shaped. 


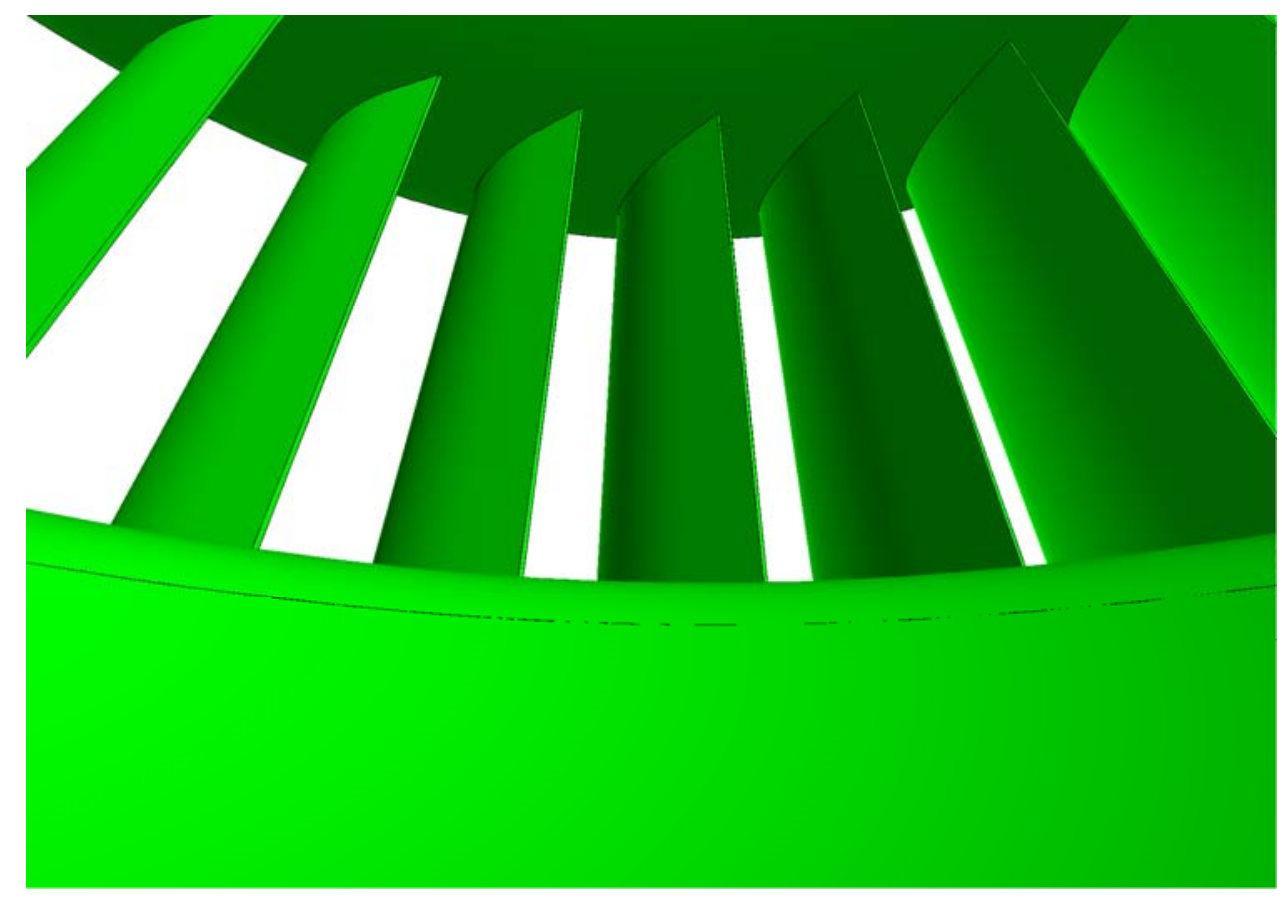

Figure 2.10. Unit 8 (AHT) Wicket Gate Overhang Has Been Removed 
Biological Assessment of the Advanced Turbine Design at Wanapum Dam, 2005 


\subsection{Blade Strike Modeling for the Wanapum Original and Advanced Turbine Design Runners}

\subsection{Introduction}

Bio-Indexing of hydroturbines has been identified as an important means to optimize passage conditions for fish through hydroturbines by identifying operations for existing and new design turbines that minimize the probability of injury to fish. Cost-effective implementation of bio-indexing requires the use of tools such as numerical and physical turbine models to generate hypotheses for turbine operations that can be tested at prototype scales using live fish. Blade strike has been proposed as an index variable for the biological performance of turbines and blade strike models are candidates as tools for BioIndexing hypothesis generation.

Injuries and mortality of fish that pass through hydroelectric turbines can result from several mechanisms, such as rapid and extreme pressure changes, shear stress, turbulence, strike, cavitation, and grinding. (For overviews, see Coutant and Whitney 2000; Odeh and Sommers 2000; Cada 2001). Fish are most vulnerable to injury during turbine passage in the immediate vicinity of the turbine runner. Here they can be injured by direct contact with turbine runner blades or exposure to the hydraulic environment where hazardous conditions may exist.

In previous studies (Ploskey and Carlson 2004; Deng et al. 2005a, 2007), deterministic and stochastic blade-strike models were developed for 1) the new minimum gap and original Kaplan runner turbines at the Bonneville Dam and 2) the 1:25-scale physical model of a McNary Dam turbine. The performance of the numerical blade-strike models was then evaluated by comparing predictions of fish mortality resulting from strike by turbine runner blades with 1) observations of fish injury made using live fish at Bonneville Dam by Normandeau Associates et al. (2000) and 2) predictions of blade strike made observing neutrally buoyant beads passing through a 1:25-scale physical turbine model by USACE (2004). Fish orientation at the time of entry into the plane of the leading edges of the turbine runner blades was found to be one of the most significant factors and uncertainties in blade-strike modeling, and the use of stochastic blade-strike models was recommended because they consider the aspect of fish approaching the leading edges of a turbine runner's blades.

In this study, the blade-strike models were applied to the conventional and AHT turbines at Wanapum Dam, the model predictions were compared with the experimental results using live fish and Sensor Fish, and the biological performance of the new turbines was evaluated.

\subsection{Methods}

\subsubsection{Model Formulation}

"Critical passage time" $t_{c r}$ is defined as the time between sweeps of two successive blades as

$$
t_{c r}=\frac{1}{n \cdot \frac{N}{60}}
$$


where $n$ is the number of blades and $N$ is the runner speed in revolutions per minute (RPM). The time a fish needs to pass safely through the plane of the leading edges of the runner blades is

$$
t=\frac{l \cdot \cos \theta}{V_{\text {axial }}}
$$

where $l$ is the fish length, $V_{\text {axial }}$ is axial velocity, $\theta$ is the angle between $V_{\text {axial }}$ vector, and the absolute water velocity vector.

A fish will experience a blade strike if it does not pass through this plane within $t_{c r}$, and the probability of strike is then expressed as

$$
P=\frac{t}{t_{c r}}=\frac{l \cdot \cos \theta \cdot n \cdot \frac{N}{60}}{V_{\text {axial }}}
$$

Von Raben (1957) observed that his blade-strike model always produced an estimate of blade strike that was higher than the proportion of live fish he observed to be injured during passage through the turbine he was modeling. To account for the obvious fact that not all fish struck by a turbine blade were injured, Von Raben introduced the idea of a mutilation ratio (MR). MR was simply the ratio between the proportion of fish he estimated to be struck by a turbine blade and the proportion he observed to be injured. To deal with the same issue in his experiments, Turnpenny et al. (2000) empirically developed a regression equation of MR for different fish lengths:

$$
M R=0.15533 \operatorname{Ln}(l)+0.0125
$$

where $M R$ is mutilation ratio, $\mathrm{Ln}$ is natural logarithm, and $l$ is fish length (in centimeters).

$V_{\text {axial }}$ is estimated by dividing the turbine discharge $Q$ by the turbine blade-swept area $A_{\text {tip }}$ :

$$
V_{\text {axial }}=\frac{Q}{A_{\text {tip }}}=\frac{Q}{\pi\left(R_{\text {tip }}^{2}-R_{\text {hub }}^{2}\right)}
$$

where $R_{t i p}$ and $R_{h u b}$ are the radii of circles formed by the runner blade tip and runner hub, respectively. The angle between axial and absolute velocity vectors $(\theta)$ is given by

$$
\theta=90-\alpha=90-\sin ^{-1}\left(\frac{V_{\text {axial }}}{V_{1}}\right)
$$

where $\alpha$ is the angle between tangential and absolute velocity vectors (see Figures 3.1 and 3.2). 


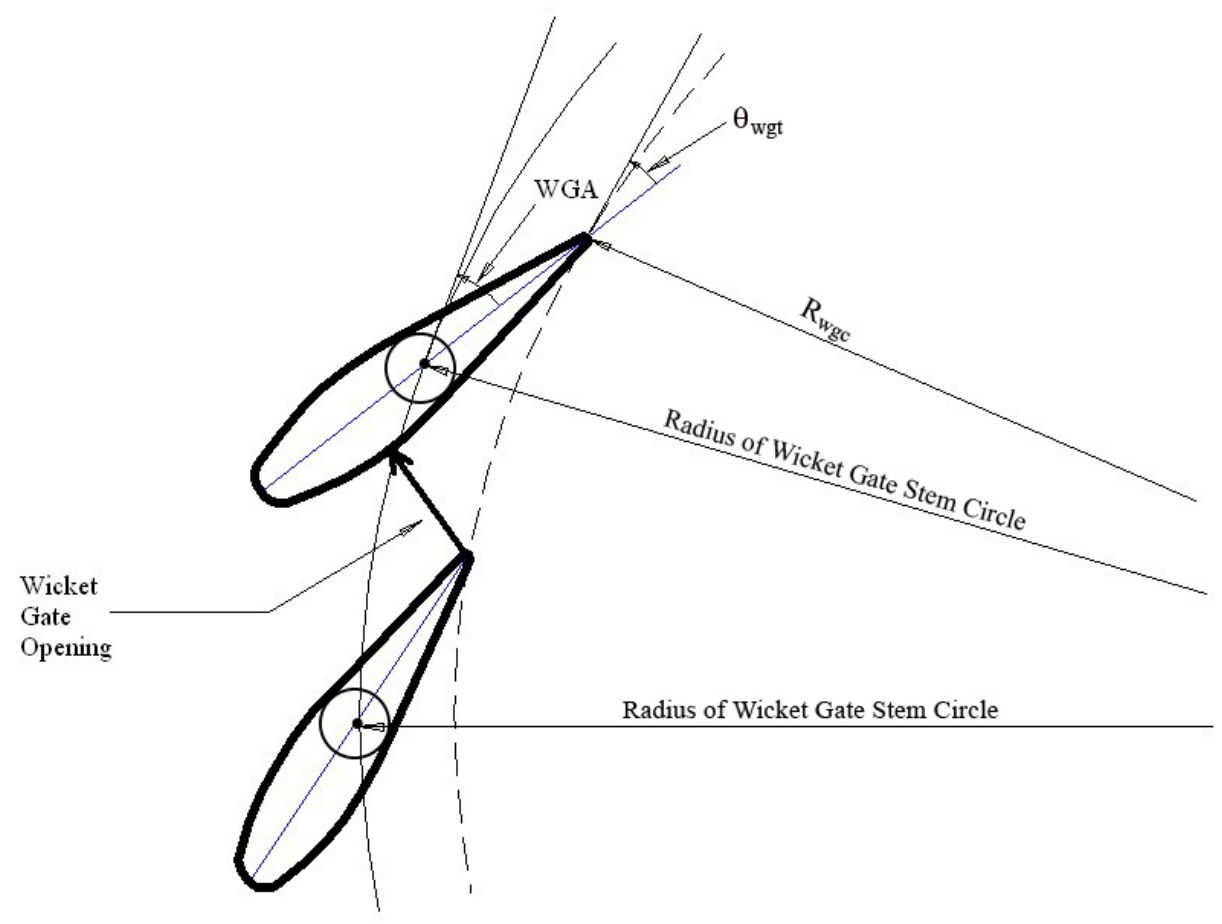

Figure 3.1. Definition of Wicket Gate Angle (WGA), Wicket Gate Opening (WGO), $R_{w g c}$, and $\theta_{\text {wgt }}$ (the angle between the absolute velocity and tangential velocity at the downstream tip of wicket gate)

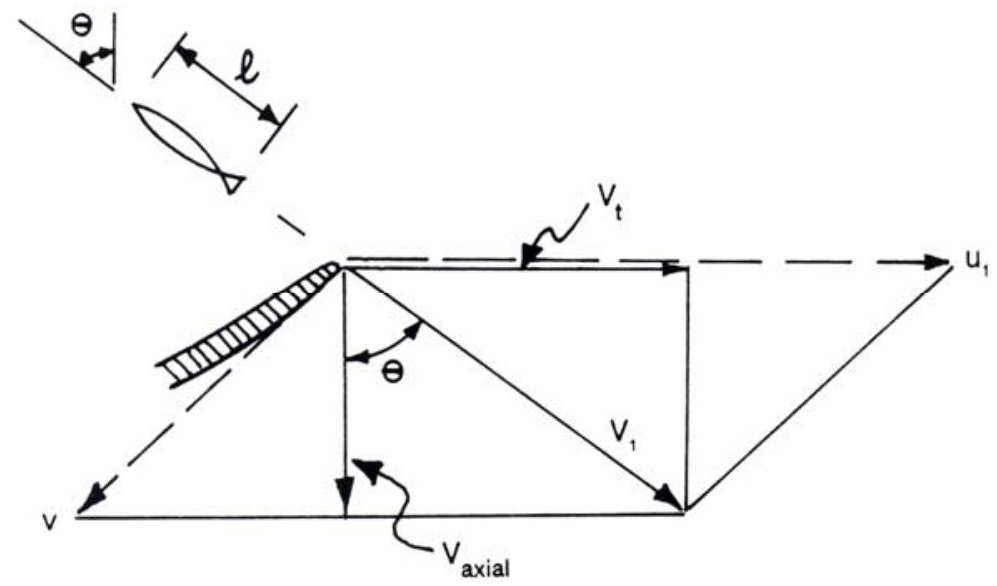

Figure 3.2. Water Velocity Vectors at the Runner Blade (Bell 1991). The diagram shows a fish of length $l$ in flow approaching the leading edge of a runner blade in a Kaplan turbine, velocity vectors, and associated angles. $\mathrm{V}_{\mathrm{t}}=$ tangential velocity; $\mathrm{V}_{1}=$ absolute velocity; $\mathrm{V}_{\text {axial }}=$ axial velocity; $\mathrm{u}_{1}=$ blade peripheral velocity; $\mathrm{v}=$ velocity relative to the blade; $\theta=$ the angle between axial (parallel to the runner axis) and absolute velocity vectors.

\subsubsection{Application to Wanapum Dam Turbines}

Following many years of economic, engineering, and biological study and assessment, Grant County PUD began the process of upgrading and replacing the 10 Kaplan turbines at the Wanapum Dam in April 
2004. The new turbine (in Unit 8, also called AHT), developed by Voith Siemens Hydro, Inc., features many elements included in the U.S. Department of Energy's Advanced Hydropower Turbine System (AHTS) concept for improved operational performance and better passage conditions for fish. Design changes include increasing the number of runner blades and minimizing the gap between the blade and hub and between the blade tip and the discharge ring at all blade tilts, the stay vane-wicket gate cascade, and the draft tube (Table 2.1).

In order to test the hypothesis that the AHT (Unit 8) performs biologically as well as or better than original Wanapum Dam turbines, a comprehensive biological study was conducted from February to April 2005. A total of 24 passage conditions (treatments) were sampled for each turbine unit. Treatments consisted of combinations of two turbines (conventional and AHT), four turbine discharges $(9,11,15$, and $17 \mathrm{kcfs}$ ), three intake bays (A, B, or C), and two release elevations (10 ft or $30 \mathrm{ft}$ below the turbine intake ceiling). Approximately 10,000 live test fish and 1,000 Sensor Fish releases were conducted concurrently during the course of the study. The live fish were released to evaluate statistically the injury and survival rate for the two turbines. Sensor Fish were deployed to characterize the exposure that fish experienced during turbine passage such as the rates and severity of contacts (strikes by runner blades and collisions on stationary structures), and exposure to severe turbulence and shear and to changes in pressure.

The numerical deterministic and stochastic blade-strike models were run using the operational parameters of the biological study. The model predictions were then compared with the injury rates of live fish and the rate of collisions between Sensor Fish and runner blades. The operations parameters used wicket gate opening (WGO) to define wicket gate positions. Because the blade-strike model requires $R_{w g c}$ (the radius of wicket gate circle) and $\theta_{\text {wgt }}$ (the angle between the absolute velocity and tangential velocity at the downstream tip of the wicket gate), the minimum distance between two adjacent gates was computed using a linear search algorithm for any given wicket gate angle and developed as a relationship for the wicket gate geometry over the operation range (Figures 3.3 and 3.4):

$$
\begin{aligned}
& \begin{cases}\mathrm{R}_{\mathrm{wgc}}=-0.7787 \mathrm{WGO}+200.33 & \text { for Unit } 8 \\
\theta_{\mathrm{wgt}}=0.001631 \mathrm{WGO}^{3}-0.01745 \mathrm{WGO}^{2}+2.1657 \mathrm{WGO}-2.53 & \end{cases} \\
& \text { and }
\end{aligned}
$$

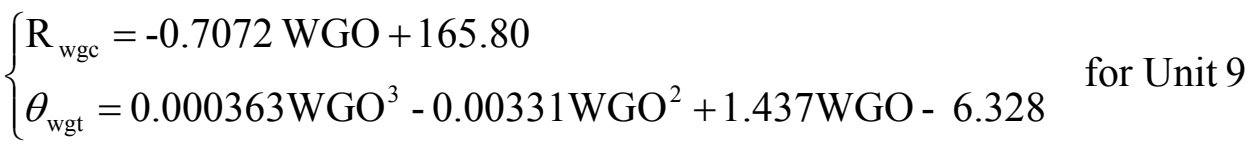



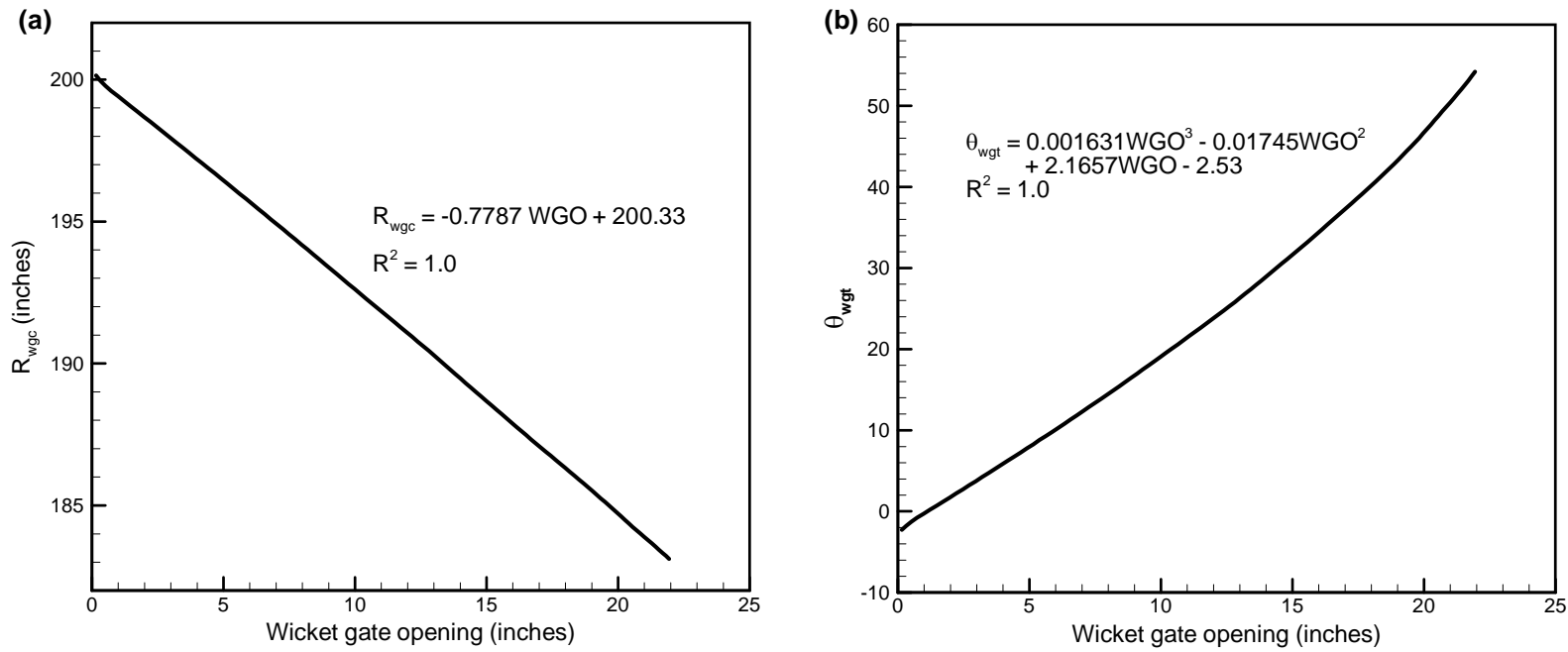

Figure 3.3. Geometry Relationship of Unit 8 (AHTS): (a) $\mathrm{R}_{\mathrm{wgc}}$; (b) $\theta_{\mathrm{wgt}}$
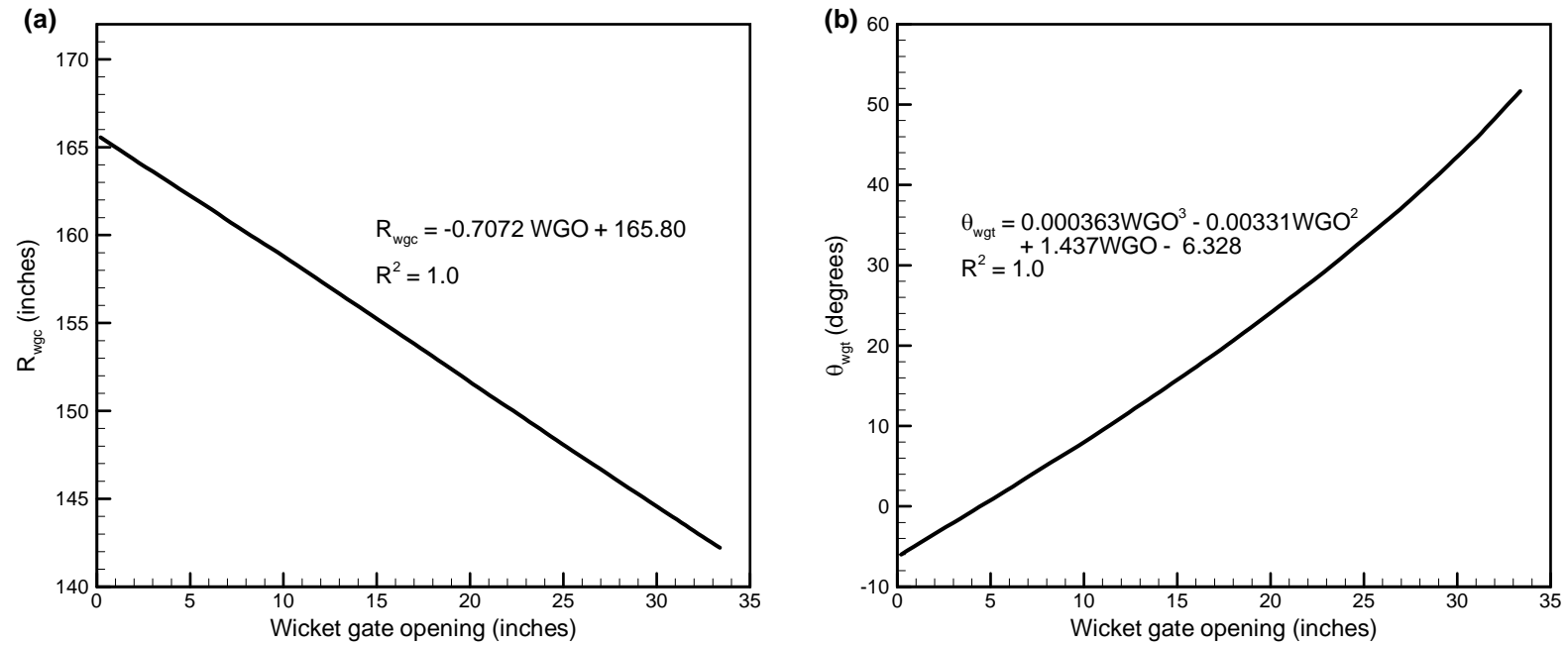

Figure 3.4. Geometry Relationship of Unit 9 (conventional unit): (a) $\mathrm{R}_{\mathrm{wgc}}$; (b) $\theta_{\mathrm{wgt}}$

\subsection{Results}

\subsubsection{Deterministic Model Results}

The deterministic blade-strike model was implemented for $10-\mathrm{ft}$ and $30-\mathrm{ft}$ releases at five discharges $(9,11,15,17$, and $18.5 \mathrm{kcfs})$ for the new AHT unit and four discharges $(9,11,15$, and $17 \mathrm{kcfs})$ for the conventional unit. The model predictions of blade-strike probabilities were compared to the Sensor Fish results (Chapter 4) under the same operational parameters. Severe events (acceleration magnitude of Sensor Fish larger than $95 \mathrm{~g}$ ) under the collision category were selected for the comparison.

For both units, Sensor Fish results were more variable than the predictions of the numerical model (Figures 3.5 and 3.6), especially for the existing unit. This trend was still evident when predictions from the two release locations were combined (Figure 3.7). This observation is consistent with the findings of our previous study (Deng et al. 2005a) that one obvious difference between the blade strike model results 
and physical model observations was the higher variability between test conditions seen in physical model observations using neutrally buoyant particles.

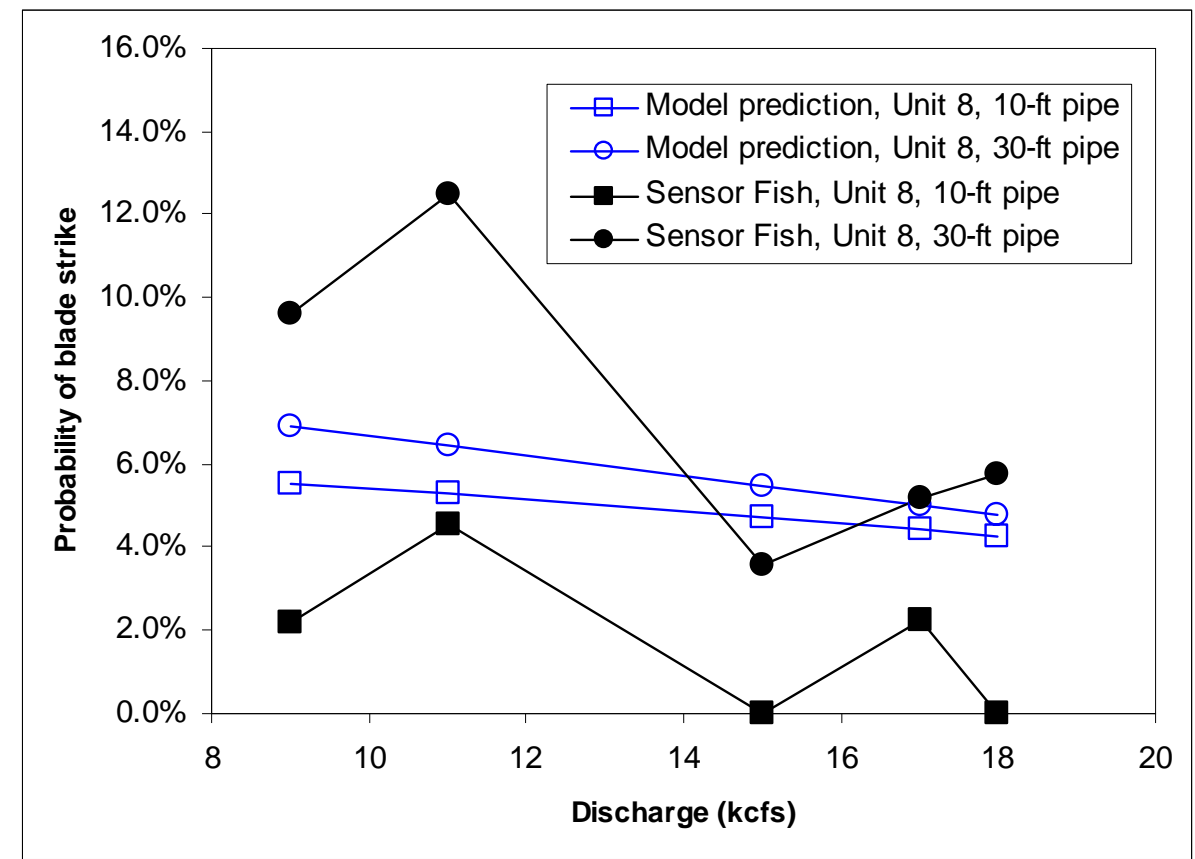

Figure 3.5. Prediction of Blade Strike by the Deterministic Model as a Function of Discharge and Comparison with Sensor Fish Results, AHTS Unit (Unit 8)

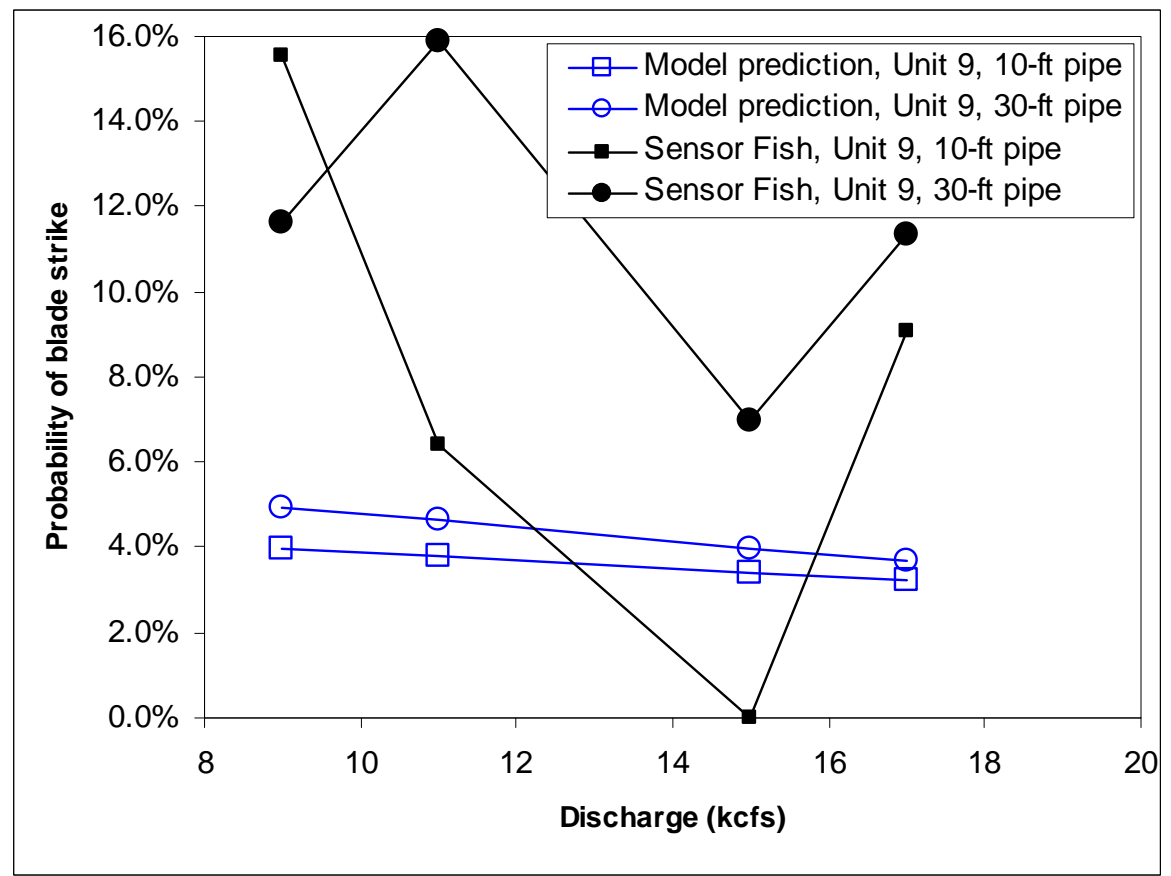

Figure 3.6. Prediction of Blade Strike by the Deterministic Model as a Function of Discharge and Comparison with Sensor Fish Results, Existing Unit (Unit 9) 


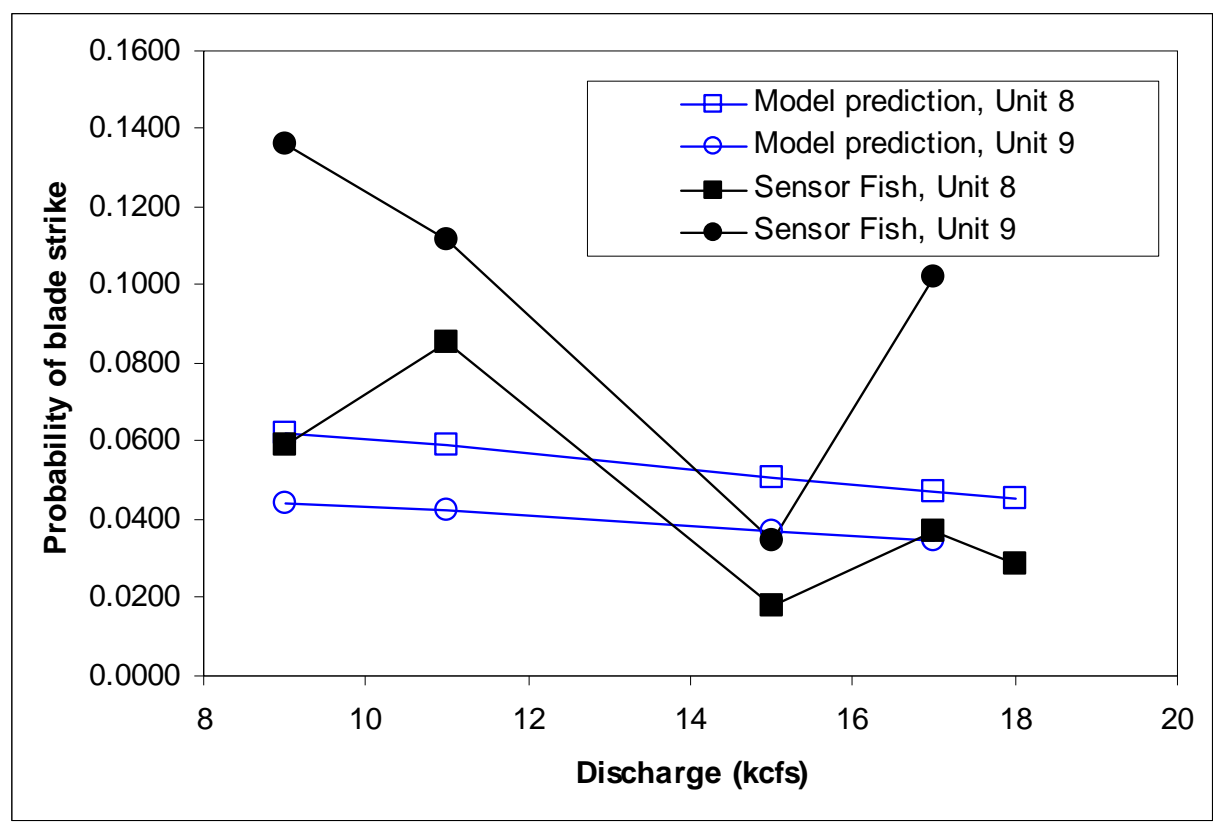

Figure 3.7. Comparison of the Predictions of Blade Strike by the Deterministic Model for Both Units for the 10- and 30-ft Release Locations Combined as a Function of Discharge and Comparison with Sensor Fish Results

Modeled injury rates were obtained by applying the empirical equation for MR to account for the observation that not all fish struck by a turbine blade were injured. For both units, the predicted injury rates (Tables 3.1 and 3.2) were higher than the rates of visible injury or mechanical injury reported by Normandeau et al. (2005). In addition, the high variability between the two fish release locations was not captured in the deterministic model. The average injury rates by combining the two locations for each discharge were closer to the biological field test results but the over-prediction by the model was still obvious (Figures 3.8 and 3.9).

Table 3.1. Comparison of Blade-Strike Injury Rates Predicted by the Deterministic Model with Injury Types and Rates Observed for Juvenile Chinook Salmon after Passage through the AHT Unit 8 Turbine (live fish data adapted from Normandeau et al. 2005)

\begin{tabular}{|c|c|c|c|c|c|c||}
\hline $\begin{array}{c}\text { Discharge } \\
(\mathrm{kcfs})\end{array}$ & $\begin{array}{c}\text { Release } \\
\text { Location (ft) }\end{array}$ & $\begin{array}{c}\text { Predicted } \\
\text { Injury Rate }\end{array}$ & $\begin{array}{c}\text { Visibly } \\
\text { Injured }\end{array}$ & $\begin{array}{c}48-\mathrm{hr} \\
\text { Mortality }\end{array}$ & Shear & Mechanical \\
\hline \multirow{2}{*}{9} & 10 & $4.2 \%$ & $0.5 \%$ & $0.0 \%$ & $1.1 \%$ & $0.5 \%$ \\
\cline { 2 - 7 } & 30 & $5.2 \%$ & $2.8 \%$ & $3.0 \%$ & $1.6 \%$ & $0.2 \%$ \\
\hline \multirow{2}{*}{11} & 10 & $4.0 \%$ & $0.0 \%$ & $0.0 \%$ & $1.1 \%$ & $0.4 \%$ \\
\cline { 2 - 7 } & 30 & $4.9 \%$ & $3.2 \%$ & $3.2 \%$ & $1.7 \%$ & $1.1 \%$ \\
\hline \multirow{2}{*}{15} & 10 & $3.5 \%$ & $0.5 \%$ & $0.7 \%$ & $0.5 \%$ & $0.2 \%$ \\
\hline \multirow{2}{*}{17} & 30 & $4.1 \%$ & $4.3 \%$ & $3.8 \%$ & $0.7 \%$ & $2.0 \%$ \\
\cline { 2 - 7 } & 30 & $3.3 \%$ & $2.7 \%$ & $2.5 \%$ & $1.1 \%$ & $0.7 \%$ \\
\hline \multirow{3}{*}{ Pooled } & 10 & $3.8 \%$ & $3.0 \%$ & $3.0 \%$ & $0.7 \%$ & $0.7 \%$ \\
\cline { 2 - 7 } & 30 & $4.8 \%$ & $0.9 \%$ & $0.8 \%$ & $1.0 \%$ & $0.5 \%$ \\
\cline { 2 - 7 } & $10 \& 30$ & $4.1 \%$ & $2.1 \%$ & $2.0 \%$ & $1.1 \%$ & $0.7 \%$ \\
\hline
\end{tabular}


Table 3.2. Comparison of Blade-Strike Injury Rates Predicted by the Deterministic Model with Injury Types and Rates Observed for Juvenile Chinook Salmon after Passage through the Conventional Unit 9 Turbine (live fish data adapted from Normandeau et al. 2005)

\begin{tabular}{|c|c|c|c|c|c|c||}
\hline $\begin{array}{c}\text { Discharge } \\
(\mathrm{kcfs})\end{array}$ & $\begin{array}{c}\text { Release } \\
\text { Location (ft) }\end{array}$ & $\begin{array}{c}\text { Predicted } \\
\text { Injury rate }\end{array}$ & $\begin{array}{c}\text { Visibly } \\
\text { injured }\end{array}$ & $\begin{array}{c}48-\mathrm{hr} \\
\text { Mortality }\end{array}$ & Shear & Mechanical \\
\hline \multirow{2}{*}{9} & 10 & $3.0 \%$ & $1.9 \%$ & $1.9 \%$ & $0.5 \%$ & $0.5 \%$ \\
\cline { 2 - 7 } & 30 & $3.7 \%$ & $1.9 \%$ & $1.7 \%$ & $0.9 \%$ & $2.1 \%$ \\
\hline \multirow{3}{*}{11} & 10 & $2.9 \%$ & $1.8 \%$ & $1.0 \%$ & $0.4 \%$ & $0.0 \%$ \\
\cline { 2 - 7 } & 30 & $3.5 \%$ & $2.9 \%$ & $2.9 \%$ & $1.1 \%$ & $2.1 \%$ \\
\hline \multirow{3}{*}{15} & 10 & $2.6 \%$ & $1.3 \%$ & $1.0 \%$ & $0.5 \%$ & $0.2 \%$ \\
\hline \multirow{3}{*}{17} & 30 & $3.0 \%$ & $3.0 \%$ & $2.6 \%$ & $1.3 \%$ & $2.5 \%$ \\
\cline { 2 - 7 } & 30 & $2.4 \%$ & $2.3 \%$ & $2.2 \%$ & $1.6 \%$ & $0.9 \%$ \\
\hline \multirow{3}{*}{ Pooled } & 10 & $2.8 \%$ & $1.9 \%$ & $1.5 \%$ & $1.1 \%$ & $2.1 \%$ \\
\cline { 2 - 7 } & 30 & $3.7 \%$ & $1.8 \%$ & $1.5 \%$ & $0.8 \%$ & $0.4 \%$ \\
\cline { 2 - 7 } & $10 \& 30$ & $3.1 \%$ & $2.1 \%$ & $1.9 \%$ & $0.9 \%$ & $1.3 \%$ \\
\hline
\end{tabular}

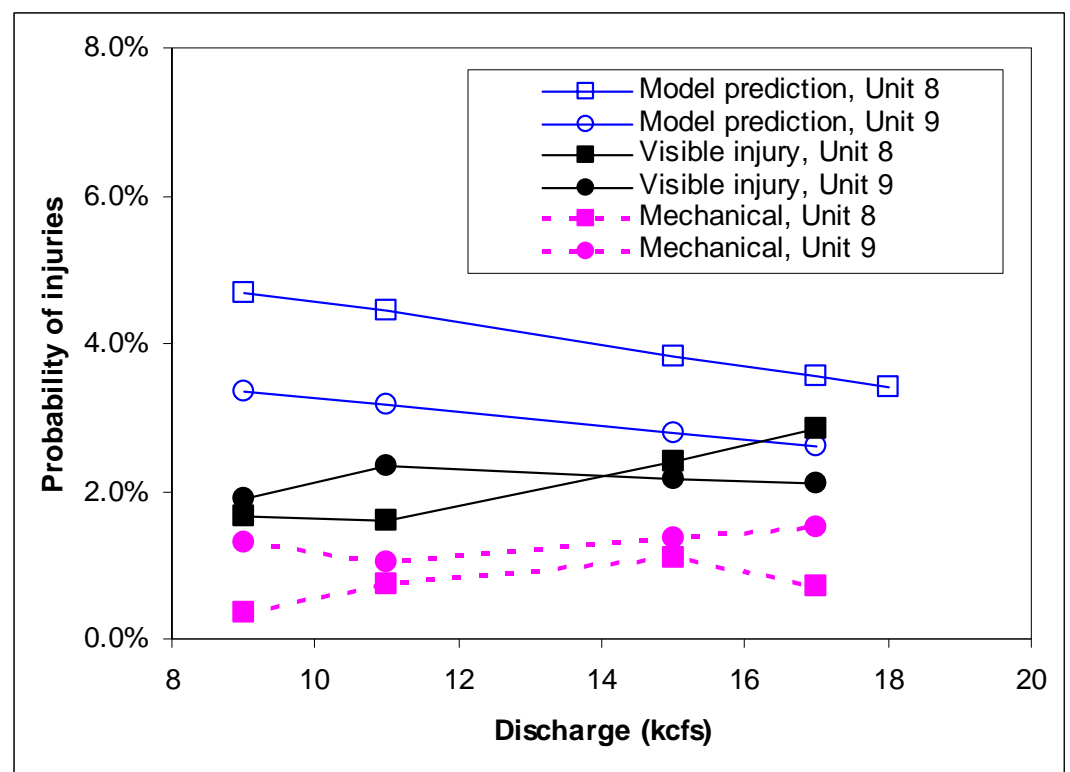

Figure 3.8. Average of the Predicted Injury Rate by the Deterministic Model as a Function of Discharge and Comparison with Different Injury Types and Injury Rates for Juvenile Chinook Salmon 

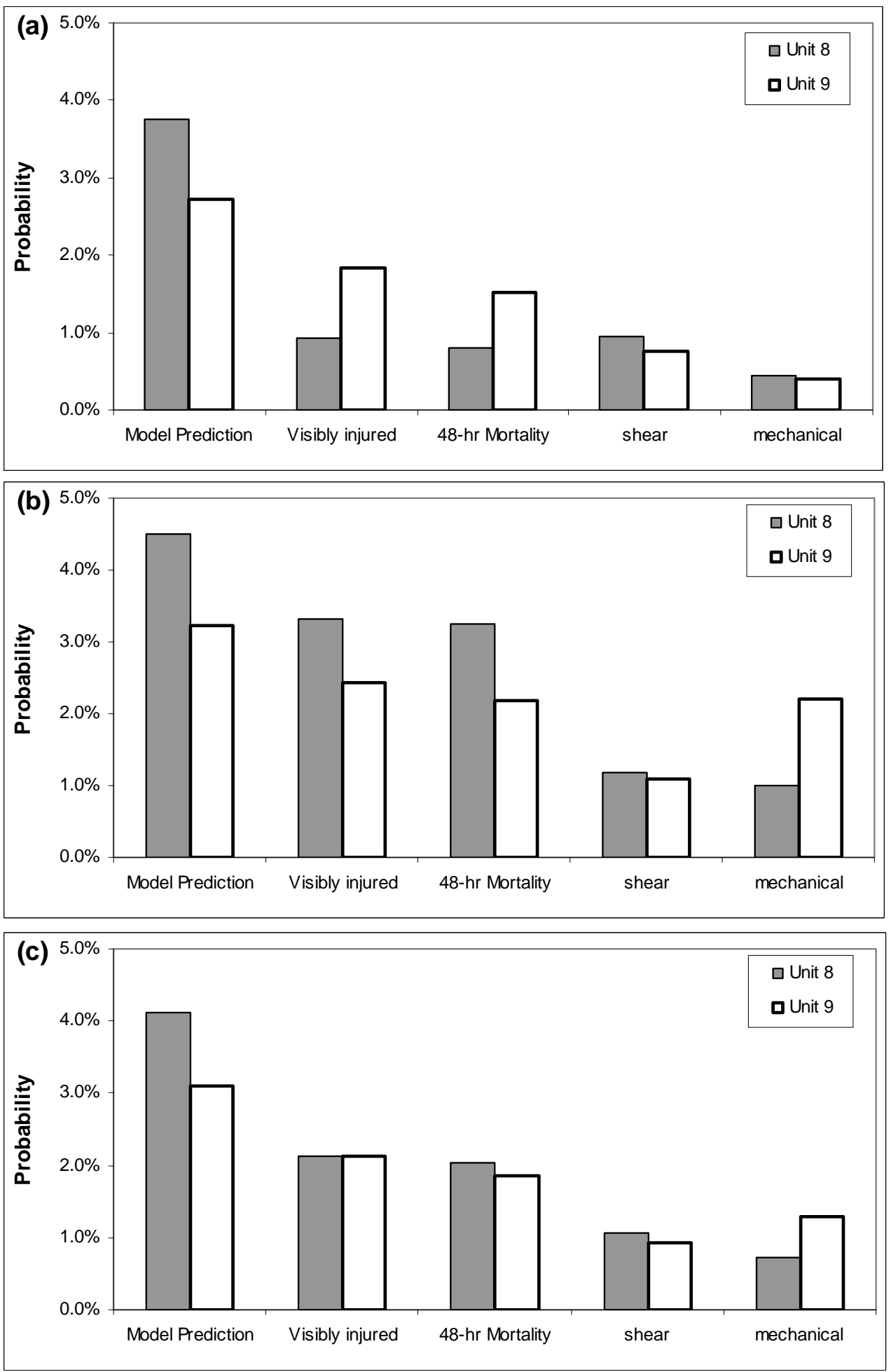

Figure 3.9. Comparing Average Injury Rate Predicted by the Deterministic Model with Empirical Estimates of Visible Injury, 48-hr Mortality, Shear Injury, and Mechanical Injury (a) 10-ft release; (b) 30-ft release; (c) all releases combined. 


\subsubsection{Stochastic Model Results}

For both the Sensor Fish and juvenile salmon, three variables were assigned distributions of possible values in the stochastic simulations. Discharge was assigned a uniform distribution ranging from the minimum to the maximum observed for each turbine at each turbine discharge treatment in the survival study. Distributions were applied for two variables with the greatest uncertainty: fish-passage radius and fish length relative to the leading edge of the runner blade. Fish-passage radius is the radius of a circle with its origin at the center of the runner and its circumference at the location where a fish passed the runner blade. The distribution of fish-passage radius was assumed uniform between the runner hub and discharge ring radii so that the model predicted an average injury rate for fish equally distributed along the runner blades. The mean lengths of released fish and Sensor Fish were $169 \mathrm{~mm}$ (135 to $215 \mathrm{~mm}$ ) and $90.3 \mathrm{~mm}$, respectively, but the orientation of individuals passing the runner blades was unknown. Our previous study showed that the aspect that juvenile fish present to the leading edge of the turbine runner blades was the most significant factor in our models. To account for the uncertainty in test fish orientation during runner passage, we modeled several different normal and uniform distributions of relative fish length at the time of turbine runner entry.

For both Sensor Fish and juvenile fish, the predicted results using the stochastic model were similar for the normal or uniform distribution of relative fish length, as long as the distribution covered any possible orientation or relative length at the instant of passage through the plane of the leading edges of the turbine runner blades. Therefore, only results using the normal distribution were reported.

For both turbine units, similar to the deterministic model, the high variability in the experimental results for different discharges was not present in the predicted blade-strike probabilities (Figure 3.10), and the strike rates were highly correlated with the relative fish length and negatively correlated with discharges (Figure 3.11). In addition, the modeled results were lower than the experimental results.

For all tested discharges of both units, the injury rates predicted by the stochastic model (Figure 3.12) were in close agreement with the rates of visible injury and higher than the mechanical injury rate of the experimental data. The close agreement can be better demonstrated by pooling all test discharges together (Figure 3.13). Even though the injury rates for the original turbine (Unit 9) were slightly lower than those for the new AHTS turbine (Unit 8), there is no significant difference statistically in blade-strike injury probabilities between the two turbines. In addition, the modeled injury rates are highly correlated with the relative fish length or the orientation of fish approaching the leading edge of the runner blades (Figure 3.14). 


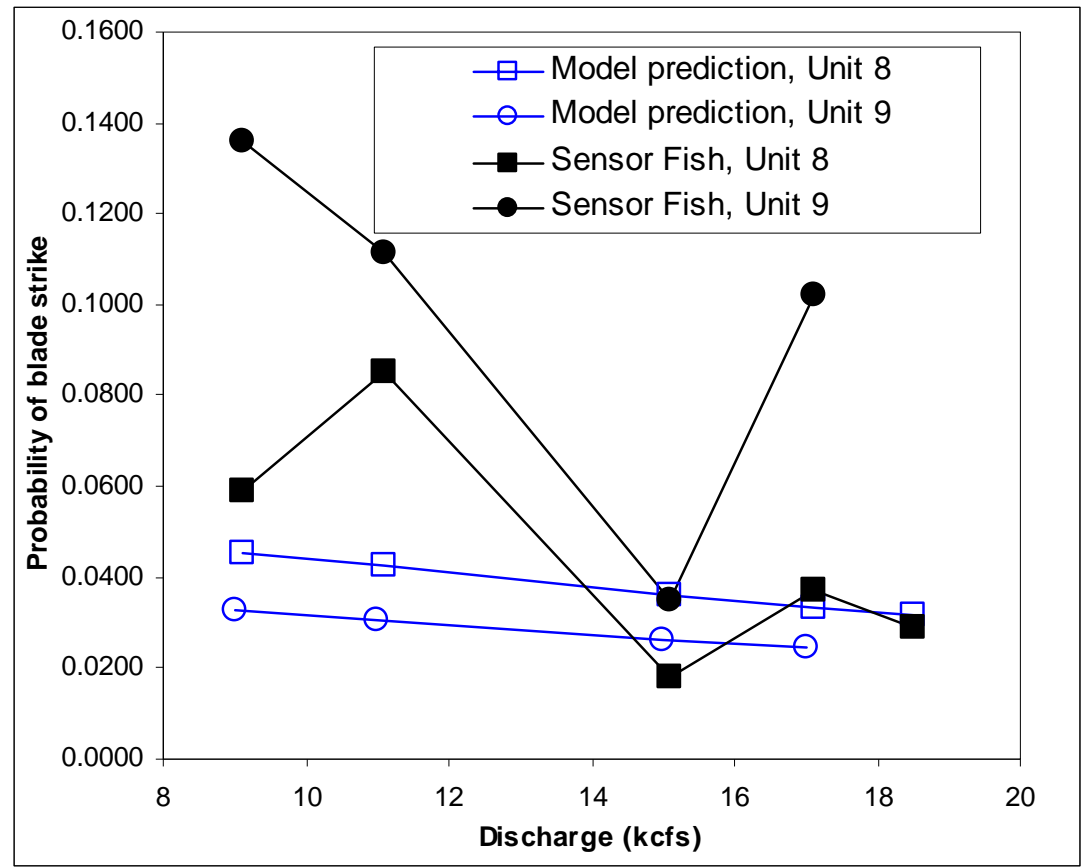

Figure 3.10. Predictions of Blade Strike by the Stochastic Model as a Function of Discharge and Comparison with Sensor Fish Results
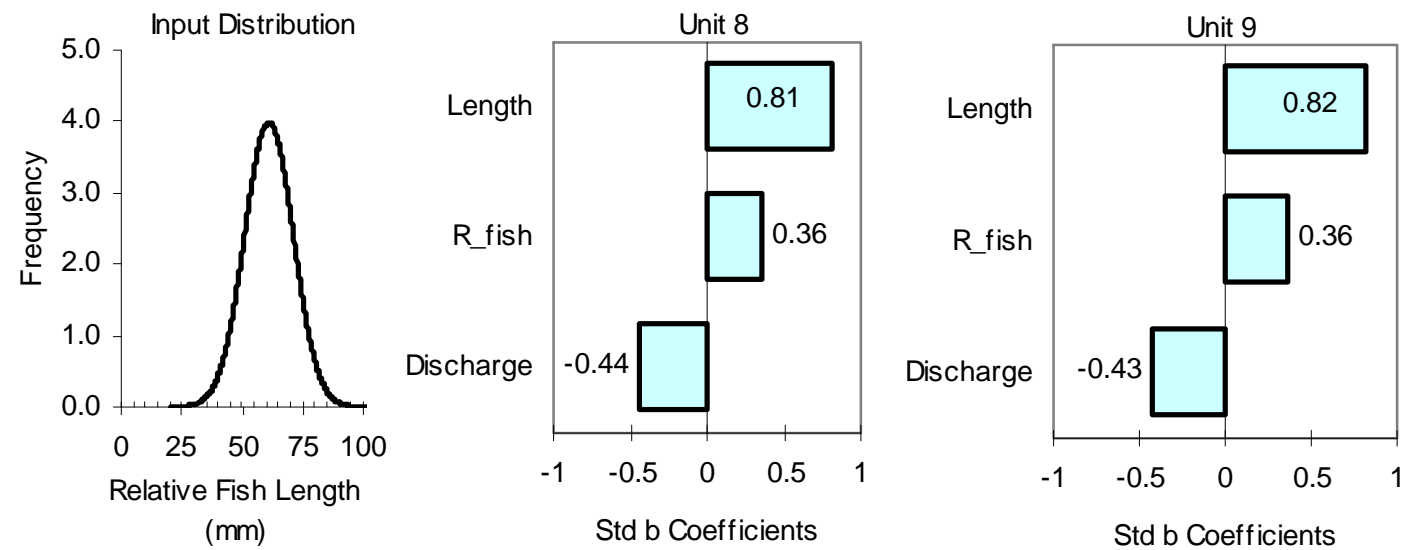

Figure 3.11. Distribution of Assumed Relative Sensor Fish Length (left) and Standardized Regression Coefficients (right) Indicating the Sensitivity of Stochastic Blade Strike Predictions to Relative Fish Length, Discharge, and Fish-Passage Radius (R_fish) 


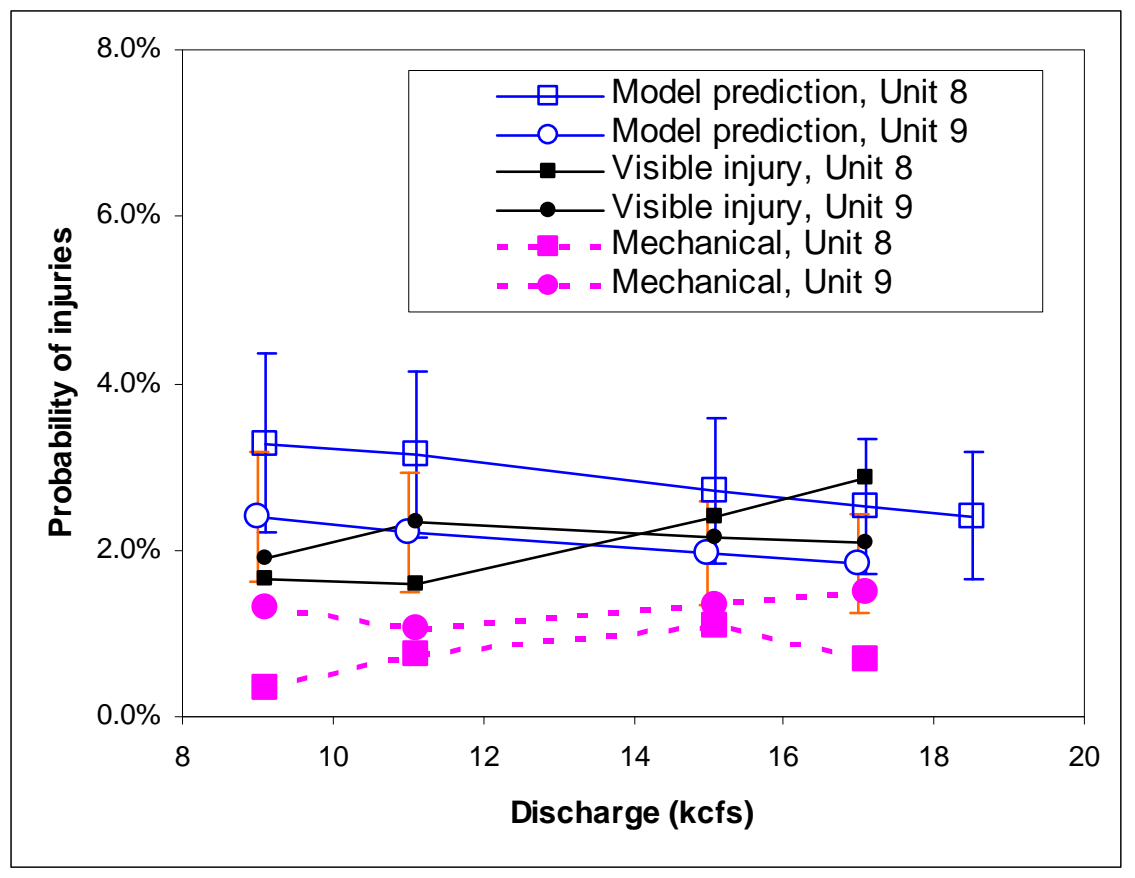

Figure 3.12. Predictions of Blade Strike Injury Rate by the Stochastic Model as a Function of Discharge and Comparison with Different Injury Types and Injury Rates for Juvenile Chinook Salmon

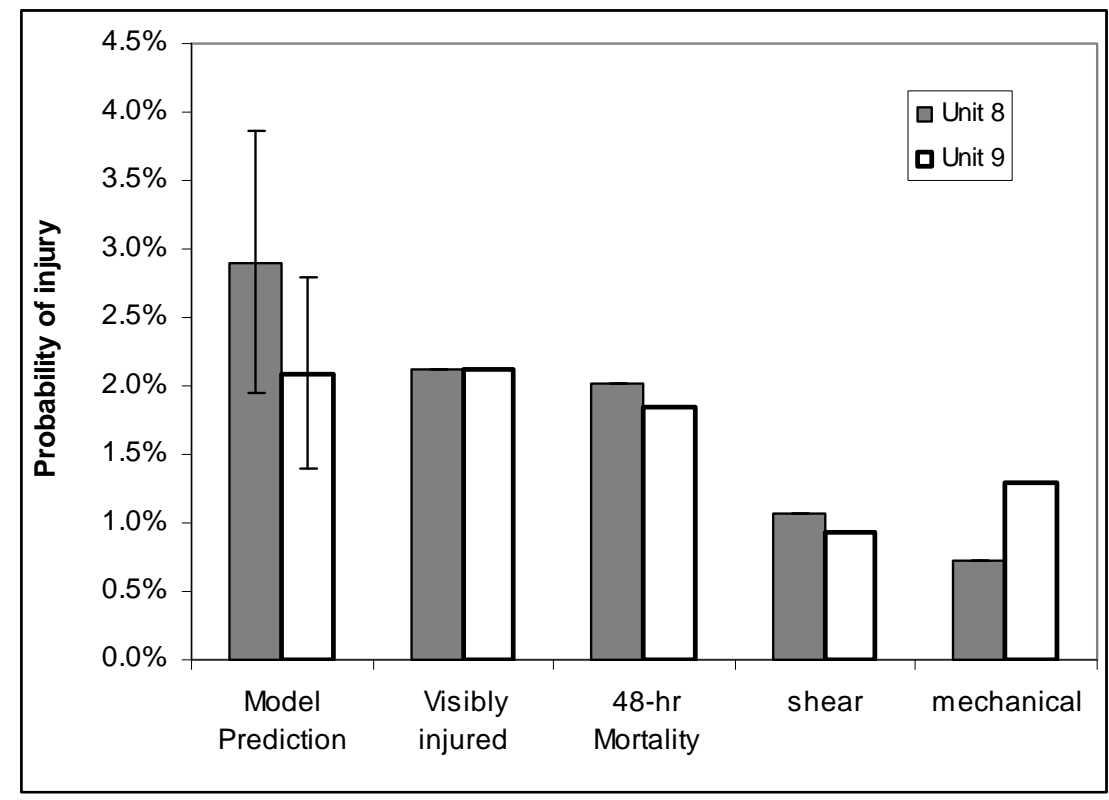

Figure 3.13. Comparing Average Injury Rate Predicted by the Stochastic Model with Empirical Estimates of Visible Injury, 48-hr Mortality, Shear, and Mechanical Injury 

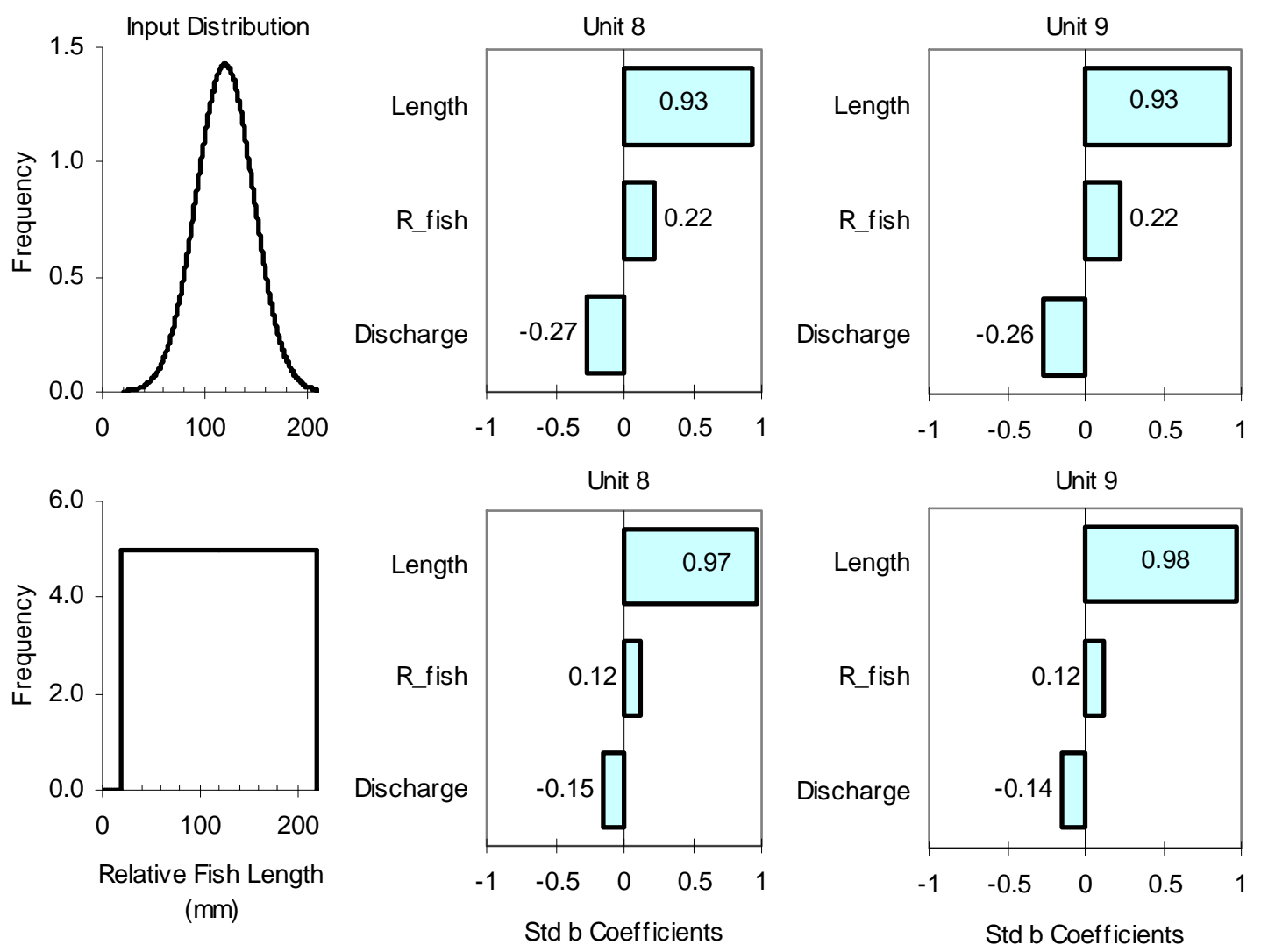

Figure 3.14. Distribution of Assumed Relative Fish Length (left) and Standardized Regression Coefficients (right) indicating the Sensitivity of the Stochastic Injury Predictions to Relative Fish Length, Discharge, and Fish Passage Radius (R_fish)

\subsection{Discussion}

Both deterministic and stochastic blade-strike models were applied for the conventional turbine and new AHT. The modeled probabilities were compared to the Sensor Fish results (Carlson et al. 2006) and the biological studies using juvenile fish (Normandeau et al. 2005) under the same operational parameters.

For both units, there was higher variability in the experimental results between different release locations or discharges than in the numerical results. This observation is consistent with the findings of our previous study in a 1:25-scale physical model (Deng et al. 2005a) showing that the rate of severe contact of neutrally buoyant particles had higher variability between test conditions than the modeled results.

The modeled blade strike probabilities for both units were lower than the experimental results using the Sensor Fish. There are two possible explanations for the under-prediction by the numerical models: 1) because the Sensor Fish has a rigid cylindrical body, any contact between the runner blades and any part of the Sensor Fish body would lead to a strike, which may not be true for a juvenile fish with a flexible body. 2) Because the flows around the runner are highly non-uniform and turbulent, Sensor Fish are not accelerated to the local flow velocity before they are carried by the flow to another location where 
the velocity is different. The Sensor Fish would lag behind the local flows leading to large slip velocity, tumbling of its body, and delay of its "escape" from the region before the next runner blade sweeps.

Injury rates by the deterministic model were higher than the experimental rates of visible injury or mechanical injury but the injury rates predicted by the stochastic model (Figure 3.12) were in close agreement with the rates of visible injury. Fish orientation at the time of entry into the plane of the leading edges of the turbine runner blades is one of the most significant factors and uncertainties in the models. The better agreement between the experimental data and the stochastic model is due to the fact that the stochastic blade-strike model considers the aspect of fish approaching the leading edges of a turbine runner's blades. The AHT has slightly higher modeled injury rates than the conventional turbine, but no statistical evidence to suggest that there is significant difference in blade-strike injury probabilities between the two turbines, which is consistent with the experiment results using Sensor Fish and juvenile fish. 


\subsection{Integrated Analysis of Sensor Fish Data}

\subsection{Introduction}

In spring 2005, Sensor Fish studies were conducted at Wanapum Dam to evaluate advanced turbine design concurrently with balloon-tagged live fish studies conducted by Normandeau Associates. While balloon tag field studies are a necessary prerequisite to evaluation of turbine biological performance, they are limited in that they cannot provide insight into the specific hydraulic conditions or physical stresses that fish experience inside the turbines or the specific causes of the biological response. To overcome this deficiency, an autonomous sensor device (the Sensor Fish) developed by Pacific Northwest National Laboratory (PNNL) was released concurrently with live fish as a means of measuring hydraulic conditions such as pressure, acceleration, and rotation acting on a body in situ during downstream passage (Carlson et al. 2003; Deng et al. 2004).

For the evaluation of the existing and advanced turbines at Wanapum Dam, Sensor Fish were released, along with live balloon-tagged fish into three intake bays at two release elevations at four discharge conditions. The results of these studies were summarized by Carlson et al. (2006).

The overall goal of this study was to employ computational fluid dynamics (CFD) simulations and other analytical techniques to expand the application of Sensor Fish data. Specific objectives were as follows:

- Develop and apply a methodology to classify Sensor Fish acceleration events and to analyze those events for general regions within the turbine system.

- Statistically analyze Sensor Fish data together with live fish biological response data.

- Use Sensor Fish data to determine whether the advanced turbine design features led to improved biological performance.

\subsection{Methods}

In both turbines, Sensor Fish were injected at the centerline of each of three intake bays and at two elevations (498 feet and 478 feet) at the same locations and interspersed with the balloon-tagged fish as shown in Figure 4.1. The two release pipe elevations were $10 \mathrm{ft}$ and $30 \mathrm{ft}$ lower than the turbine roof elevation (508-ft). A total of four discharge conditions $(9,11,15$, and 17 thousand cubic feet per second (kcfs) were studied and 891 Sensor Fish were released. Carlson et al. (2006) provides additional details on the Sensor Fish study methods. 


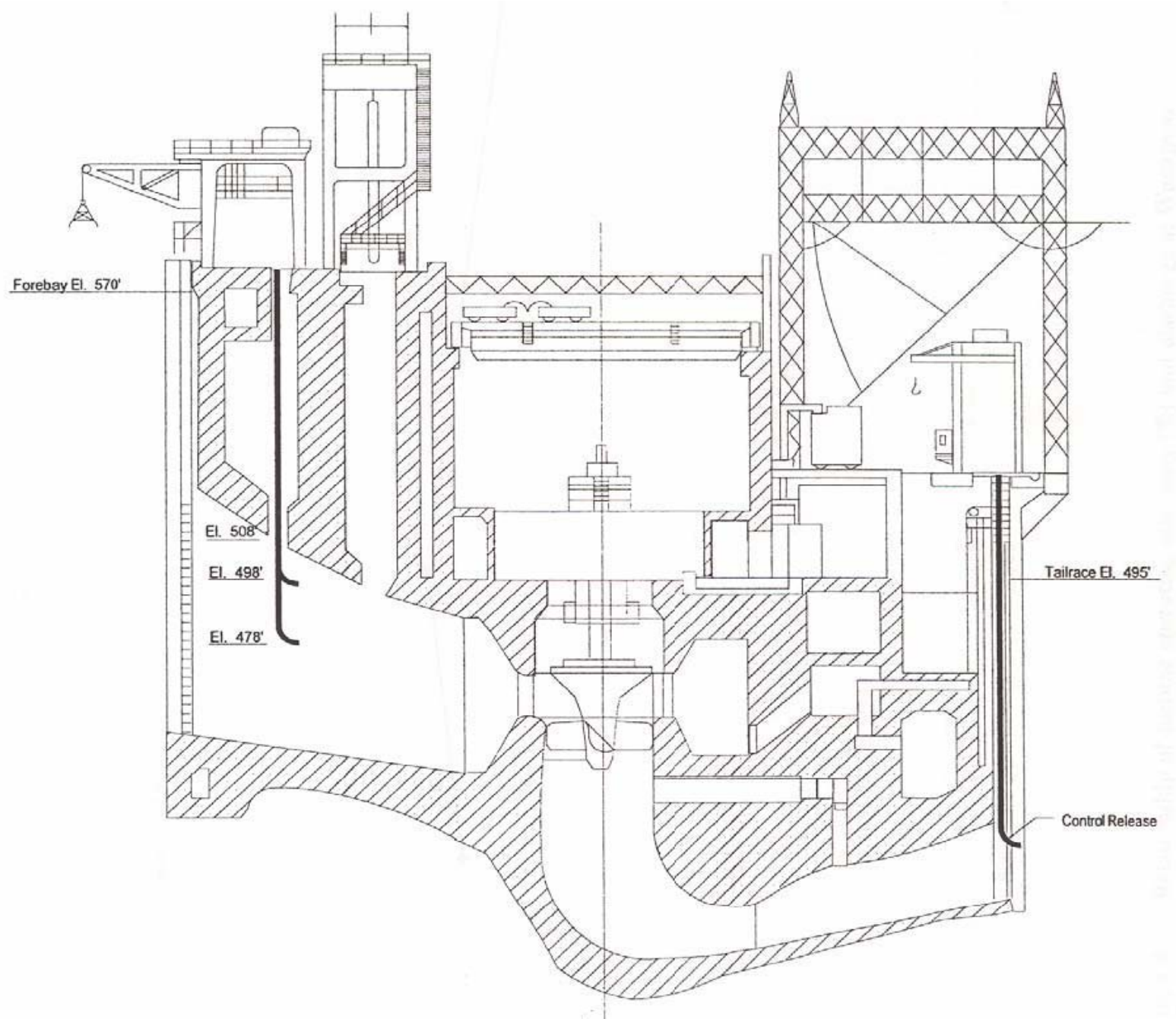

Figure 4.1. Location of Live Fish and Sensor Fish Release Pipes in Wanapum Turbine Intake for Units 8 and 9

\subsubsection{Sensor Fish}

The Sensor Fish (Figure 4.2) is an autonomous device developed at PNNL to better understand the physical conditions fish experience during passage through hydro turbines and other dam bypass alternatives (Carlson et al. 2003). It measures the three components of linear acceleration (up-down, forward-back, and side-to-side) and three components of angular velocities (pitch, roll, and yaw), plus pressure and temperature. The sampling frequency is $2,000 \mathrm{~Hz}$; the pressure transducer, linear accelerometers, and rate gyros have sensitivities of $\pm 0.1 \mathrm{psi}, \pm 100 \mathrm{~g}$, and \pm 1080 degrees/s respectively (Deng et al. 2004). The Sensor Fish Device is $24.5 \mathrm{~mm}$ in diameter and $90 \mathrm{~mm}$ in length, weighs 42 grams, and is nearly neutrally buoyant in fresh water. All Sensor Fish Devices were tested in a calibration apparatus. The relative errors of both the linear acceleration and angular velocity measurements were less than $5 \%$. 


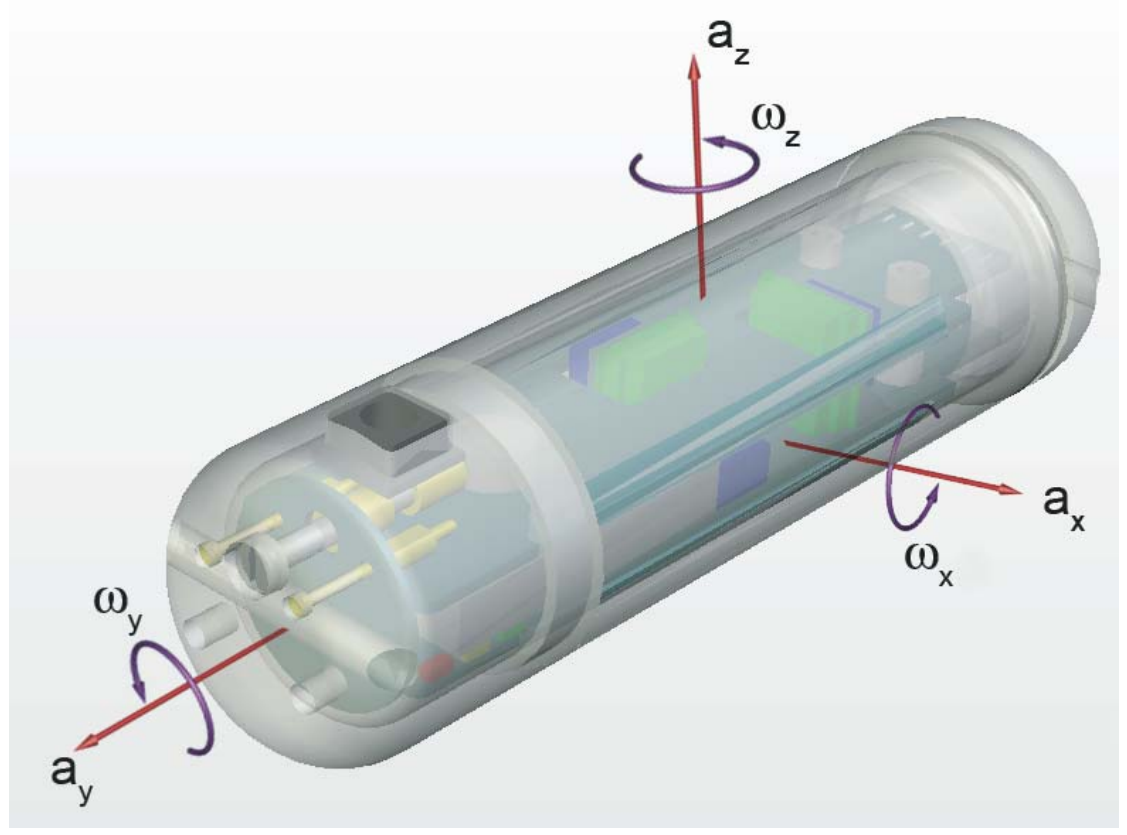

Figure 4.2. The Sensor Fish. Drawing shows the measurement axes for the three components of linear acceleration (up-down, forward-back, and side-to-side) and three components of angular velocities (pitch, roll, and yaw)

Pressure samples are used to estimate the depth of the Sensor Fish (when hydrostatic pressure conditions can be assumed) and other hydraulic phenomena, while accelerometer and rate gyro output is used to measure the Sensor Fish's response to turbulence, strike, and scraping. The remainder of the Sensor Fish's electronics consist of rechargeable batteries, a power supply, an analog-to-digital converter, memory, and communication components. The digital samples acquired during passage are stored in a nonvolatile memory. The memory is accessed after the Sensor Fish is recovered and the acquired data are downloaded to a computer for processing and analysis.

The Sensor Fish is designed to move passively as a near neutrally buoyant object through severe hydraulic environments. The Sensor Fish does not behave like a live fish nor does it have structures that emulate the more sensitive features of live fish, such as eyes; therefore, linkage between the output of the Sensor Fish and injuries to live fish requires concurrent observations of injury to live test fish or some other means to interpret accelerometer output within the context of fish injury.

\subsubsection{Computational Fluid Dynamics Modeling}

The CFD model (STAR-CD, CD-Adapco 1999) was used to solve the unsteady Reynolds-averaged Navier-Stokes equations, together with the k-epsilon turbulence model. STAR-CD is a general purpose finite-volume CFD code that uses an unstructured, hybrid computational mesh. The computational domains included the complete intake, stay vanes, wicket gates, blades, and draft tube. The computational geometry was defined from CAD files provided by Voith Siemens Hydropower. The mesh was generated using Gridgen software (Pointwise 1998).

The so-called arbitrary sliding interface (ASI) technique was used to simulate the motion of the blades and capture the interaction between the wicket gate wakes and blades (rotor-stator interaction). 
The unsteady simulations were computationally intensive and were carried out on a Silicon Graphics Altix parallel computer using as many as 48 processors.

Simulations were performed for the computational domain shown in Figure 4.3. The upstream boundary condition was a uniform inflow velocity corresponding to the upstream inlet area and a discharge of $17 \mathrm{kcfs}$. The downstream boundary was an outflow condition. A slip surface was applied to the forebay and tailrace water surfaces. Standard wall functions were used at all other solid boundaries. The motion of the turbine runner was set to $85.7 \mathrm{rpm}$ (Table 2.1).

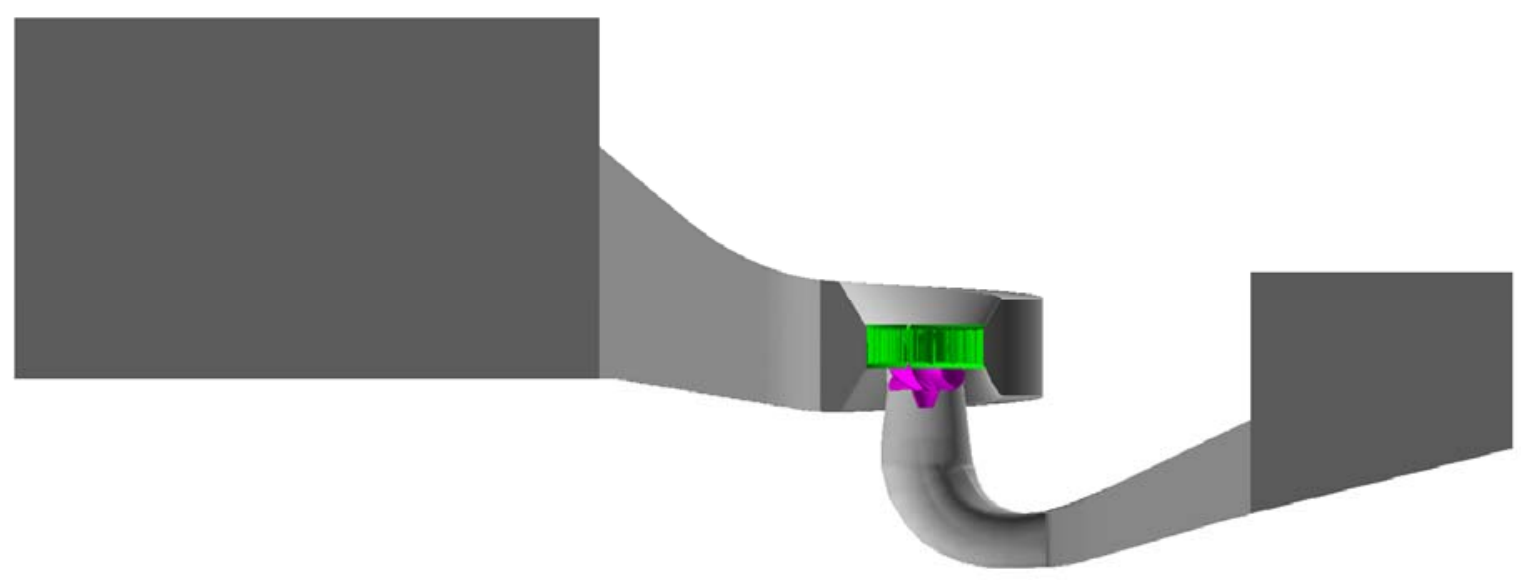

Figure 4.3. Overall Computational Domain Used for the Unit 9 (conventional) Turbine CFD Simulation. A similar domain was used for Unit 8 (AHT).

\subsubsection{Data Analysis}

Sensor Fish pressure and acceleration measurements were analyzed to identify characteristic signatures in each passage time history. Figure 4.4 shows general features such as the time of passage from the injection pipe exit into the turbine intake, through the stay vane-wicket gate cascade, through the runner and runner wake, and through the draft tube.

These distinctive "signature" events were used, together with the CFD and streamline plots, to estimate the probable locations and times of collision or shear exposure events. Representative time history "templates" were developed from the CFD results and compared to Sensor Fish measurements. An example is shown in Figure 4.5 where particles are released just upstream of the stay vanes and wicket gates. The pressure time histories from these particle tracks are shown in Figure 4.6 and were used to classify the regions in the turbine where the Sensor Fish likely traveled. In a similar manner, pressure distributions in the runner region (Figure 4.7) were used to estimate when the Sensor Fish exited that zone. Note that the minimum pressure (nadir) does not necessarily occur at the trailing edge of the runner blade. Using the CFD results as a guide, Sensor Fish acceleration events for each release were classified into four regions (Figure 4.8): intake, wicket gate/stay vane, runner, and draft tube. 


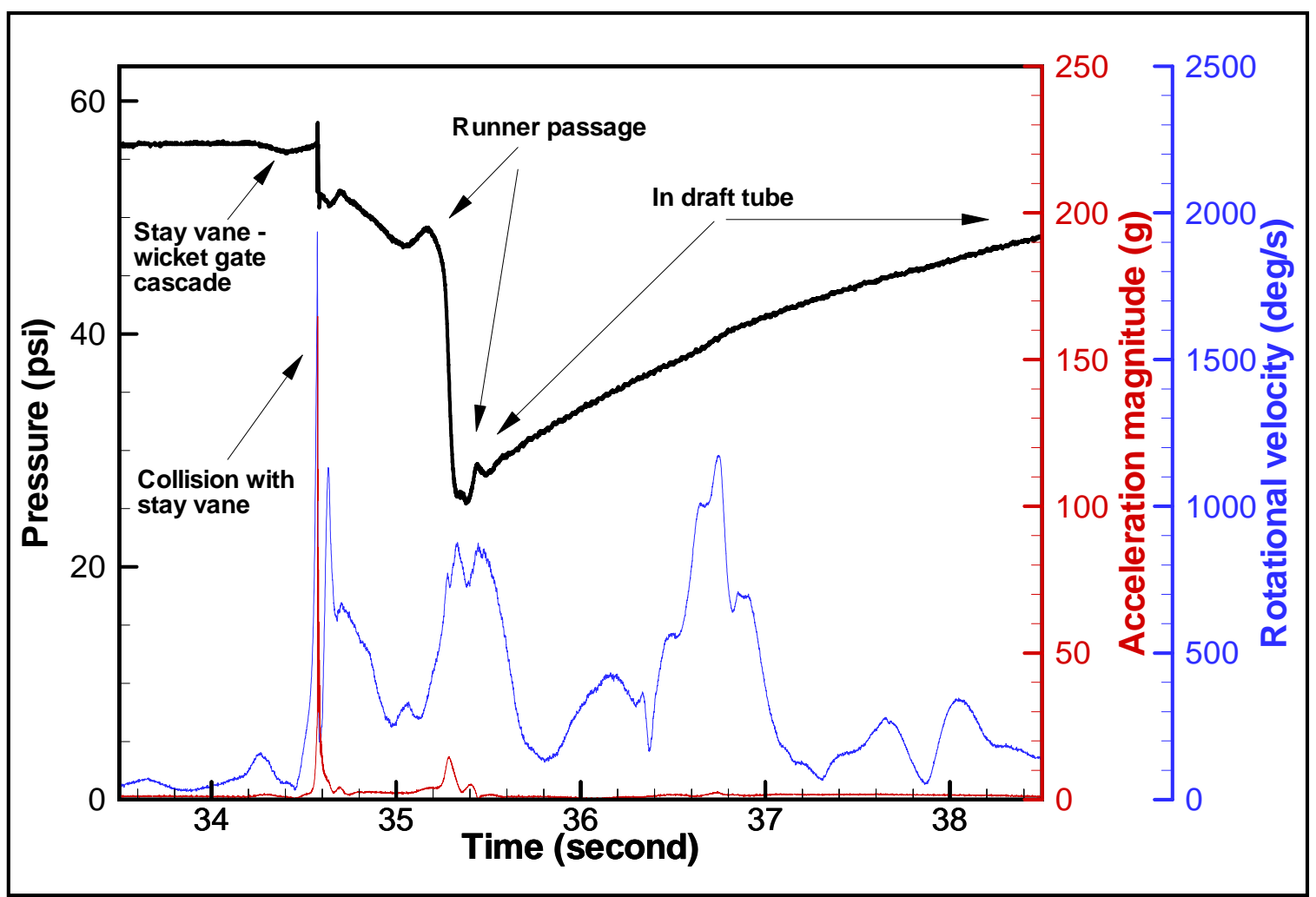

Figure 4.4. Example of Turbine Passage Measurements using the Sensor Fish

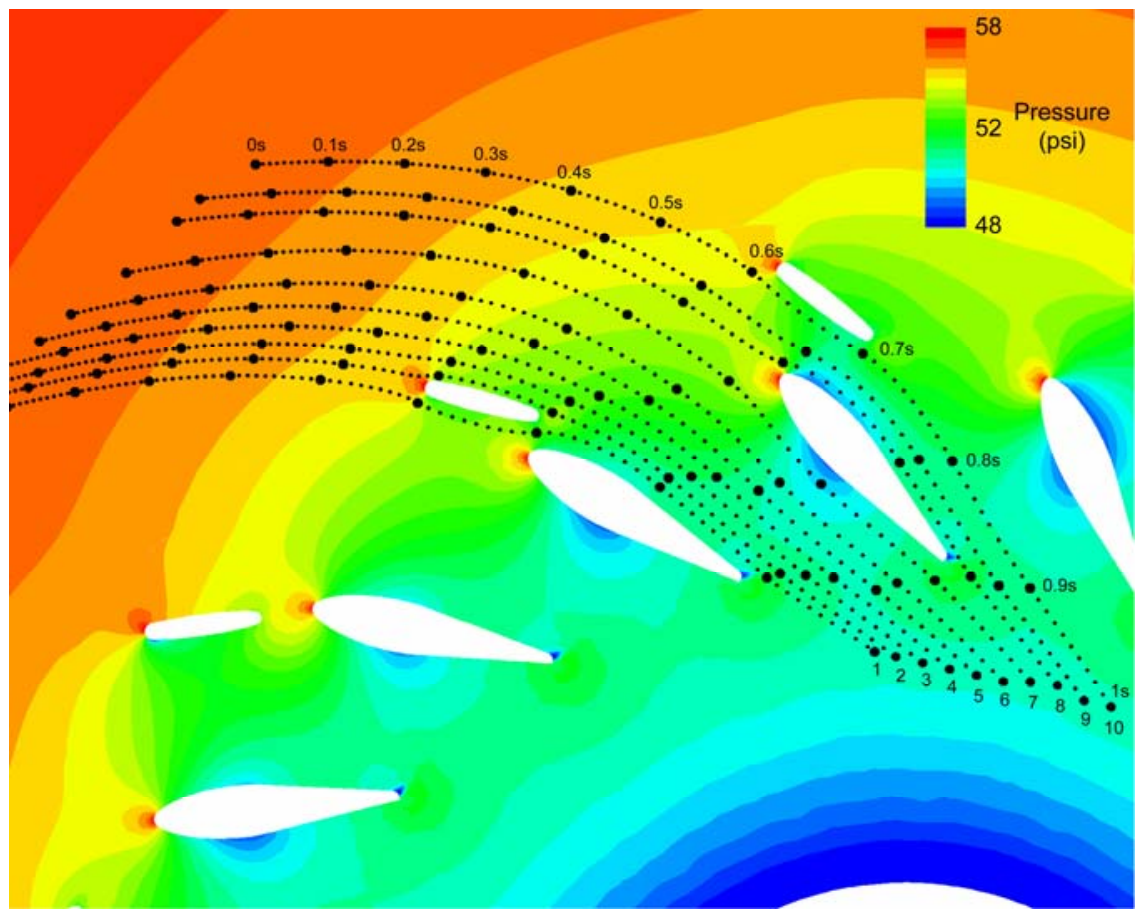

Figure 4.5. Particle Paths in CFD Output along which Typical Pressure Change Profiles Were Determined. Simulation corresponds to $17 \mathrm{kcfs}$ for Unit 9. 

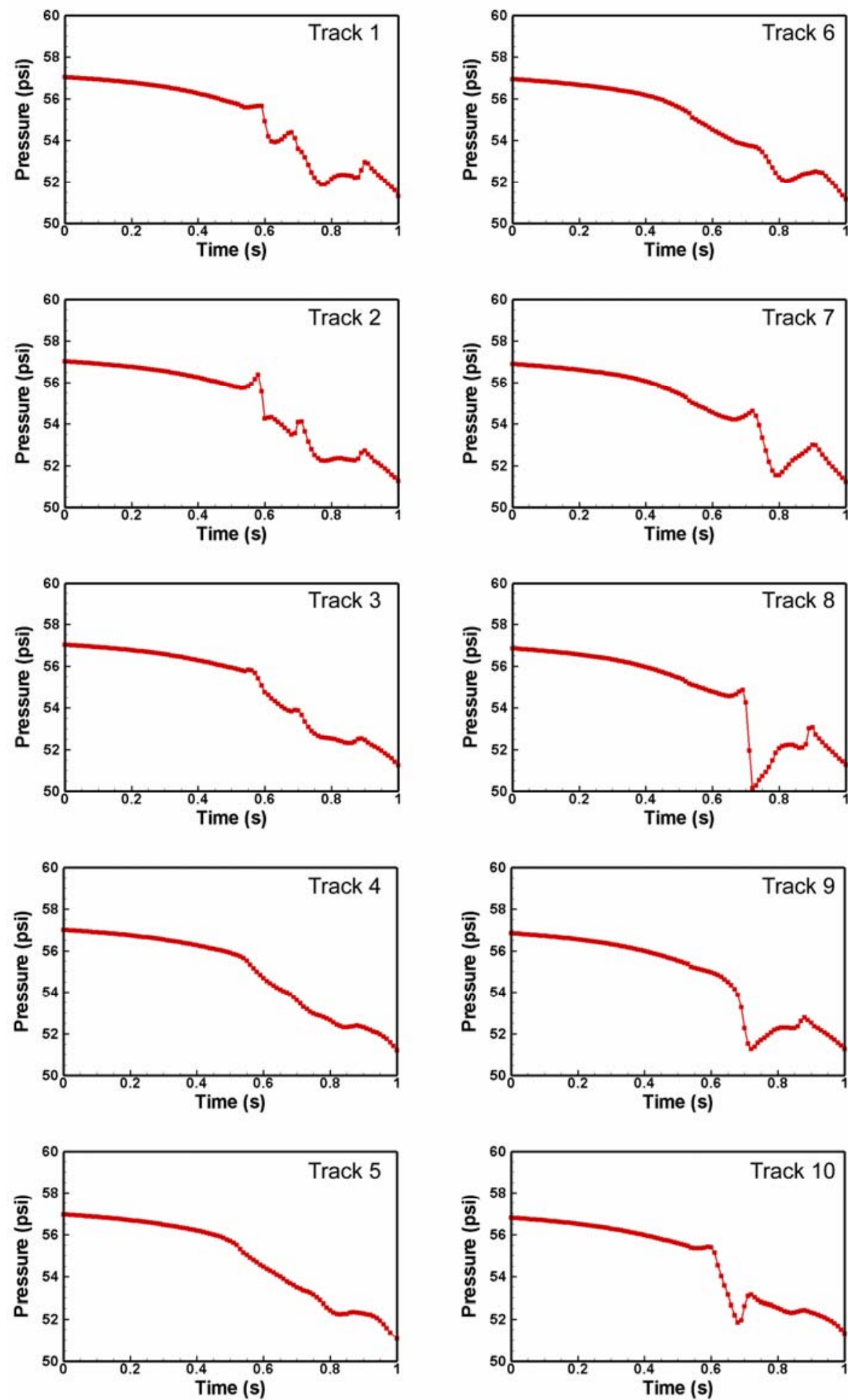

Figure 4.6. Profiles of Pressure along the Trajectories shown in Figure 4.5. These typical profiles were used to develop pressure change signatures used to estimate when and where the Sensor Fish approached and exited the stay vane and wicket gate region. 


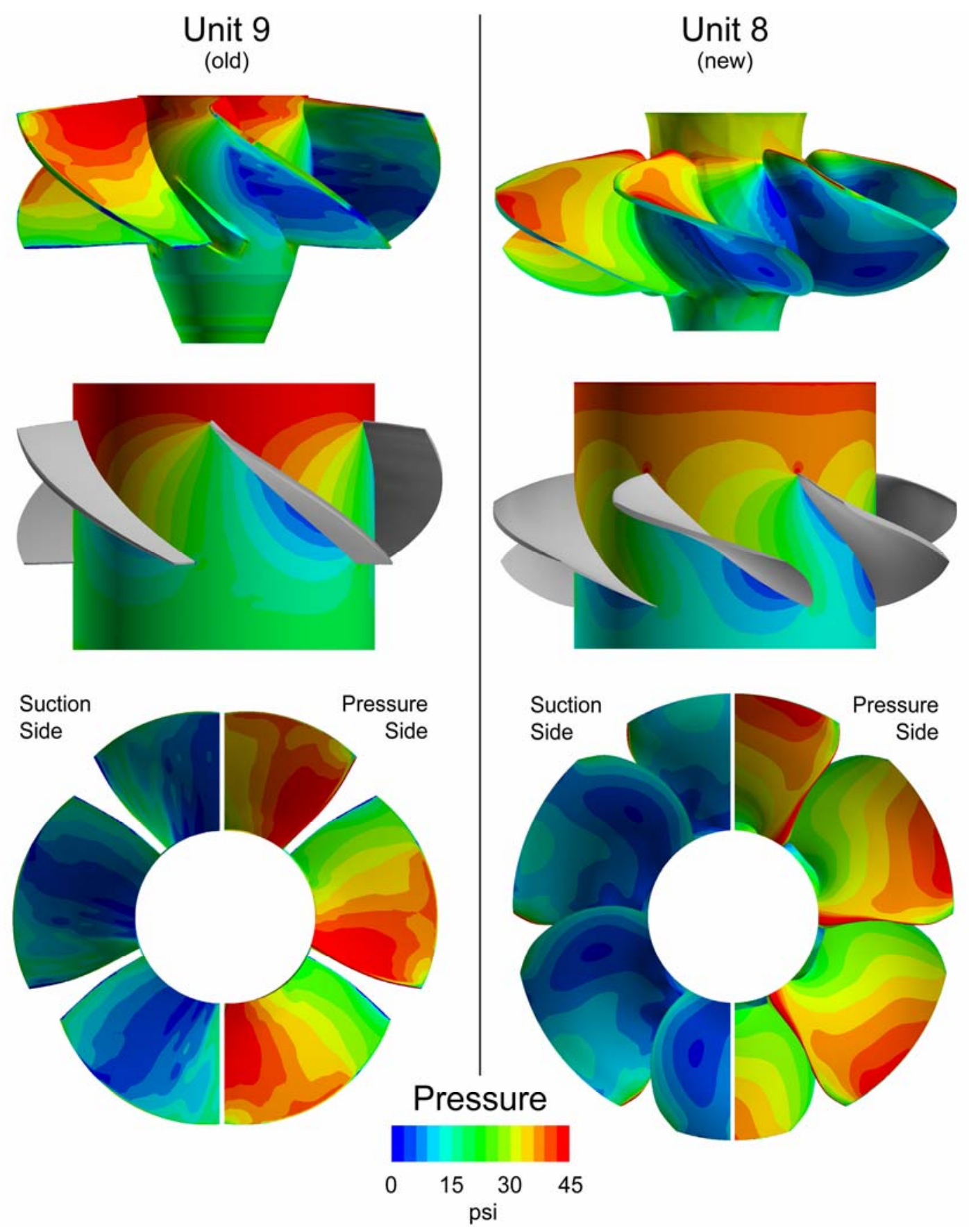

Figure 4.7. Typical Pressure Distribution Used for Estimating when the Sensor Fish Exited the Runner Region. Simulations are for a discharge of $17 \mathrm{kcfs}$ for both turbine units. 

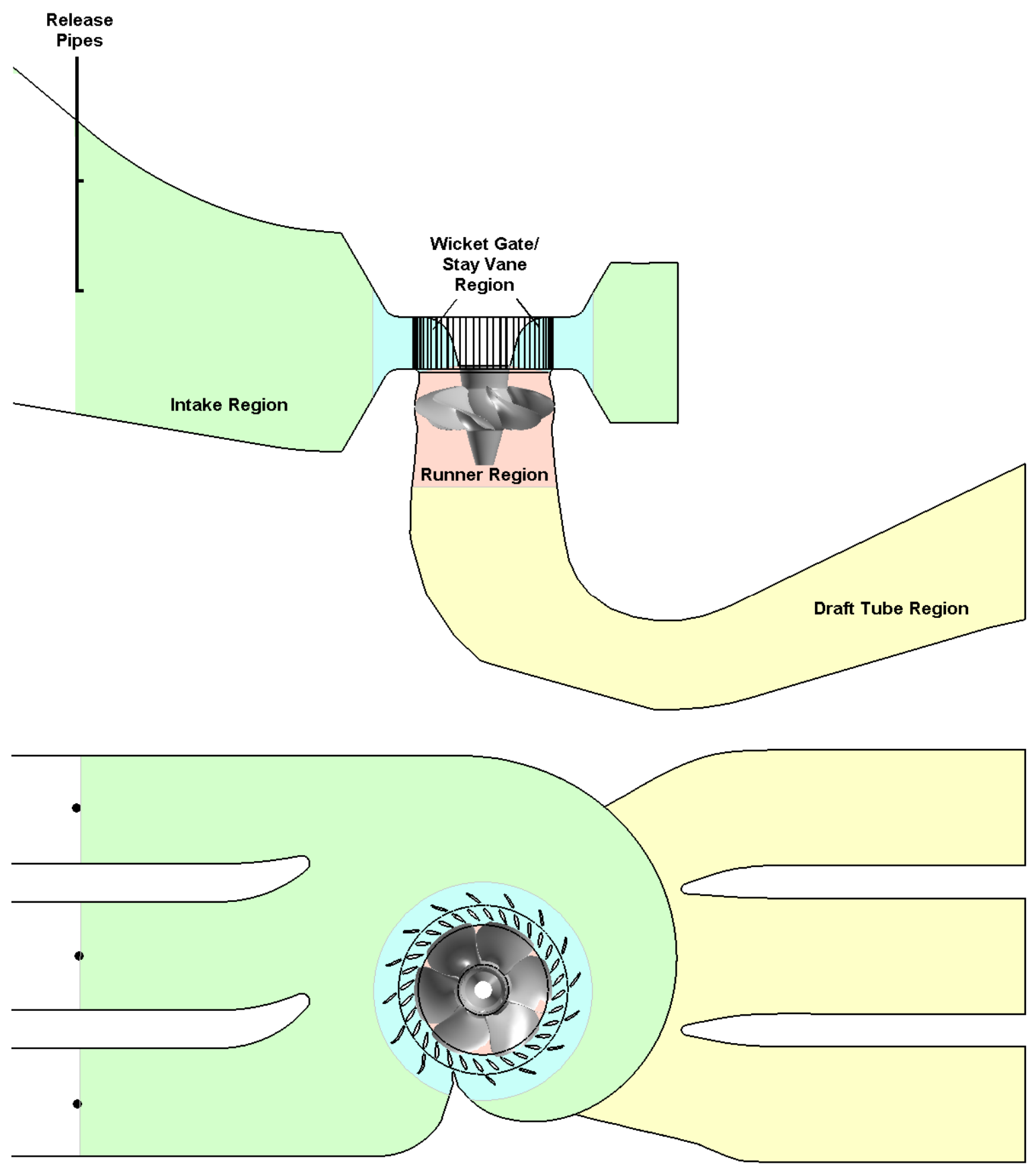

Figure 4.8. Side and Top Views of Turbine Intake, Scrollcase, and Draft Tube

When Sensor Fish are in contact with solid structures or impacted by turbulent shear, high-amplitude impulses occur in the acceleration and rotational velocity time history. If the acceleration reaches a certain threshold, the exposure is counted as a significant exposure event. Based on previous laboratory studies (Deng et al. 2005b), the significant event is further categorized into three levels according to the acceleration magnitude: severe, medium, and slight. The associated values of acceleration magnitude for these levels are shown in Table 4.1. 
Table 4.1. Classification of Sensor Fish Significant Acceleration Events

\begin{tabular}{|c|c|}
\hline Significant Event Type & Acceleration Range \\
\hline Slight & $50 g>|a| \geq 25 g$ \\
\hline Medium & $95 g>|a| \geq 50 g$ \\
\hline Severe & $|a| \geq 95 g$ \\
\hline
\end{tabular}

The identification of an event as collision or shear is based on the different characteristics of acceleration and rotational velocity during the significant exposure event. Observations of Sensor Fish response in a laboratory flume show that a collision event creates a much narrower peak in acceleration and rotational velocity than does a shear event. In this study, peak duration was defined as the duration of acceleration within $70 \%$ of the peak value, and collision and shear events were distinguished by the following criteria: 1) the significant event is a collision event when peak duration is less than 0.0075 second (Figure 4.9(a)); 2) the significant event is a shear event when peak duration is longer than 0.0075 second (Figure 4.9(a)(b)). Pressure and rotational measurements were then used for validation of the classification (Figure 4.9(c)(d)).
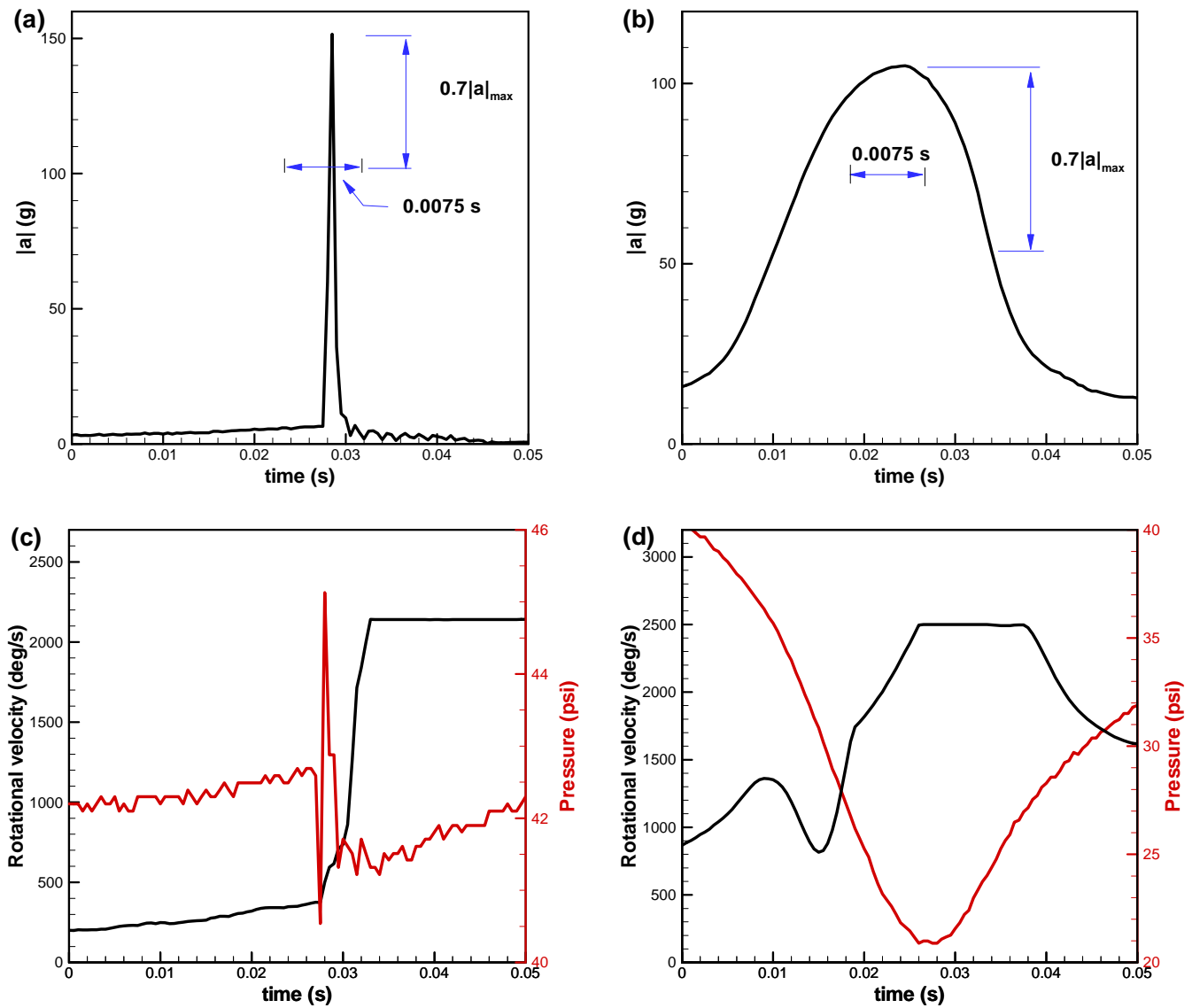

Figure 4.9. Duration of Acceleration within $70 \%$ of the Peak Value is (a) $<0.0075$ second for a collision event; (b) $>0.0075$ second for a shear event. Pressure and rotation increase more dramatically during (c) a collision event than during (d) a shear event. 
Standard deviations of the probabilities of collisions or shear events were derived using the bootstrapping method. Bootstrapping is a statistical method for estimating a sampling distribution by creating more bootstrapped samples by drawing, with replacement, from the original sample (Efron and Tibshirani 1993). This method is very useful in the evaluation of standard errors and confidence intervals of parameters such as mean, median, proportion, odds ratio, correlation, or regression coefficient, especially where there are no other simple alternatives.

\subsubsection{Shear Injury Response Relationship}

In a set of separate laboratory studies, juvenile fall Chinook salmon (Oncorhynchus tshawythscha) and Sensor Fish were exposed to turbulent shear flows to determine how hydraulic conditions affected fish injury response (Neitzel et al. 2004). The studies were designed to establish correlation metrics between Sensor Fish measurements and live fish injuries by conducting concurrent releases in a range of turbulent shear flows. Comparisons were made for two exposure scenarios. In the fast-fish-to-slow-water scenario, test fish were carried by the fast-moving water of a submerged turbulent jet into the standing water of a flume. In the slow-fish-to-fast-water scenario, test fish were introduced into a turbulent jet from standing water through an introduction tube placed just outside the edge of the jet. Motion-tracking analysis was performed on high-speed, high-resolution digital videos of all the releases at water jet velocities ranging from 3 to $22.9 \mathrm{~m} / \mathrm{s}$. Velocities of the Sensor Fish were very similar to those of live fish, but maximum accelerations of live fish were larger than those of Sensor Fish for all the nozzle velocities of both scenarios.

At the present time it is not possible to determine from Sensor Fish data which type of exposure scenario a given shear event represents. However, in a turbine, the Sensor Fish is predominately entrained in fast-moving water and thus it is likely that most shear exposures would be of the fast-fish-to-slowwater type. Figure 4.10 shows the probability of minor and major biological injury for Sensor Fish acceleration measurements for the fast-fish-to-slow-water exposure. Minor injury was classified as visible but not life-threatening injuries, such as minor bruising, operculum damage, slight gill bleeding, minor isthmus tear, minor descaling, or temporary disorientation. Major injury was classified as life-threatening injuries such as severe bruising, bleeding, tearing, creasing, multiple injuries, or prolonged swimming impairment, disorientation, and loss of equilibrium. These classifications followed those established by Neitzel et al. (2004).

The response curves in Figure 4.10 were used to estimate the rates of shear injury from the time histories of Sensor Fish acceleration measurements in Wanapum Units 8 and 9. For example, a 10\% probability of major shear injury was found to occur at Sensor Fish accelerations of $513 \mathrm{~m} / \mathrm{s}^{2}$ for the fastfish-to-slow-water scenario. 

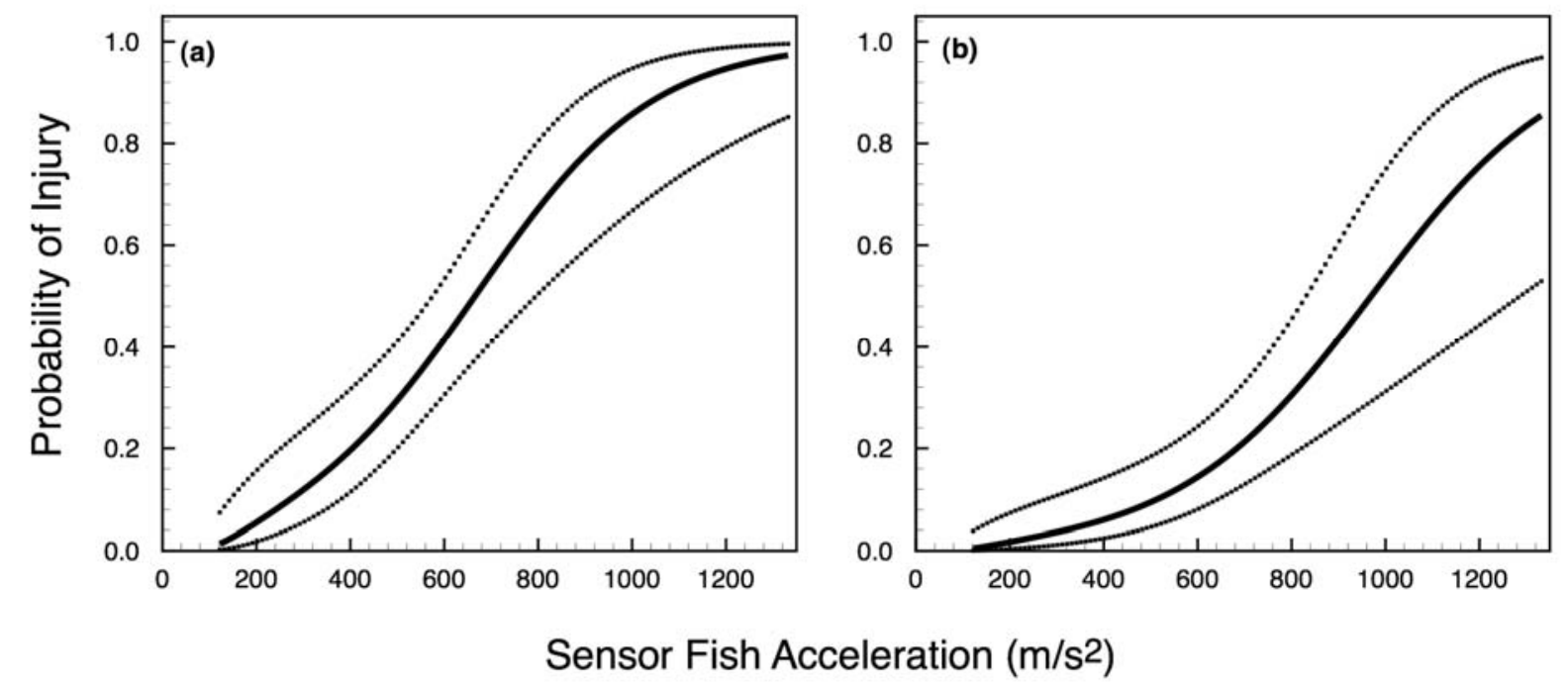

Figure 4.10. Fitted Probability of Minor and Major Injuries as a Function of Sensor Fish Acceleration (with 95\% predictive confidence intervals) as Derived from Binary Logistic Regression. (a) Minor injury for fast-fish-to-slow-water scenario; (b) major injury for fast-fish-to-slowwater scenario.

\subsection{Results and Discussion}

\subsubsection{Sensor Fish Collision and Shear Events}

The Sensor Fish data were divided into four different regions for each release condition (turbine, discharge, release pipe depth, intake bay). The acceleration events recorded for each release were classified as either collision or shear and further by the severity level (severe, medium, or slight). Data were pooled by discharges and release pipes. Note that the three intake bays were pooled together because of the small sample size (15 to 20) for individual treatments. Tabulated results are presented in Appendix A.

\subsubsection{Probabilities of Severe Events}

Severe acceleration events were primarily collisions. Of 891 total releases, there were 185 severe collision events compared to 18 severe shear events. When all four regions were pooled together (Figure 4.11), the two units had statistically indistinguishable probability of severe collisions at $20.5 \% \pm$ $1.8 \%$ and $21.1 \% \pm 2.2 \%$. In addition, the probabilities for both medium and slight collision were similar for both units (Figure 4.11). Unit 8 (AHT) had fewer severe shear events $(1.1 \% \pm 0.5 \%)$ than the conventional Unit $9(3.4 \% \pm 1.2 \%)$, but Unit 8 had more slight shear events $(29.3 \% \pm 2.0 \%)$ than Unit 9 $(19.7 \% \pm 2.5 \%)$.

With all the shear and collision events combined (Figure 4.12), while Unit 8 produced slightly lower probability of severe events $(21.3 \% \pm 1.8 \%)$ than Unit $9(23.7 \pm 2.2 \%)$, there was no statistical evidence to suggest a significant difference of severe or medium events for these two units. However, for both units, the Sensor Fish released from the 30-ft pipe experienced a significantly higher probability of experiencing a severe or medium event than one released from the 10-ft pipe (Figure 4.13). 
In the intake region for both units, there were only very few slight events ( 6 collision and 1 shear); there were no severe or medium events. When all discharges and release elevations are combined, the number of severe events in the stay-vane/wicket-gate and draft tube regions was effectively the same for both units (Figure 4.14). However, there is considerably more variability when the data are broken down by discharge and release elevation (Figures 4.15 through 4.18). Unit 8 had a lower probability of severe events in the runner region compared to Unit 9.

In the stay-vane/wicket-gate region (Table A.1 in Appendix A), Unit 8 had a slightly higher probability of severe collision $(13.6 \% \pm 1.5 \%)$ than Unit $9(10.7 \% \pm 1.7 \%)$. Both units had very few severe shear events $(0.4 \%$ and $0.8 \%$, respectively), but Unit 8 had more slight shear events $(14.2 \% \pm$ $1.5 \%)$ than Unit $9(6.2 \% \pm 1.3 \%)$.

Unit 9 had more severe collision events $(9.6 \% \pm 1.6 \%)$ and more severe shear events $(3.9 \% \pm 1 \%)$ than Unit $8(4.9 \% \pm 0.9 \%$ for severe collision and $0.7 \% \pm 1.1 \%$ for shear $)$.

In the draft tube region (Table A.3), there were very few slight shear events (a total of four) and no severe or medium shear events for both units. In addition, the percentage of severe collisions was almost identical for Unit $8(3.4 \% \pm 0.8 \%)$ and Unit $9(3.4 \pm 1.0 \%)$.

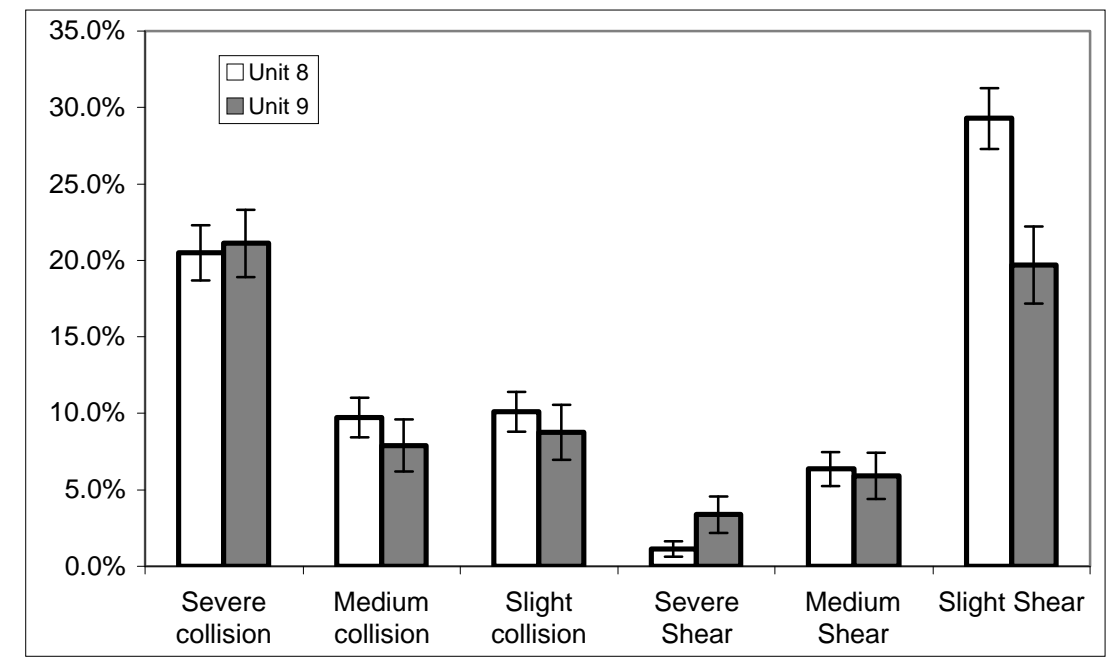

Figure 4.11. Comparison of Probabilities of Collision and Shear Events for the Two Units. All regions, discharges, and release elevations were combined. 


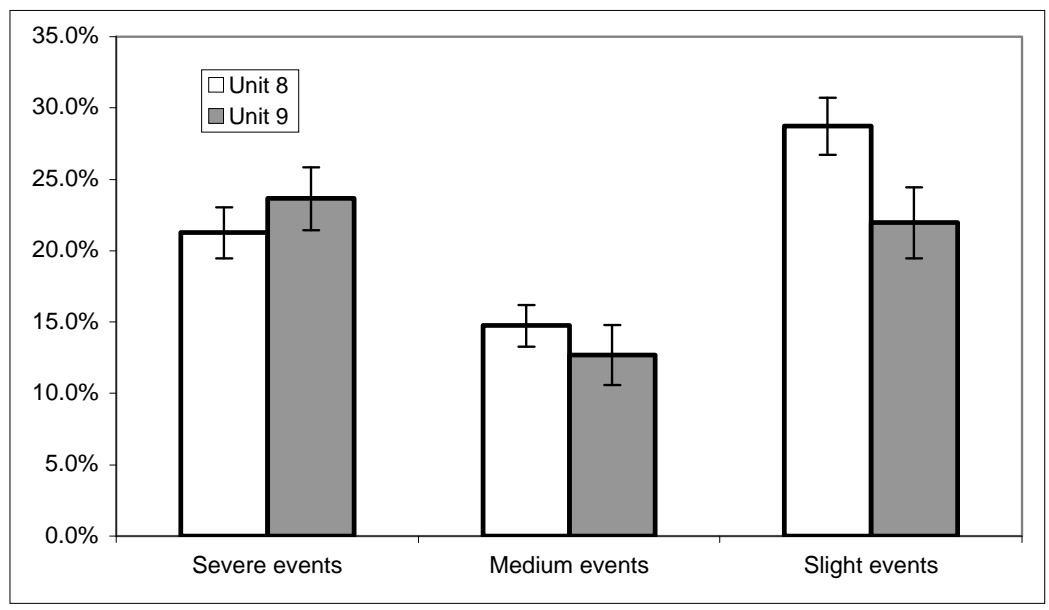

Figure 4.12. Comparison of Probabilities of Significant Events (shear and collision combined) for the Two Units. All regions, discharges, and release elevations were combined.

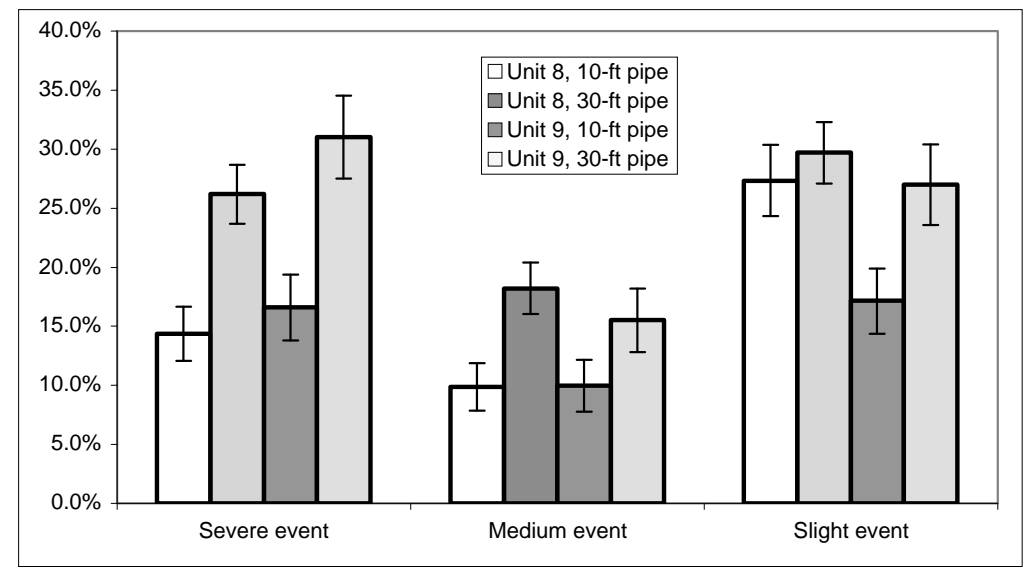

Figure 4.13. Comparison of Probabilities of Significant Events by Different Release Pipe Elevations. All regions and discharges were combined.

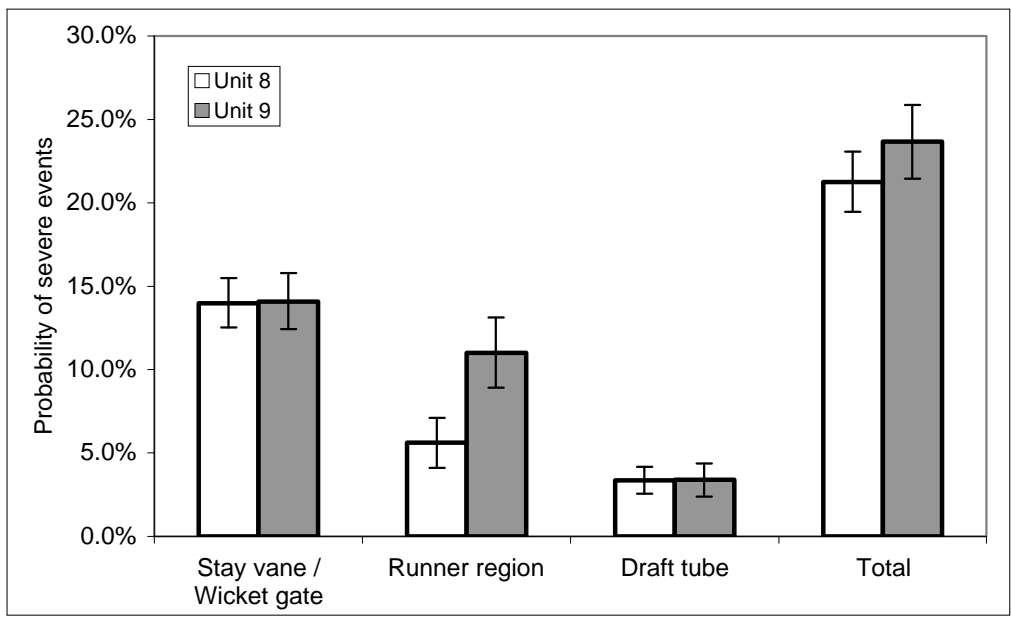

Figure 4.14. Comparison of Probabilities of Severe Collision or Shear Events in Different Regions of the Turbine. All discharges and release elevations were combined. 


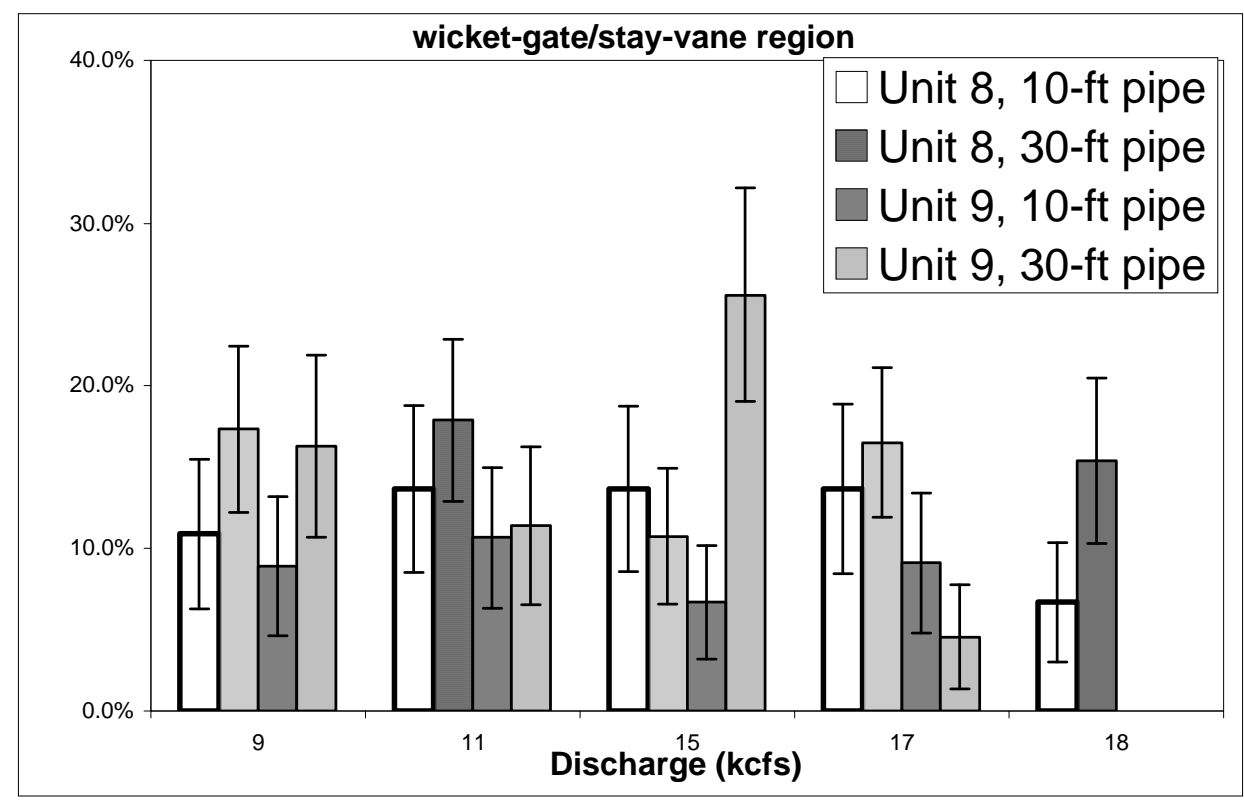

Figure 4.15. Probability of Severe Collision and Shear Events (with standard deviations) for the Wicket Gate/Stay Vane Region. Data from all intake bays were combined.

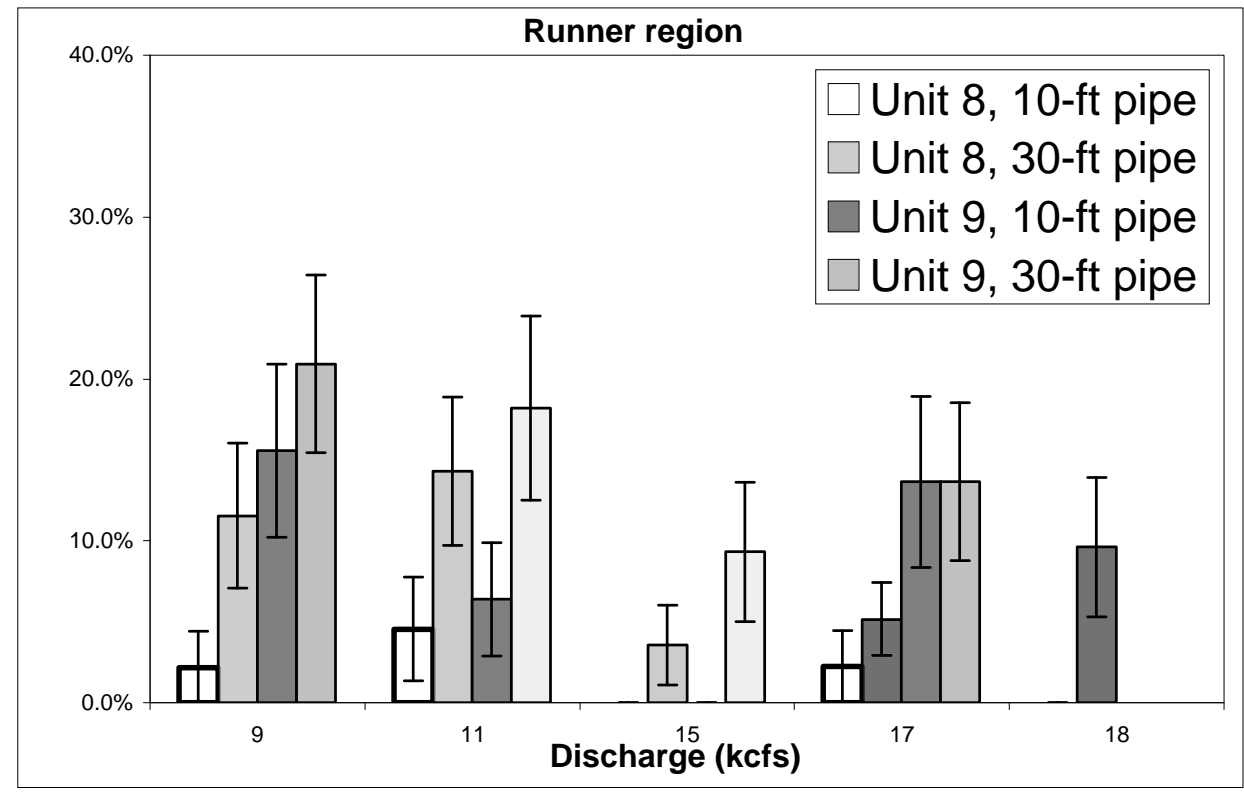

Figure 4.16. Probability of Severe Collision and Shear Events (with standard deviations) for the Runner Region. Data from all intake bays were combined. 


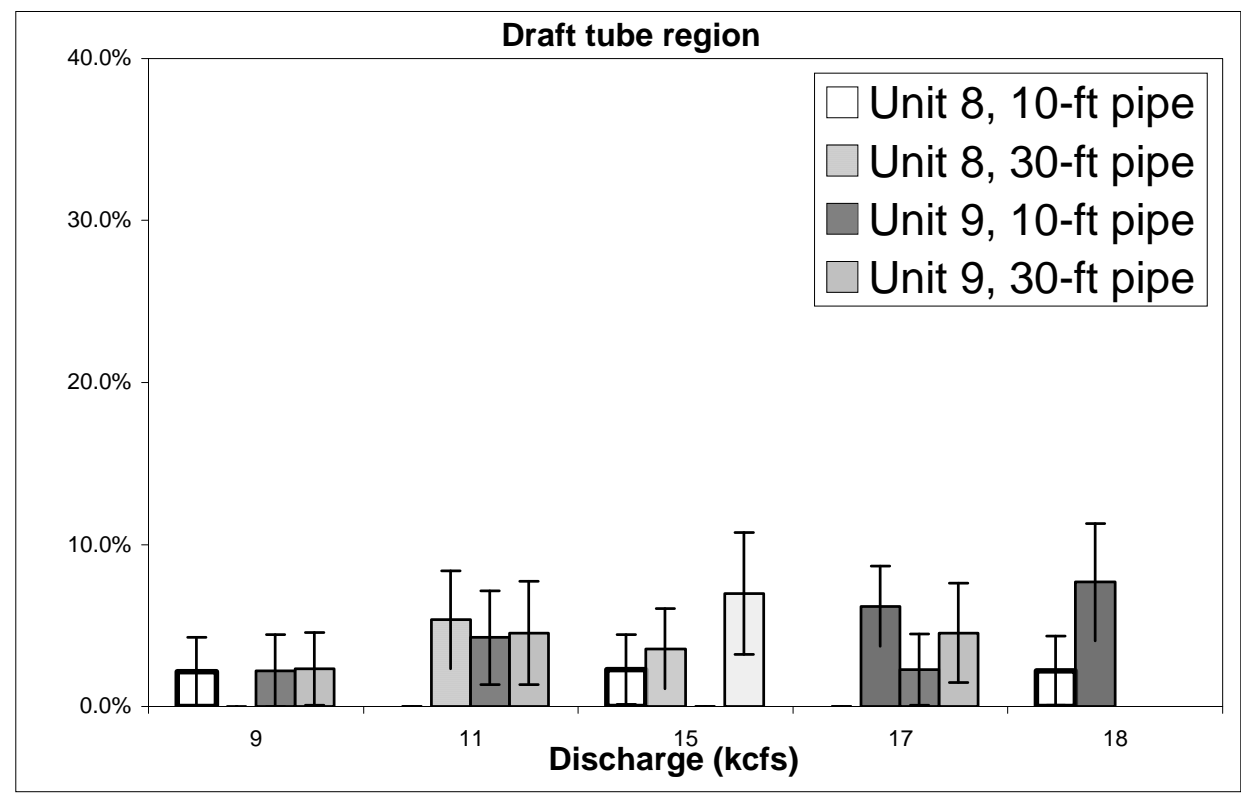

Figure 4.17. Probability of Severe Collision and Shear Events (with standard deviation) for the Draft Tube Region. Data from all intake bays were combined.

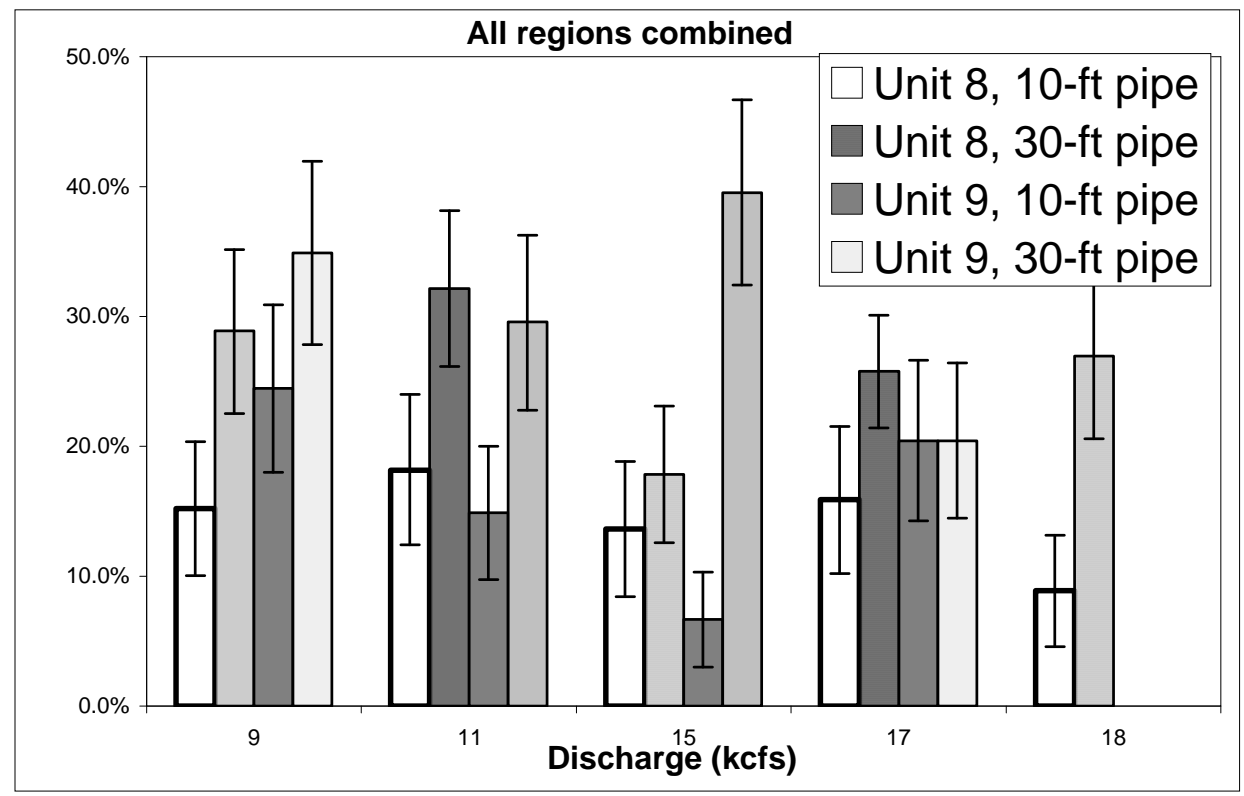

Figure 4.18. Probability of Severe Collision and Shear Events (with standard deviations) for all Regions and Intake Bays Combined

\subsubsection{Relative Importance of Experimental Factors and their Interactions with Severe Events}

The Sensor Fish data were further analyzed to ascertain the relative importance of the experimental factors and their interactions on the counts of severe Sensor Fish events (collisions or shear events) for the overall turbine passage and by each region within the turbine. 
Two statistical analyses were performed. The first was a binomial model of severe events per trial on four experimental factors (unit, discharge, release pipe depth, intake bay). The second analysis performed a ridge regression of a binomial model of severe events per trial on four experimental factors by turbine region (intake, stay-vane/wicket-gate, runner, and draft tube).

A binomial (logistic) regression model was fit taking events per trial as the response variable on four experimental factors. Results for the main effects model are shown in Table 4.2.

Table 4.2. Main Effects Model. Key: NumDF $=$ Numerator degrees of freedom; DenDF $=$ Denominator degrees of freedom; FValue $=$ Value of F-statistic; ProbF $=$ Value for F-stat with NumDF and DenDF degrees of freedom. F-stat is defined as the ratio of sum squared error; $\mathrm{ChiSq}=$ Value of Chi-square statistic; ProbChiSq $=$ P-value for Chi-square with NumDF degrees of freedom.

\begin{tabular}{||l|r|r|r|r|r|r|r|r|r||}
\hline Source & $\begin{array}{l}\text { Change } \\
\text { in } \\
\text { Deviance }\end{array}$ & $\begin{array}{l}\text { Residual } \\
\text { Deviance }\end{array}$ & NumDF & DenDF & FValue & ProbF & ChiSq & ProbChiSq & \\
\hline Intercept & & 54.6511 & & & & & & & \\
\hline Pipe & 14.3414 & 40.3097 & 1 & 40 & 16.57 & 0.0002 & 16.57 & $<.0001$ & $\star \star \star$ \\
\hline Q & 3.3299 & 36.9798 & 3 & 40 & 1.28 & 0.2935 & 3.85 & 0.2784 & \\
\hline Unit & 1.3532 & 35.6266 & 1 & 40 & 1.56 & 0.2184 & 1.56 & 0.2111 & \\
\hline Bay & 1.0104 & 34.6162 & 2 & 40 & 0.58 & 0.5625 & 1.17 & 0.5578 & \\
\hline
\end{tabular}

Intake bay of release showed the lowest predictive power and was subsequently dropped from the analysis. The next model took the three main effects and all possible interactions (Table 4.3).

Table 4.3. Saturated Model. Key: NumDF $=$ Numerator degrees of freedom; DenDF $=$ Denominator degrees of freedom; FValue $=$ Value of F-statistic; ProbF $=$ Value for F-stat with NumDF and DenDF degrees of freedom. F-stat is defined as the ratio of sum squared error; $\mathrm{ChiSq}=$ Value of Chi-square statistic; ProbChiSq = P-value for Chi-square with NumDF degrees of freedom.

\begin{tabular}{|c|c|c|c|c|c|c|c|c|c|}
\hline Source & $\begin{array}{l}\text { Residual } \\
\text { Deviance }\end{array}$ & Deviance & NumDF & DenDF & FValue & ProbF & ChiSq & ProbChiSq & \\
\hline Intercept & 54.65 & & & & & & & & \\
\hline Pipe & 40.31 & 14.34 & 1 & 32 & 20.12 & $<.0001$ & 20.12 & $<.0001$ & $\star \star * *$ \\
\hline $\mathrm{Q}$ & 36.98 & 3.33 & 3 & 32 & 1.56 & 0.219 & 4.670 & 0.198 & \\
\hline pipe*Q & 33.24 & 3.74 & 3 & 32 & 1.75 & 0.176 & 5.250 & 0.154 & \\
\hline Unit & 32.05 & 1.18 & 1 & 32 & 1.66 & 0.207 & 1.660 & 0.198 & \\
\hline Unit*pipe & 32.05 & 0.00 & 1 & 32 & 0.00 & 0.979 & 0.000 & 0.979 & \\
\hline Unit* $Q$ & 29.56 & 2.49 & 3 & 32 & 1.16 & 0.339 & 3.490 & 0.322 & \\
\hline Unit* pipe ${ }^{\star} Q$ & 22.81 & 6.75 & 3 & 32 & 3.16 & 0.038 & 9.480 & 0.024 & $* *$ \\
\hline
\end{tabular}

From the results in Table 4.3, only the three-way interaction of unit, release pipe depth, and discharge showed significance. In the next step of the analysis, all two-way interactions were dropped and a final model was fit with three main effects and three-way interaction (Table 4.4). This step facilitated estimation of specific differences in severe event rates between units 8 and 9 at all combined levels of discharge (Q) and release pipe depth (Table 4.5). 
Table 4.4. Final Model with Three Main Effects and Three-Way Interaction. Key: NumDF = Numerator degrees of freedom; DenDF $=$ Denominator degrees of freedom; FValue $=$ Value of F-statistic; ProbF = Value for F-stat with NumDF and DenDF degrees of freedom. F-stat is defined as the ratio of sum squared error; $\mathrm{ChiSq}=$ Value of Chi-square statistic; ProbChiSq $=\mathrm{P}$-value for Chi-square with NumDF degrees of freedom.

\begin{tabular}{|c|c|c|c|c|c|c|c||}
\hline Source & NumDF & DenDF & FValue & ProbF & ChiSq & ProbChiSq & \\
\hline pipe & 1 & 32 & 21.95 & $<.0001$ & 21.95 & $<.0001$ & $* \star *$ \\
\hline $\mathrm{Q}$ & 3 & 32 & 1.91 & 0.1473 & 5.74 & 0.1250 & \\
\hline unit & 1 & 32 & 0.84 & 0.3662 & 0.84 & 0.3594 & \\
\hline Unit $^{\star}$ pipe ${ }^{\star} \mathrm{Q}$ & 10 & 32 & 1.80 & 0.1014 & 17.98 & 0.0552 & $*$ \\
\hline
\end{tabular}

Table 4.5. Least Squares Means and Differences in Model Predicted Mean Event Rates between Units 8 and 9 by Discharge Level (Q) and Release Pipe (Note estimate (Est) and SE(Est) values in Table 4.5 are on the logit scale.) Highlight indicates statistically significant results.

\begin{tabular}{|c|c|c|c|c|c|c|c|c|c|c|c|c|c|}
\hline & & \multicolumn{3}{|c|}{ Unit 8} & \multicolumn{3}{|c|}{ Unit 9} & \multicolumn{5}{|c|}{ Unit 8 - Unit 9} & \\
\hline pipe & $\mathrm{Q}$ & $\begin{array}{c}\text { Est } \\
\text { (logit) }\end{array}$ & SE(Est) & $\begin{array}{c}\text { Pred. } \\
\text { event } \\
\text { rate }\end{array}$ & $\begin{array}{c}\text { Est } \\
\text { (logit) }\end{array}$ & SE(Est) & $\begin{array}{l}\text { Pred. } \\
\text { event } \\
\text { rate }\end{array}$ & $\begin{array}{l}\text { Est. } \\
\text { (logit) }\end{array}$ & SE(Est) & DF & ChiSq & ProbChiSq & \\
\hline 10 & 9 & -1.718 & 0.347 & 0.152 & -1.128 & 0.293 & 0.244 & -0.589 & 0.454 & 1 & 1.69 & 0.194 & \\
\hline 30 & 9 & -0.903 & 0.258 & 0.288 & -0.624 & 0.270 & 0.349 & -0.279 & 0.374 & 1 & 0.56 & 0.456 & \\
\hline 10 & 11 & -1.504 & 0.330 & 0.182 & -1.584 & 0.328 & 0.170 & 0.080 & 0.465 & 1 & 0.03 & 0.863 & \\
\hline 30 & 11 & -0.666 & 0.238 & 0.339 & -0.869 & 0.279 & 0.295 & 0.203 & 0.367 & 1 & 0.3 & 0.581 & \\
\hline 10 & 15 & -1.846 & 0.371 & 0.136 & -2.639 & 0.505 & 0.067 & 0.793 & 0.626 & 1 & 1.6 & 0.205 & \\
\hline 30 & 15 & -1.526 & 0.295 & 0.179 & -0.425 & 0.263 & 0.395 & -1.101 & 0.395 & 1 & 7.77 & 0.005 & ** \\
\hline 10 & 17 & -1.665 & 0.348 & 0.159 & -1.099 & 0.294 & 0.250 & -0.566 & 0.456 & 1 & 1.55 & 0.214 & \\
\hline 30 & 17 & -1.058 & 0.196 & 0.258 & -1.358 & 0.316 & 0.205 & 0.300 & 0.371 & 1 & 0.65 & 0.419 & \\
\hline
\end{tabular}

The only significant difference in severe event rates between Units 8 and 9 occurred at the discharge (Q) of $15 \mathrm{kcfs}$ for the 30 -ft pipe. Under this configuration, there were 10 severe events in 56 releases for Unit 8 and 17 severe events in 43 releases for Unit 9.

The final model for severe event rates for overall passage was then carried over to analyze severe event rates by region within the turbine (Table 4.6). When the Sensor Fish passage data were broken out by turbine region, there were several cases where no severe events occurred. For the Intake region there are no severe events in either turbine unit so this region was dropped from further analyses. However, in the other three regions, there were cases of zero severe event counts that compromised the fit of the binomial model. In these instances a method known as "ridge-regression" (Neter et al. 1990) was used to impute a small positive bias $(\mathrm{k}=0.1)$ for the zero counts before fitting the model. This method trades a small bias for a large gain in precision when estimating model coefficients and standard errors, allowing better estimates to be made. 
Table 4.6. Least Squares Means and Differences in Mean Event Rates between Units 8 and 9 by Turbine Region. SVWG = stay-vane/wicket-gate. Highlight indicates statistically significant results.

\begin{tabular}{|c|c|c|c|c|c|c|c|c|c|c|c|c|c|}
\hline & & & & Unit 8 & & & Unit 9 & & $\begin{array}{l}\text { Dif } \\
\text { Unit }\end{array}$ & $\begin{array}{l}\text { e: } \\
\text { hit } 9\end{array}$ & & & \\
\hline $\begin{array}{l}\text { Turbine } \\
\text { Region }\end{array}$ & pipe & $\mathrm{Q}$ & $\begin{array}{c}\text { Est. } \\
\text { (logit) }\end{array}$ & SE(Est) & \begin{tabular}{|c} 
Pred. \\
event \\
rate \\
\end{tabular} & $\begin{array}{c}\text { Est. } \\
\text { (logit) }\end{array}$ & $S E(E s t)$ & $\begin{array}{c}\text { Pred. } \\
\text { event } \\
\text { rate }\end{array}$ & $\begin{array}{l}\text { Est. } \\
\text { (logit) }\end{array}$ & $S E(E s t)$ & DF & Chisq & $P($ ChiSq) \\
\hline SVWG & 10 & 9 & $\mid-2.104$ & 0.474 & 0.109 & -2.327 & 0.524 & 0.089 & 0.223 & 0.706 & 1 & 0.10 & 0.752 \\
\hline SVWG & 30 & 9 & -1.564 & 0.367 & 0.173 & -1.638 & 0.413 & 0.163 & 0.074 & 0.552 & 1 & 0.02 & 0.894 \\
\hline SVWG & 10 & 11 & -1.846 & 0.439 & 0.136 & -2.128 & 0.473 & 0.106 & 0.282 & 0.646 & 1 & 0.19 & 0.662 \\
\hline SVWG & 30 & 11 & -1.526 & 0.349 & 0.179 & -2.054 & 0.475 & 0.114 & 0.528 & 0.589 & 1 & 0.80 & 0.370 \\
\hline SVWG & 10 & 15 & -1.846 & 0.439 & 0.136 & -2.639 & 0.598 & 0.067 & 0.793 & 0.742 & 1 & 1.14 & 0.285 \\
\hline SVWG & 30 & 15 & -2.120 & 0.432 & 0.107 & \begin{tabular}{|l|}
-1.068 \\
\end{tabular} & 0.350 & 0.256 & -1.052 & 0.556 & 1 & 3.59 & 0.058 \\
\hline SVWG & 10 & 17 & -1.846 & 0.439 & 0.136 & -2.303 & 0.524 & 0.091 & 0.457 & 0.684 & 1 & 0.45 & 0.504 \\
\hline SVWG & 30 & 17 & -1.622 & 0.274 & 0.165 & -3.045 & 0.724 & 0.045 & 1.423 & 0.774 & 1 & 3.38 & 0.066 \\
\hline Runner & 10 & 9 & -3.807 & 1.011 & 0.022 & -1.692 & 0.411 & 0.156 & -2.115 & 1.092 & 1 & 3.75 & 0.053 \\
\hline Runner & 30 & 9 & -2.037 & 0.434 & 0.115 & -1.329 & 0.375 & 0.209 & -0.708 & 0.574 & 1 & 1.52 & 0.217 \\
\hline Runner & 10 & 11 & -3.045 & 0.724 & 0.045 & -2.686 & 0.597 & 0.064 & -0.359 & 0.938 & 1 & 0.15 & 0.702 \\
\hline Runner & 30 & 11 & -1.792 & 0.382 & 0.143 & -1.504 & 0.391 & 0.182 & -0.288 & 0.547 & 1 & 0.28 & 0.599 \\
\hline Runner & 10 & 15 & -6.084 & 3.166 & 0.002 & -6.107 & 3.166 & 0.002 & 0.023 & 4.477 & 1 & 0.00 & 0.996 \\
\hline Runner & 30 & 15 & -3.296 & 0.720 & 0.036 & -2.277 & 0.525 & 0.093 & -1.019 & 0.891 & 1 & \begin{tabular}{|l|}
1.31 \\
\end{tabular} & 0.253 \\
\hline Runner & 10 & 17 & $|-3.761|$ & 1.012 & 0.023 & -1.846 & 0.439 & 0.136 & -1.915 & 1.103 & 1 & 3.02 & 0.082 \\
\hline Runner & 30 & 17 & -2.912 & 0.459 & 0.052 & -1.846 & 0.439 & 0.136 & -1.067 & 0.636 & 1 & 2.82 & 0.093 \\
\hline Draft Tube & 10 & 9 & $\mid-3.807$ & 1.011 & 0.022 & -3.784 & 1.011 & 0.022 & -0.023 & 1.430 & 1 & 0.00 & 0.988 \\
\hline Draft Tube & 30 & 9 & -6.252 & 3.165 & 0.002 & -3.738 & 1.012 & 0.023 & -2.514 & 3.323 & 1 & 0.57 & 0.449 \\
\hline Draft Tube & 10 & 11 & -6.084 & 3.166 & 0.002 & -3.114 & 0.723 & 0.043 & -2.971 & 3.247 & 1 & 0.84 & 0.360 \\
\hline Draft Tube & 30 & 11 & -2.872 & 0.593 & 0.054 & -3.045 & 0.724 & 0.045 & 0.173 & 0.936 & 1 & 0.03 & 0.854 \\
\hline Draft Tube & 10 & 15 & -3.761 & 1.012 & 0.023 & -6.107 & 3.166 & 0.002 & 2.346 & 3.324 & 1 & 0.50 & 0.480 \\
\hline Draft Tube & 30 & 15 & -3.296 & 0.720 & 0.036 & -2.590 & 0.599 & 0.070 & -0.706 & 0.936 & 1 & 0.57 & 0.451 \\
\hline Draft Tube & 10 & 17 & -6.084 & 3.166 & 0.002 & -3.761 & 1.012 & 0.023 & -2.323 & 3.324 & 1 & 0.49 & 0.485 \\
\hline Draft Tube & 30 & 17 & -2.719 & 0.421 & 0.062 & -3.045 & 0.724 & 0.045 & 0.325 & 0.838 & 1 & 0.15 & 0.698 \\
\hline
\end{tabular}

There were two significant $(\mathrm{P}<0.1)$ differences in severe event rates between Units 8 and 9 in the stay-vane/wicket-gate (SVWG) region and three in the runner region (Table 4.6). The numbers of severe events for each region were as follows: 
Stay-vane/wicket-gate (SVWG) region:

1. $\mathrm{Q}=15 \mathrm{kcfs}$ and pipe $=30-\mathrm{ft}$ :

a. Unit 8: 6 events in 56 releases

b. Unit 9: 11 events in 43 releases

2. $\mathrm{Q}=17 \mathrm{kcfs}$ and pipe $=30-\mathrm{ft}$ :

a. Unit 8: 16 events in 97 releases

b. Unit 9: 2 events in 44 releases

Runner region:

1. $\mathrm{Q}=9 \mathrm{kcfs}$ and pipe $=10-\mathrm{ft}$ :

a. Unit 8: 1 event in 46 releases

b. Unit 9: 7 events in 45 releases

2. $\mathrm{Q}=17 \mathrm{kcfs}$ and pipe $=10-\mathrm{ft}$ :

a. Unit 8: 1 event in 44 releases

b. Unit 9: 6 events in 44 releases

3. $\mathrm{Q}=17 \mathrm{kcfs}$ and pipe $=30-\mathrm{ft}$ :

a. Unit 8: 5 events in 97 releases

b. Unit 9: 6 events in 44 releases

\subsubsection{Correlation Between Sensor Fish Pressure Nadir and Collision Events}

Initial analysis of Sensor Fish releases at Unit 9 Bay B by Dresser et al. (2006) showed, for a limited set of releases, an apparent correlation between collisions and measured pressure nadir (Figure 4.19). Sensor fish that did not experience a collision event recorded minimum pressures that were about 10 psi higher than those that experienced a strike event. To investigate whether this observation occurred in other release cases, Sensor Fish data records were analyzed to determine if a significant correlation exists between the occurrence of a collision event and the measured pressure nadir. Note that the pressure nadir that occurs in the Sensor Fish data record may or may not correspond to the absolute nadir in the turbine.

The results of the analysis are shown in Tables 4.7 and 4.8.

Table 4.7. Correlation between Sensor Fish Pressure Nadir and Occurrence of Collision in the Intake, Wicket Gate, and Blade Regions. A P-value less than 0.05 indicates a significant correlation.

\begin{tabular}{||l|c|c|c|c||}
\hline & $\begin{array}{c}\text { Unit Discharge } \\
(\mathrm{kcfs})\end{array}$ & Release Bay & $\begin{array}{c}\text { Linear Correlation } \\
\text { Coefficient }\end{array}$ & P-value \\
\hline All releases & & & -0.03 & 0.38 \\
\hline Unit 8, all releases & & & -0.02 & 0.7 \\
\hline Unit 9, all releases & & & -0.08 & 0.14 \\
\hline \multirow{3}{*}{ Unit 9 } & \multirow{3}{*}{17} & $\mathrm{~A}$ & 0.2 & 0.2 \\
\cline { 3 - 5 } & & $\mathrm{B}$ & -0.6 & 0.001 \\
\cline { 3 - 5 } & \multirow{3}{*}{ Unit 8 } & $\mathrm{C}$ & -0.1 & 0.5 \\
\cline { 3 - 5 } & \multirow{2}{*}{17} & $\mathrm{~A}$ & 0.1 & 0.4 \\
\hline Unit 9 & 15 & $\mathrm{~B}$ & -0.15 & 0.3 \\
\hline Unit 9 & 11 & $\mathrm{C}$ & -0.27 & 0.13 \\
\hline Unit 9 & 9 & $\mathrm{~B}$ & 0.17 & 0.3 \\
\hline
\end{tabular}


Table 4.8. Correlation between Sensor Fish Pressure Nadir and Occurrence of Strike in the Blade Region. A P-value less than 0.05 indicates a significant correlation.

\begin{tabular}{|l|c|c|c|c||}
\hline & $\begin{array}{c}\text { Unit Discharge } \\
(\mathrm{kcfs})\end{array}$ & Release Bay & $\begin{array}{c}\text { Linear Correlation } \\
\text { Coefficient }\end{array}$ & P-value \\
\hline All releases & & & -0.06 & 0.08 \\
\hline Unit 8, all releases & & & -0.06 & 0.17 \\
\hline Unit 9, all releases & & & -0.05 & 0.38 \\
\hline \multirow{3}{*}{ Unit 9 } & \multirow{3}{*}{17} & $\mathrm{~A}$ & 0 & 1 \\
\cline { 3 - 5 } & & $\mathrm{B}$ & -0.38 & 0.04 \\
\cline { 3 - 5 } & \multirow{3}{*}{ Unit 8 } & $\mathrm{C}$ & -0.09 & 0.64 \\
\cline { 3 - 5 } & \multirow{2}{*}{17} & $\mathrm{~A}$ & 0.02 & 0.90 \\
\cline { 3 - 5 } & & $\mathrm{B}$ & -0.22 & 0.10 \\
\cline { 3 - 5 } & & $\mathrm{C}$ & -0.27 & 0.13 \\
\hline
\end{tabular}

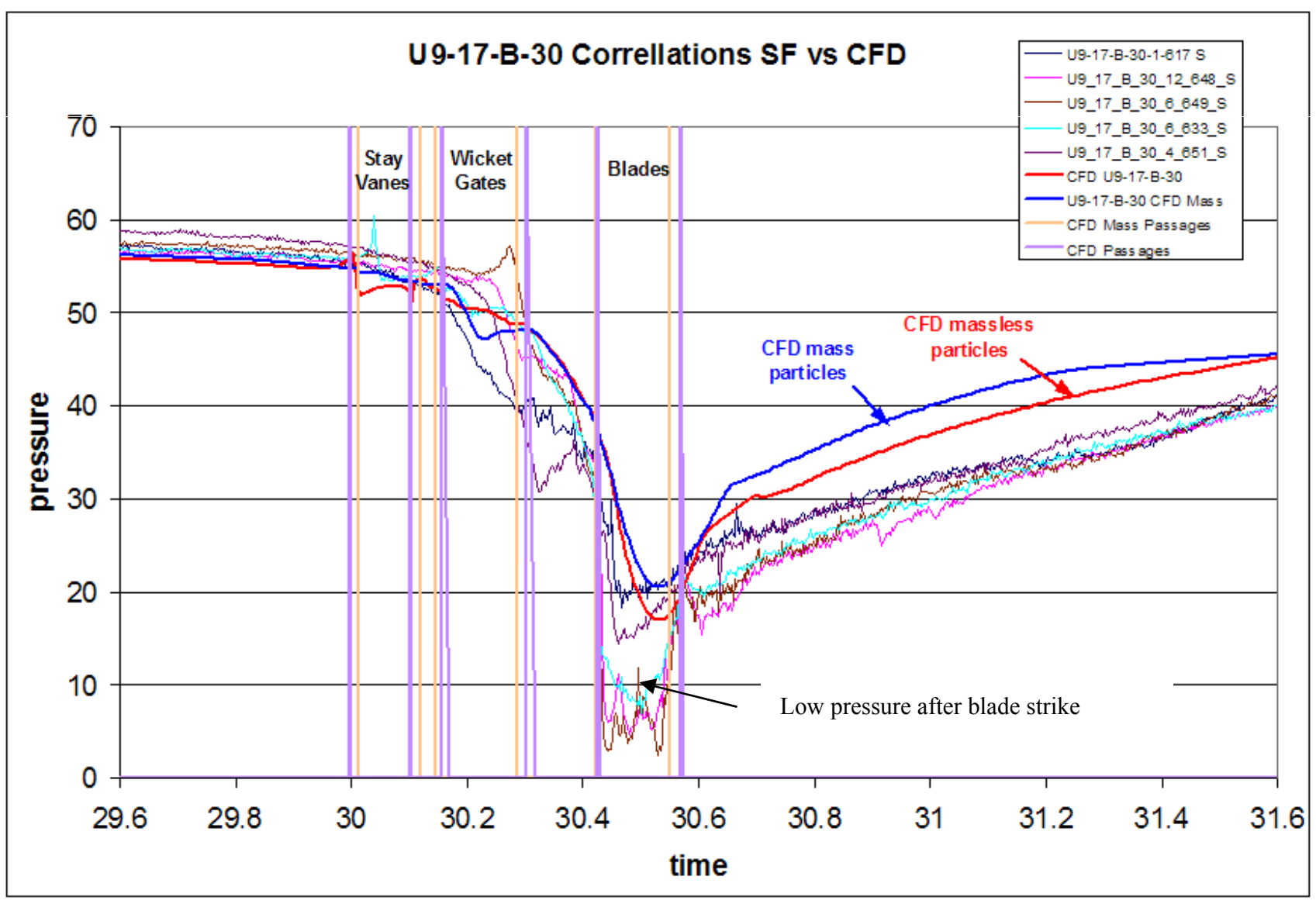

Figure 4.19. Pressure Time History from Sensor Fish Data and CFD Particles Released in Wanapum Unit 9 Bay B operating at 17 kcfs (from Dresser et al. 2006). The lowest Sensor Fish pressures were all associated with collision events.

Table 4.7 shows the correlation considering any strike that occurred in the intake, wicket gate, and blade regions. The correlation values in Table 4.8 are computed using only strikes that occurred in the blade region. In this case the small sample size and low frequency of strikes did not allow for calculation 
of correlation values for other Unit 9 Bay B discharges. In both tables, only a subset of the data is presented by individual unit, release bay, and discharge and in these cases results from the 10-ft and 30-ft release pipes have been grouped together. For all Unit 8 and 9 releases, no significant correlation between the occurrences of strike events and pressure nadir was found. A significant relationship was found to occur for Unit 9, Bay B, $17 \mathrm{kcfs}$ releases. However this relationship did not persist for any other Unit 9 Bay B releases or for Unit 8 at a discharge of $17 \mathrm{kcfs}$.

Overall the data do not indicate that Sensor Fish experiencing a collision event are consistently correlated with the measured pressure nadir.

\subsection{Comparison of Live Fish Survival and Sensor Fish Data}

The overall rates of severe events for each turbine were similar with Unit 8 (AHT) having slightly fewer events than the conventional Unit 9 (Table 4.9). This trend was not reflected in the live fish survival rate where Unit 8 had a slightly lower survival than Unit 9, although the differences are not significant.

Table 4.9. Comparison of Sensor Fish Severe Event (collision and shear) and Live Fish Survival Rates for Each Turbine. Standard error is in parentheses.

\begin{tabular}{|c|c|c|c|}
\hline Turbine & $\begin{array}{c}\text { Sensor Fish } \\
\text { Sample Size }\end{array}$ & $\begin{array}{c}\text { Severe Event }>95 \mathrm{~g} \\
(+/-\mathrm{SE})\end{array}$ & $\begin{array}{c}\text { Live Fish 48-h Survival } \\
(+/-\mathrm{SE})\end{array}$ \\
\hline Unit 8 (AHT) & 536 & $21.3 \%(1.8 \%)$ & $96.9 \%(0.7 \%)$ \\
\hline Unit 9 (Existing) & 355 & $23.7 \%(2.2 \%)$ & $97.5 \%(0.5 \%)$ \\
\hline
\end{tabular}

Sensor Fish severe events and live fish survival showed similar trends for each turbine unit (Figures 4.20 and 4.21). Each treatment consisted of about 45 Sensor Fish releases with a standard error between $3 \%$ and $7 \%$. The $30-\mathrm{ft}$ release pipe had a higher rate of severe events compared to the $10-\mathrm{ft}$ release pipe. The severe event trends corresponded to the lower survival rates for the $30-\mathrm{ft}$ release pipe except for Unit 9 at $17 \mathrm{kcfs}$. No consistent trends in severe events were evident when the data were examined for each intake bay (Figures 4.22 and 4.23). Each treatment consisted of about 15 to 20 Sensor Fish releases with a standard error between $6 \%$ and $12 \%$. 


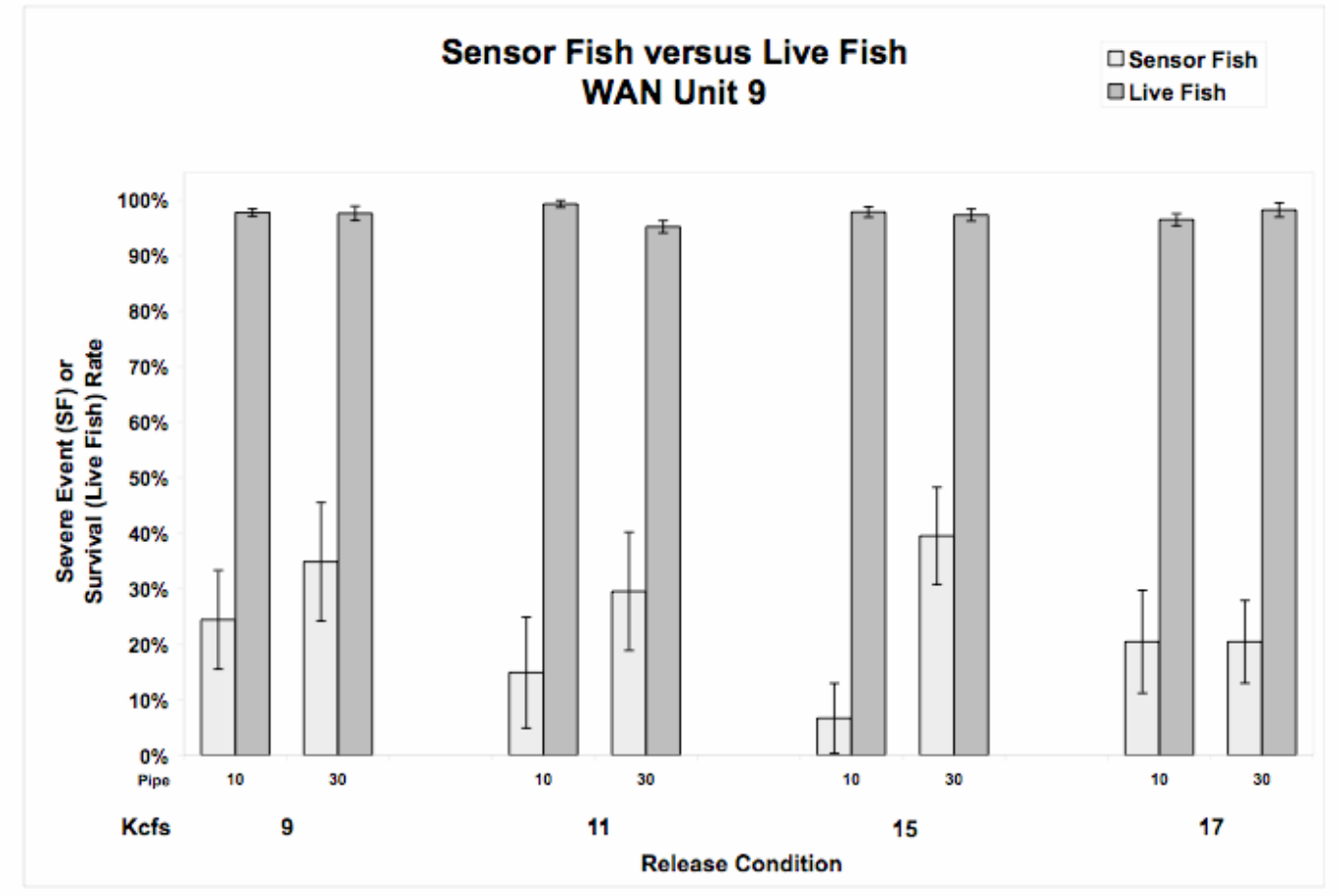

Figure 4.20. Comparison of Sensor Fish Severe Event (collision and shear) and Live Fish Survival Rates (and standard error) for Unit 9 (existing) across Discharge (kcfs) and Release Pipe (10 and $30 \mathrm{ft}$ )

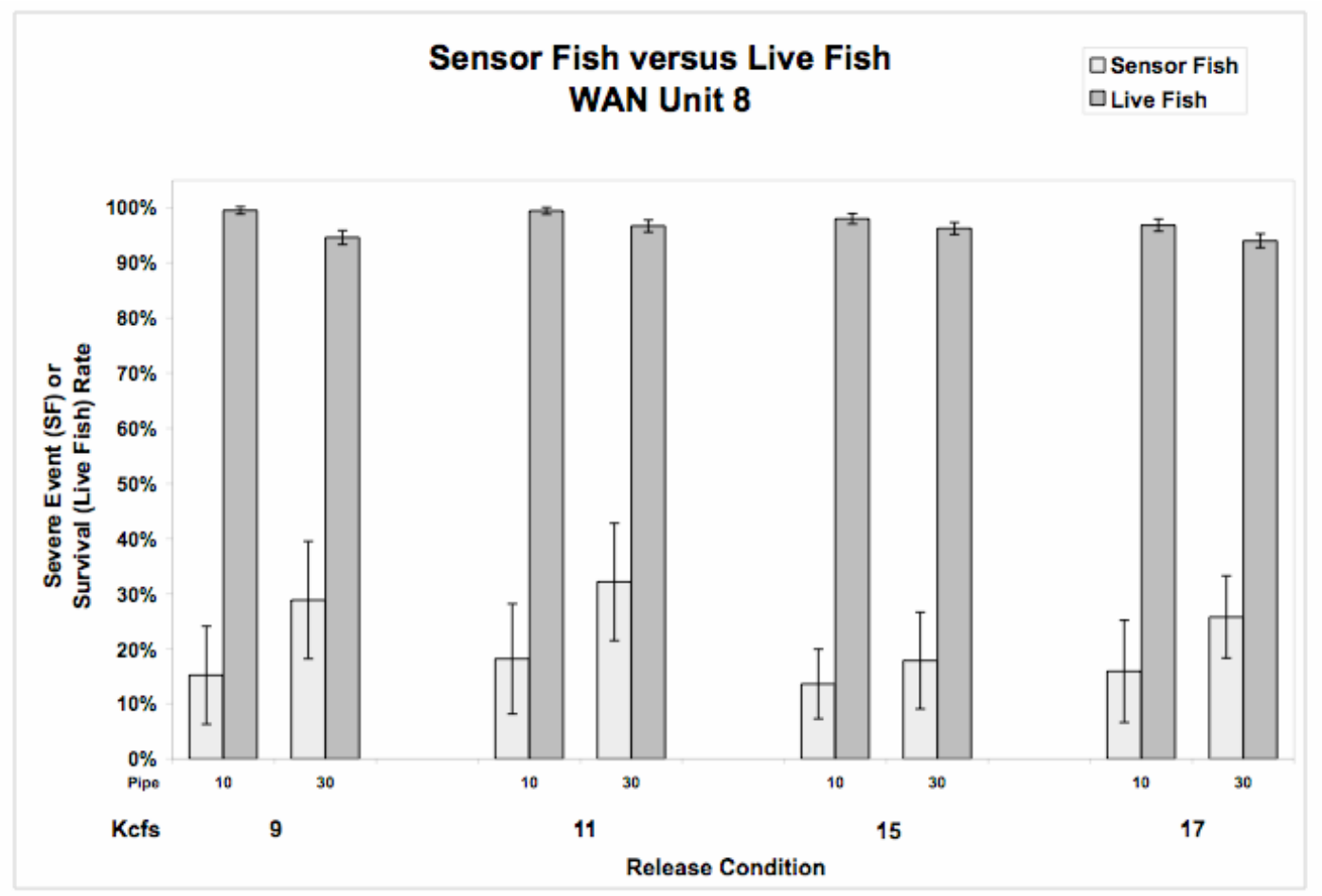

Figure 4.21. Comparison of Sensor Fish Severe Event (collision and shear) and Live Fish Survival Rates (and standard error) for Unit 8 (AHT) across Discharge (kcfs) and Release Pipe (10 and $30 \mathrm{ft}$ ) 


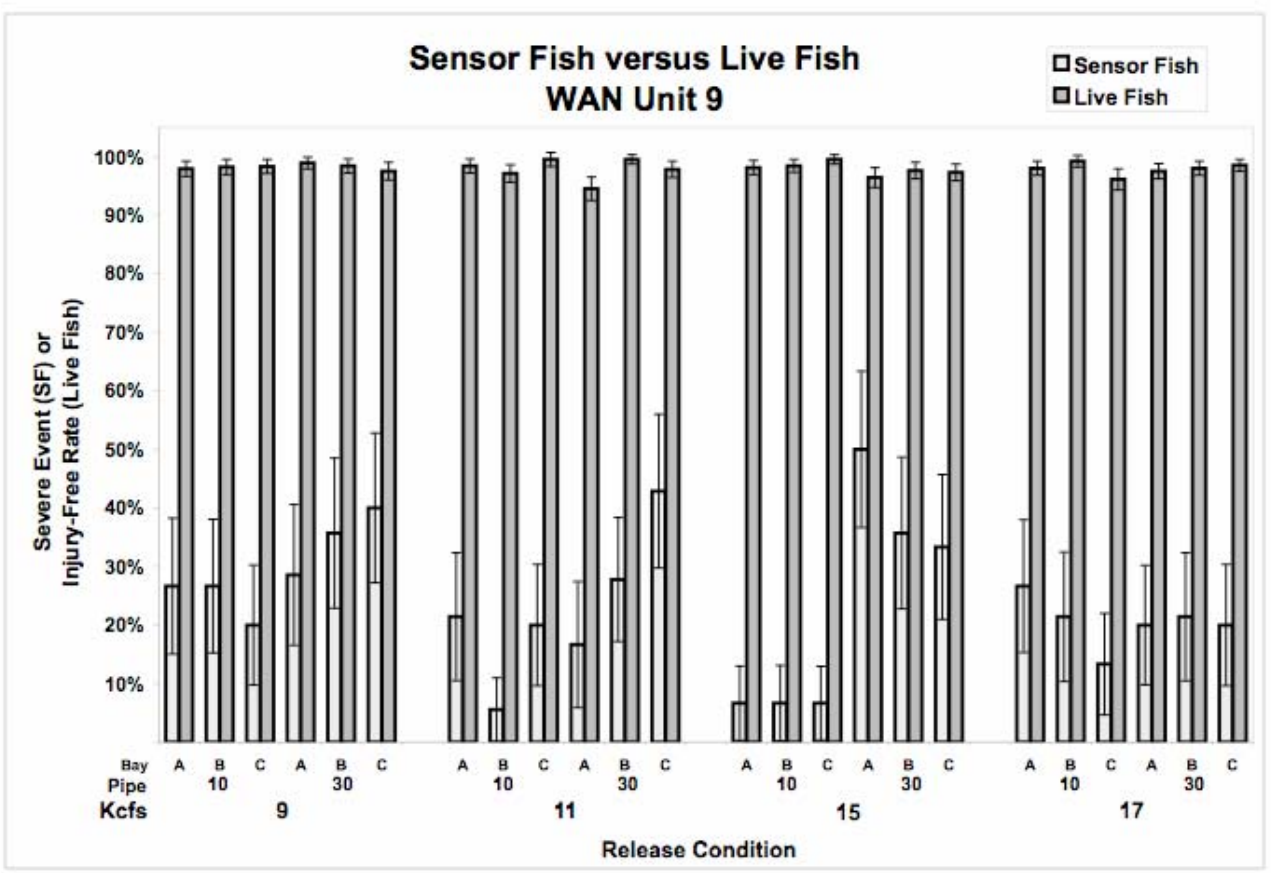

Figure 4.22. Comparison of Sensor Fish Severe Event (collision and shear) and Live Fish Injury-Free Rates (and standard error) for Unit 9 (conventional) across Discharge (kcfs), Release Pipe (10 and $30 \mathrm{ft})$, and Intake Bay

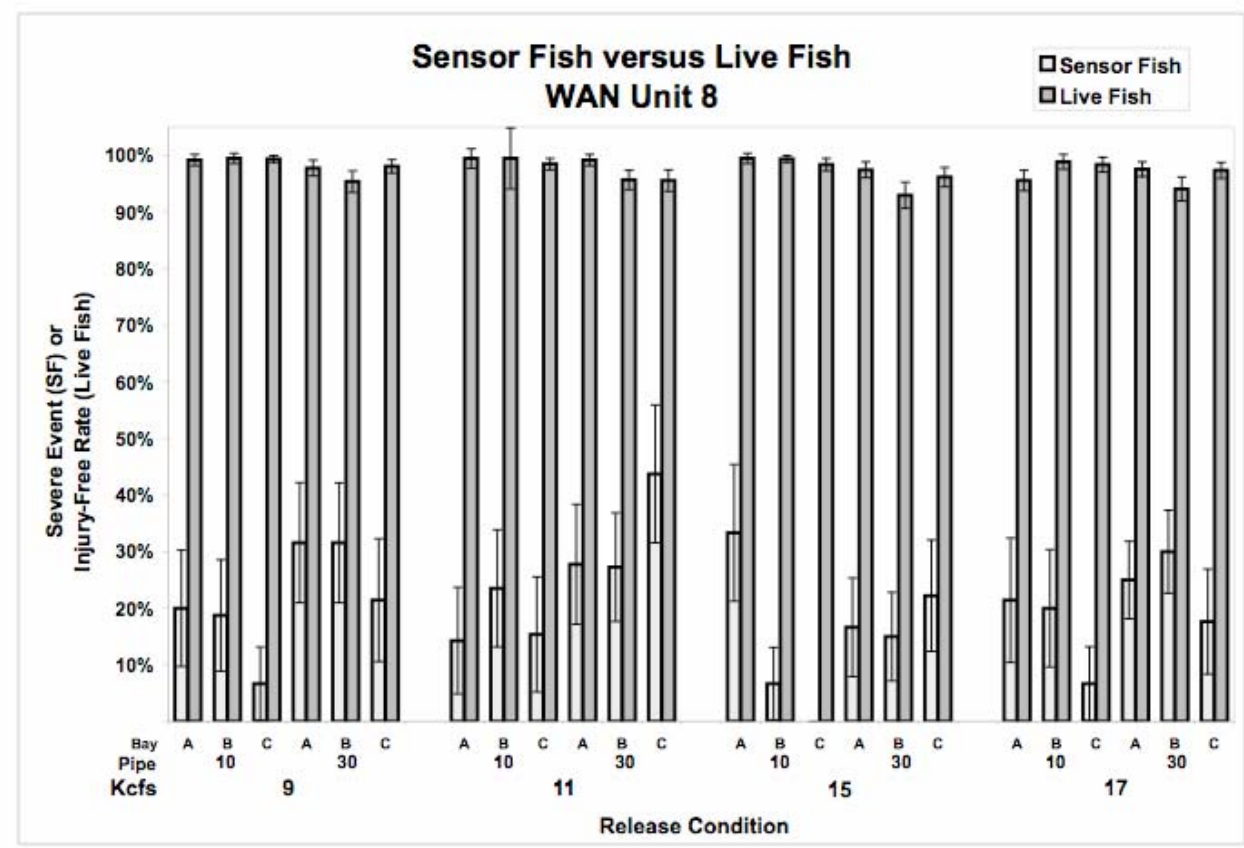

Figure 4.23. Comparison of Sensor Fish Severe Event (collision and shear) and Live Fish Injury-Free Rates (and standard error) for Unit 8 (AHT) across Discharge (kcfs), Release Pipe (10 and $30 \mathrm{ft}$ ), and Intake Bay 


\subsection{Estimates of Shear Injury Rates}

The correlations between Sensor Fish acceleration and shear-type injury presented in Section 4.2.4 were used to predict the major shear injury rates for the different regions of Units 8 and 9 (Table 4.10). The overall predicted major shear injury rates were $3.1 \%$ for Unit 8 and $4.4 \%$ for Unit 9 . This compares to observations of injuries attributed by Normandeau et al. (2005) to shear of $1.1 \%$ and $0.9 \%$ for Units 8 and 9, respectively. Probability of predicted shear injury in the intake and draft tube regions was negligible. Most predicted shear injury occurred in the stay-vane/wicket-gate and runner regions with 30$\mathrm{ft}$ releases showing higher rates. The higher rate of shear injury for the $30-\mathrm{ft}$ releases was also observed for live fish. A similar set of response relationships for collision injury is not currently available.

\subsection{Discussion}

Based on Sensor Fish measurements, we predicted a lower potential for shear-related injuries in the advanced turbine (Unit 8) than the conventional Kaplan turbine (Unit 9) (see Table 4.10). This is consistent with Grant PUD's goal of reducing fish passage injuries and mortalities. Pressure changes measured by Sensor Fish were also less severe in Unit 8. Both minimum pressure and rates of pressure change were consistently higher in Unit 9 than in Unit 8 (Figure 4.24).

The addition of more wicket gates (32 compared to 20) and changes to their geometry and alignment in Unit 8 had mixed results. For example, severe collisions in the stay-vane/wicket-gate region were greater in Unit $8(13.6 \% \pm 1.5 \%)$ than Unit $9(10.7 \% \pm 1.7 \%)$. In comparison, severe shear events were fewer and similar $(0.4 \%$ and $0.8 \%$, respectively for Units 8 and 9$)$. However, Unit 8 had more slight shear events $(14.2 \% \pm 1.5 \%)$ than Unit $9(6.2 \% \pm 1.3 \%)$. Thus, it appears that the larger number of wicket gates created a greater opportunity for collision and an increase in slight shear in the wakes of the gates.

Table 4.10. Predicted Major Shear Injury Rates from Sensor Fish Measurements. Live fish shear injury rates are from Normandeau et al. (2005).

\begin{tabular}{|c|c|c|c|c|c|c|c|c|}
\hline \multicolumn{2}{|c|}{} & \multicolumn{6}{|c|}{ Major Shear Injury Rate by Turbine Region } \\
\hline Turbine & $\begin{array}{l}\text { Release } \\
\text { Pipe } \\
\text { (Distance } \\
\text { Below } \\
\text { Roof, ft) }\end{array}$ & $\begin{array}{l}\text { Total } \\
\text { Sensor } \\
\text { Fish } \\
\text { Releases }\end{array}$ & Intake & $\begin{array}{l}\text { Stay } \\
\text { Vane/ } \\
\text { Wicket } \\
\text { Gate }\end{array}$ & Runner & $\begin{array}{l}\text { Draft } \\
\text { Tube }\end{array}$ & Total & Live Fish \\
\hline $\begin{array}{c}\text { AHTS } \\
\text { Unit 8 }\end{array}$ & 10 & 223 & $0.0 \%$ & $0.1 \%$ & $1.5 \%$ & $0.1 \%$ & $1.7 \%$ & $1.0 \%$ \\
\hline $\begin{array}{c}\text { AHTS } \\
\text { Unit 8 }\end{array}$ & 30 & 313 & $0.0 \%$ & $2.2 \%$ & $1.9 \%$ & $0.0 \%$ & $4.1 \%$ & $1.2 \%$ \\
\hline $\begin{array}{c}\text { Existing } \\
\text { Unit 9 }\end{array}$ & 10 & 181 & $0.0 \%$ & $1.2 \%$ & $1.7 \%$ & $0.1 \%$ & $3.0 \%$ & $0.8 \%$ \\
\hline Existing \\
Unit 9
\end{tabular}




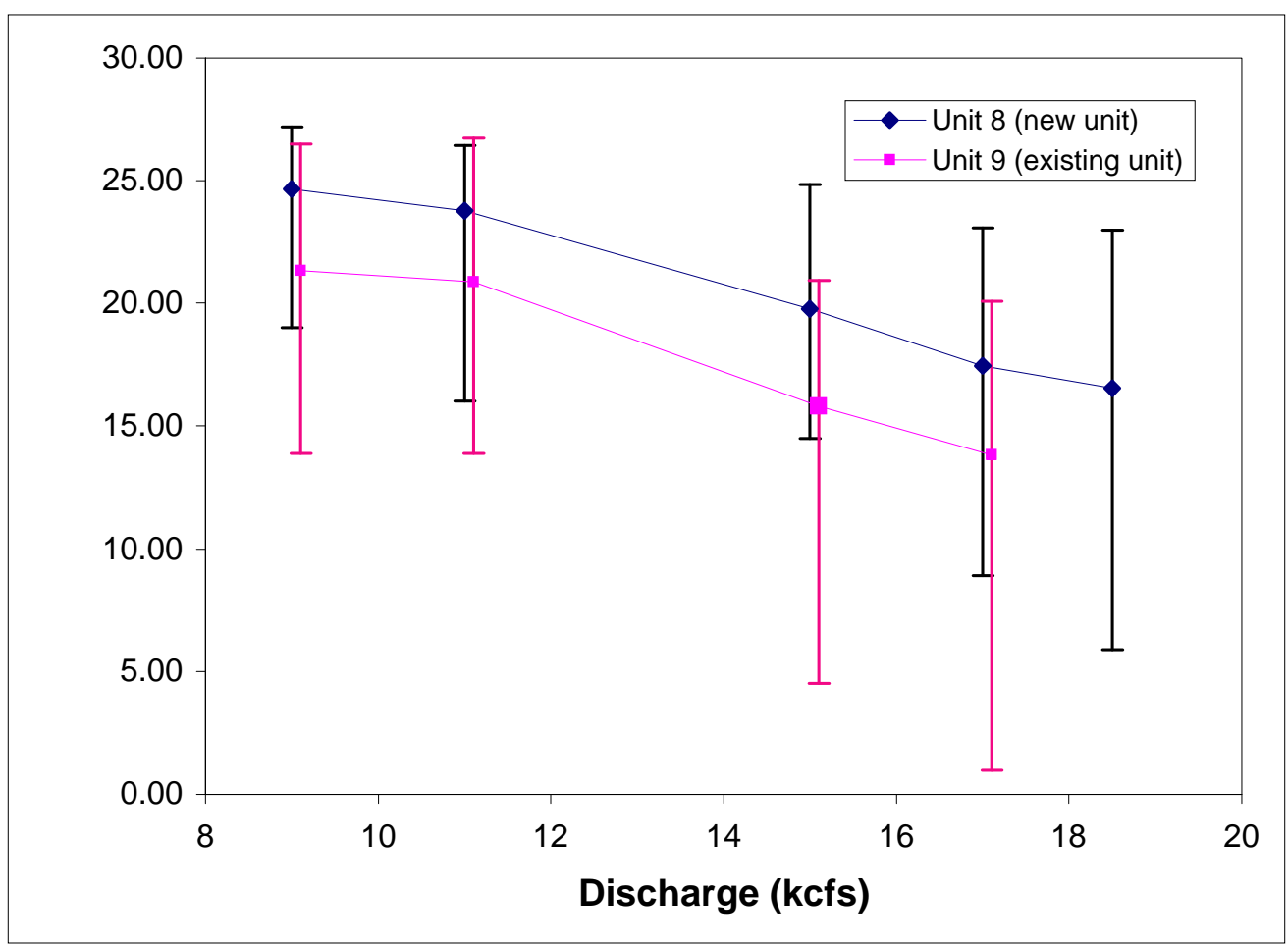

Figure 4.24. Median and Range of Lowest Pressure (nadir) Recorded by Sensor Fish in Units 8 and 9

Although Unit 8 (AHT) had a 6-blade runner, it showed a reduced rate of severe collisions $(4.9 \% \pm$ $0.9 \%)$ compared to the 5-blade runner in conventional Unit $9(9.6 \% \pm 1.6 \%)$. Severe shear was also less in Unit 8 . These results suggest that the new blade shape and the corresponding reduction turbulence in Unit 8 were effective. The draft tube in Unit 8 was also modified to improve hydraulic conditions. However, Sensor Fish did not show a significant difference in severe events between Units 8 and 9 that corresponded to passage through this region.

The frequency of severe events based on Sensor Fish pressure and acceleration measurements, coupled with CFD analysis and simulation plots, showed similar trends to fish survival determined by balloon-tag tests. This trend was consistent within each turbine unit and by entrainment depth. The Sensor Fish sample size was insufficient, however, to identify consistent responses for releases from a single pipe or intake bay. 



\subsection{Fish Dye Injury Assessment Studies}

\subsection{Introduction}

A novel technique for the detection and quantification of external fish injury, developed at PNNL, was applied to biological testing at Wanapum Dam. This detection method is a more sensitive and objective measure of external fish injury than a standard examination with the unaided eye. The procedure involves exposing fish briefly to a non-toxic dye (Noga and Udomjusonri 2002; Pouliquen and Algoet 1995) then photographing the subject under ultraviolet light, where scrapes, cuts, abrasions, descaling, or puncture wounds are revealed. Photographs are examined using image analysis software that quantifies images using exactly the same algorithms and criteria for each fish. The photos are archived allowing for post-study review or re-analysis.

This study was part of DOE's Hydropower Program to improve the fish survival and power generation capacity of the nation's hydropower. The methods were developed as a quantitative tool for assessing the safety of fish passage routes. This includes turbine units, spillways, and engineered fish bypass routes. The ability to measure changes in biological systems is a critical parameter for engineering improvements.

Laboratory studies conducted in 2003 (Moursund and Bleich 2004; Neitzel et al. 2000) provided the first calibrations of equipment through detection of injuries occurring during exposure to shear events. These tests suggested the technique had promise as a useful tool in dam passage research. The severity (intensity of the fluorescence) was well correlated with the exposure exit velocity. Dye-detected injuries were not visible to the naked eye and were in non-scaled regions of the head.

McNary Dam provided the setting for field testing the technique as an injury detection and forensics tool in 2004. Injuries were easily detectable from gatewell-released fish, but the planned experimental design was interrupted and the statistical treatments were halted very early in our data collection. Descaling was a prominent injury type, but so were injuries on and around the eye. Based on this brief sampling, the process of photography was streamlined and improvements were made to the lighting system. We also demonstrated that a permanent quantifiable record could easily be obtained with this technique. Furthermore, the use of image analysis software was shown to be able to quantify dye intensity in an objective and highly repeatable manner. Thus, even though a statistical analysis for this short field test was not possible, the utility of the technique for statistically rigorous study designs was made clear.

Having established the technique in the laboratory and a limited field trial, the goal of this study was to test the technique under turbine passage experimental conditions and protocols. The biological testing of the advanced hydropower turbine (AHT) unit at Wanapum Dam by Grant County Public Utility District \#2 provided an opportunity to test the technique. The balloon tag test procedure allowed for fish to be recovered and examined immediately after exposure to turbine passage in a statistically arranged treatment design. This injury assessment design replicated a small portion of the larger fish survival study design to test the technique under field conditions. 


\subsection{Materials and Methods}

The study was designed to compare fish injuries at the advanced turbine (Unit 8) with those at an

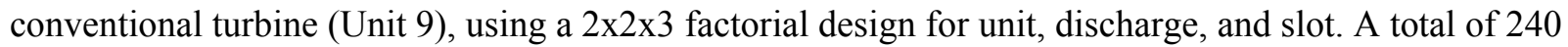
fish were released: 20 fish per treatment at each of the three slots of the two turbine units at two discharge levels, 15 and $17 \mathrm{kcfs}$. All releases were made at a constant $30-\mathrm{ft}$ release depth. The release schedule took place over 6 days (Table 5.1).

Table 5.1. PNNL Fish Dye Study Design. Release dates are shown for $2 \times 2 \times 3$ factorial design of existing and advanced turbines, at 15 and $17 \mathrm{kcfs}$, released across all turbine slots equally with a sample size of 20 fish per slot and 60 per block.

\begin{tabular}{|l|c|c|c|c|c|c||}
\hline & \multicolumn{2}{|l|}{ Unit 8 (Advanced Turbine) } & \multicolumn{3}{|c|}{ Unit 9 } \\
(Conventional Turbine)
\end{tabular}

Hatchery-raised yearling Chinook salmon (Oncorhynchus tshawytscha) were obtained for our study from Normandeau Associates, who was conducting the concurrent studies at Wanapum Dam. The fish were provided by Grant County Public Utility District \#2. Our test fish were balloon and radio tagged and recovered as part of the larger study by Normandeau Associates. The tagged fish were then released into the test turbines through a release pipe at the pre-designated unit, slot, discharge, and depth. The fish were recovered downstream after inflation of the balloon and with the aid of the radio telemetry tags. Immediately after the fish were recovered in the tailrace they were delivered to PNNL staff. A darkroom trailer was positioned on the tailrace deck for examination using the fish dye technique.

External fish injuries not visible to the naked eye have been shown to be clearly demarcated when fish were exposed to a treatment consisting of a fluorescein bath followed by a rinse bath and exposure to ultraviolet light (Noga and Udomkusonsri 2002). This PNNL study used a similar technique to detect injuries related to turbine passage, though the procedures (dye concentrations and lighting conditions) have been optimized for the dam passage scenario.

Following treatment exposure and recovery, fish were transferred to the care of PNNL staff and held in an aerated tank in the photographing trailer. When ready for dye exposure, individual fish were removed from their holding tank, anesthetized with a solution of tricaine methanesulfonate (MS-222) at a concentration of $40 \mathrm{mg} / \mathrm{L}$, placed in an aqueous sodium fluorescein solution bath (with a maintenance solution of MS-222 of $20 \mathrm{mg} / \mathrm{L}$ ) and rinsed in a fresh water bath (also with a maintenance solution of MS-222 of $20 \mathrm{mg} / \mathrm{L}$ ). The fish were examined immediately for skin damage and photographed with Nikon COOLPIX 5700® digital cameras under both ultraviolet light and white light. Following injury documentation, fish were placed into a recovery tank for at least one hour. Once fully recovered, fish were released downstream of the dam. The image archive that was created was used to examine and quantify injury types. 


\subsection{Results}

Images obtained from fish dye analysis documented several types of injuries occurring during turbine passage and not clearly detectable with the naked eye. Injuries were recorded on the head, fins, and rest of the body, with each fish often showing injuries to many different parts of the body. The number of occurrences of each type of injury is shown in Table 5.2. The advanced turbine (Unit 8) yielded statistically different results from the conventional turbine (Unit 9) in only four instances: eye injury at $15 \mathrm{kcfs}$, dorsal fin injury at $15 \mathrm{kcfs}$, anal fin injury at $15 \mathrm{kcfs}$. In each case injury rates were higher for the existing turbine. In only one category, i.e, dispersed ventral damage at 15 and $17 \mathrm{kcfs}$, did Unit 8 fish exhibit greater chance of injury. For all other injury categories there was no significant difference between Units 8 and 9. Based on these data, we chose to focus on head region injuries due to their possible statistical significance and potential to affect fish survival. Examples of head injuries received during turbine passage are clearly visible in the photographs in Figures 5.1 through 5.4, which show the dyed, turbine-passed fish under normal white light and ultraviolet light. The most pronounced difference between units in terms of head injury was injury to eyes at $15 \mathrm{kcfs}$. Eye injury occurred in nearly $30 \%$ of fish passing through Unit 9 but in less than $10 \%$ of those passing through Unit 8 at $15 \mathrm{kcfs}$. Eye injury was below $5 \%$ at both units at $17 \mathrm{kcfs}$.

Injuries to fins not including split membranes were nearly impossible to detect with the naked eye but were clearly visible with the dye. Theoretically, the impact of injuries to the fins of the fish could result in compromised propulsion and/or body control following dam passage. However, the goal of this test was to investigate the possibility of detecting differences between operational treatments and not to determine the fish's ultimate survival probability. Injuries, for example, damage to the flanks of a fish in areas that were not descaled, were observed but did not show an obvious trend.

The most common treatment combination for eye injuries was unit 9 , slot $\mathrm{C}$, at $15 \mathrm{kcfs}$. As can be seen in Table 5.2, 18 of the 22 eye injury incidents occurred in Unit 9, 21 of the 22 eye injuries occurred at $15 \mathrm{kcfs}$, and 12 of the 22 occurred in slot $\mathrm{A}$. What this table suggests is an interaction of turbine unit and discharge. These data were also plotted by turbine discharge and unit type in Figures 5.5 and 5.6. 
Table 5.2. Summary of All Injury Occurrences for Advanced (Unit 8) and Conventional (Unit 9) Turbines. Injuries occurring to the ventral surface of the body sometimes overlap with injuries occurring to the pelvic and anal fins.

\begin{tabular}{|c|c|c|c|c|c|}
\hline & \multirow[t]{2}{*}{ Injury Type } & \multicolumn{2}{|c|}{$15 \mathrm{kcfs}$} & \multicolumn{2}{|c|}{$17 \mathrm{kcfs}$} \\
\hline & & Unit 8 & Unit 9 & Unit 8 & Unit 9 \\
\hline & Sample Size (n) & 57 & 60 & 59 & 60 \\
\hline \multirow[t]{3}{*}{ Head } & Eye & 6 & 20 & 2 & 1 \\
\hline & Isthmus & 30 & 32 & 40 & 30 \\
\hline & Operculum & 14 & 12 & 14 & 10 \\
\hline \multirow[t]{6}{*}{ Fins } & Pectoral & 48 & 54 & 53 & 55 \\
\hline & Dorsal & 28 & 41 & 27 & 33 \\
\hline & Pelvic & 42 & 38 & 43 & 42 \\
\hline & Adipose & 1 & 3 & 2 & 1 \\
\hline & Anal & 39 & 47 & 43 & 33 \\
\hline & Caudal & 45 & 47 & 49 & 46 \\
\hline \multirow[t]{4}{*}{ Body } & Anal Pore & 0 & 2 & 2 & 3 \\
\hline & $\begin{array}{l}\text { Focused Ventral } \\
\text { Damage }\end{array}$ & 2 & 4 & 3 & 3 \\
\hline & $\begin{array}{l}\text { Dispersed Ventral } \\
\text { Damage }\end{array}$ & 8 & 3 & 5 & 1 \\
\hline & Total Injuries & 263 & 303 & 284 & 258 \\
\hline
\end{tabular}



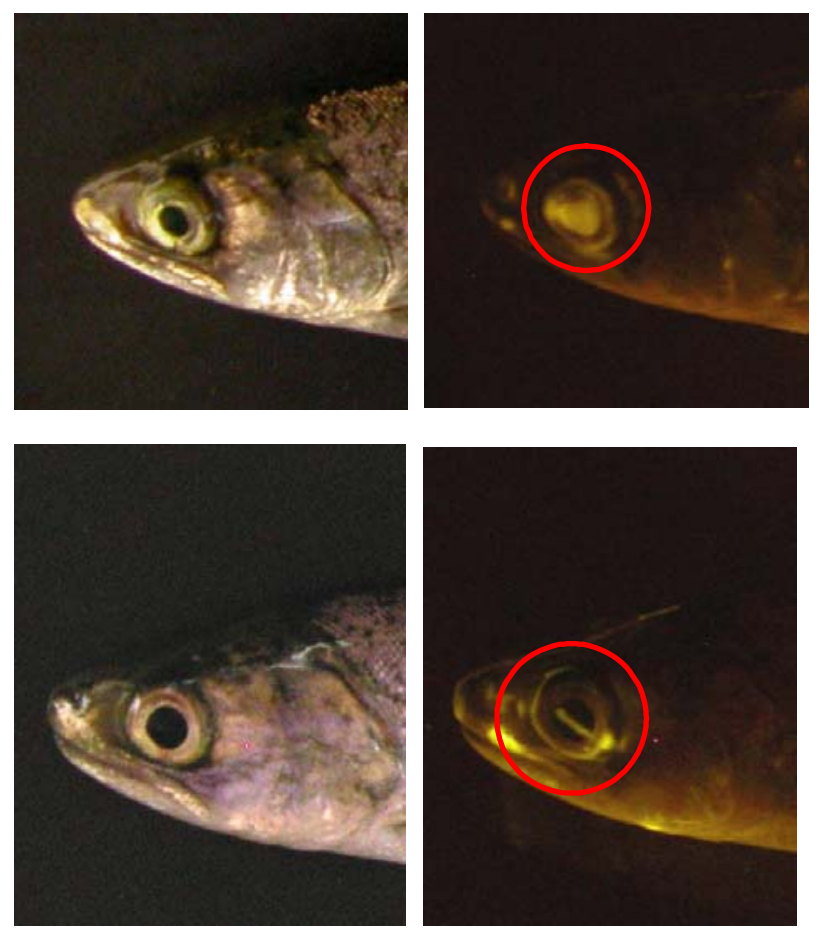

\section{Visible Light $\quad$ Dye Treated}

Figure 5.1. Eye Damage. Same dyed fish shown under white (left) and ultraviolet (right) light.

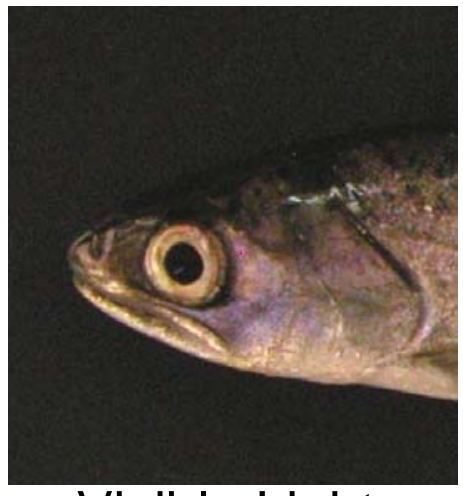

Visible Light

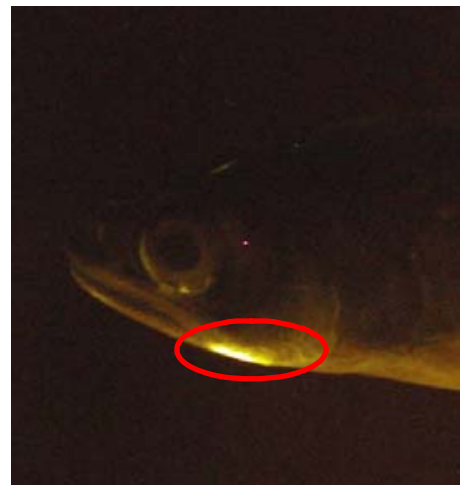

Dye Treated

Figure 5.2. Damage to Isthmus. Same dyed fish shown under white (left) and ultraviolet (right) light. 


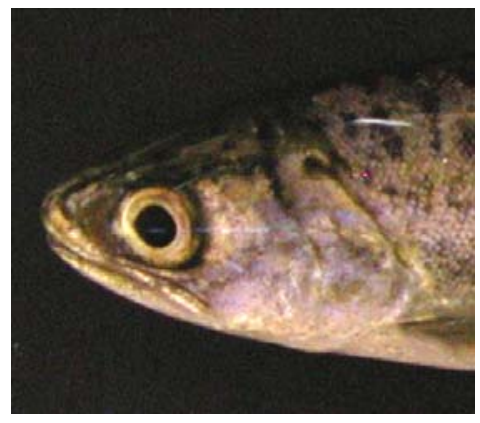

Visible Light

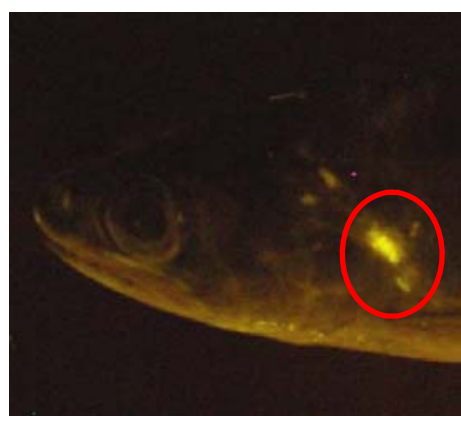

Dye Treated

Figure 5.3. Damage to Operculum. Same dyed fish shown under white (left) and ultraviolet (right) light.

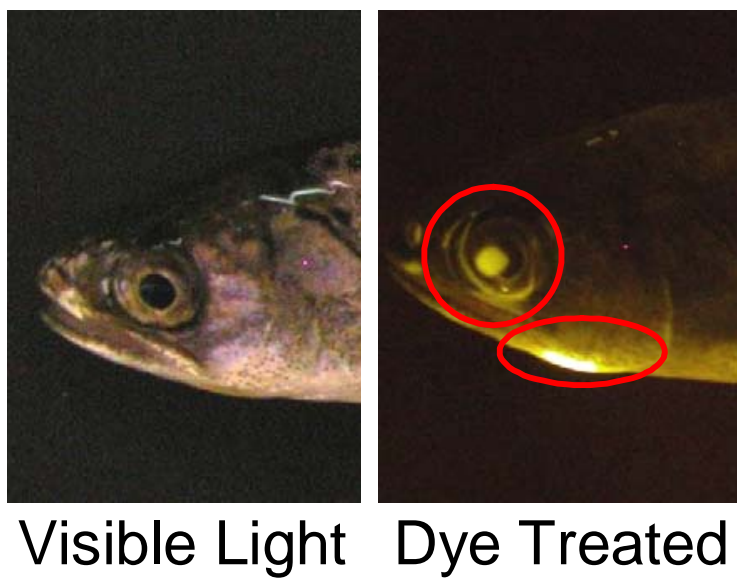

Figure 5.4. Injuries to Eye and Isthmus. Same dyed fish shown under white (left) and ultraviolet (right) light.

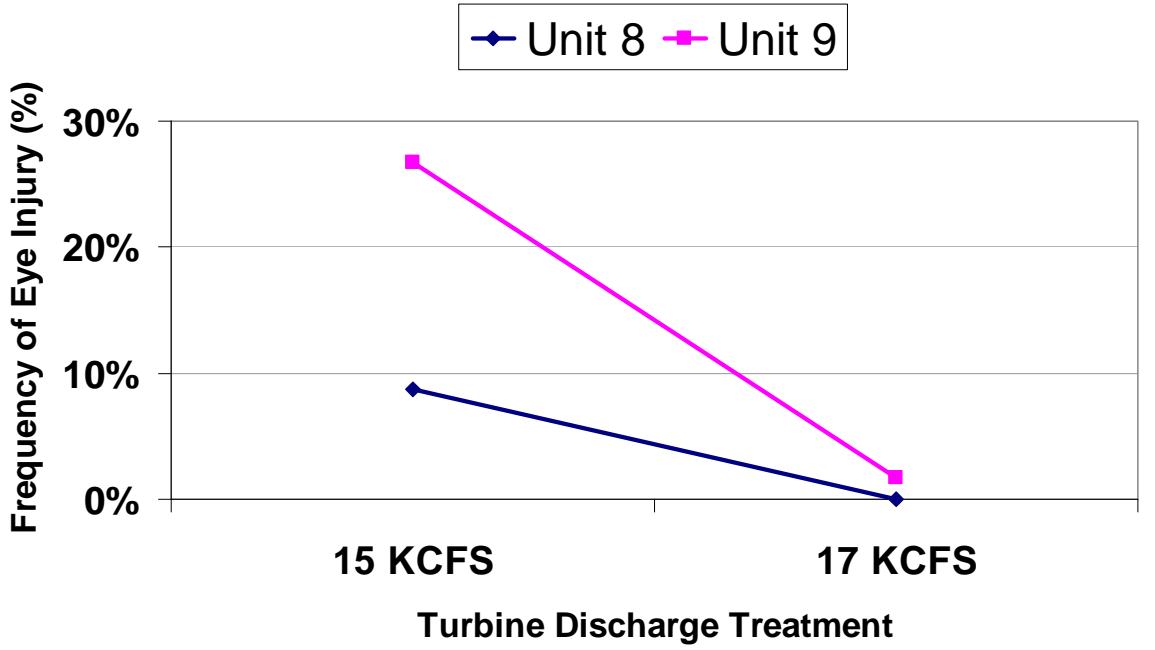

Figure 5.5. Frequency of Eye Injury Versus Turbine Discharge showing Interaction of Discharge and Unit. 


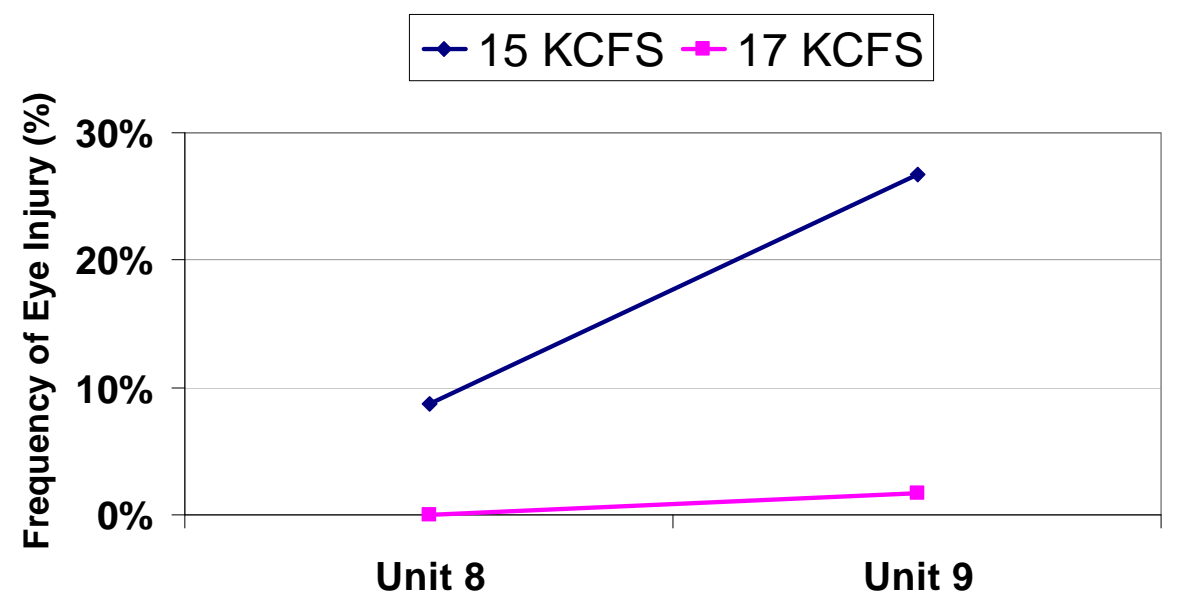

Unit Type Treatment

Figure 5.6. Frequency of Eye Injury Versus Unit Type Showing a Different View of the Interaction of Main Effects

\subsection{Discussion}

The methodology for testing fish response from passage routes at hydro projects relies on estimates of mortality and obvious physical injuries such as descaling. As fish passage routes have improved in the Columbia Basin, the differences being sought in fish survival and injury rates have been getting progressively smaller. Continued improvement requires being able to measure changes in performance on an ever finer scale.

The current state-of-the-art methods for detecting injuries following passage requires large sample sizes to detect smaller differences. For example, in studies conducted to test the effectiveness of the extended length bar screens (ESBS) at John Day Dam, differences on the order of $<1 \%$ were detected for fish exposed to the ESBS versus those exposed to the standard traveling screens. It took the examination of more than 10,000 run-of-the-river fish to yield these findings (Brege et al. 1997). For tag, release, and recovery methods those numbers may not be feasible. This dye-assisted injury detection and assessment technique is more sensitive. Improved detection sensitivity would reduce the requisite sample sizes and also have a concomitant decrease in cost.

Head injuries are difficult to detect with the naked eye without a clear sign of internal damage such as hemorrhaging of the eye, which would make the injury visible to the researcher. The head region also lacks scales, which is the sole metric for a descaling injury study. Damage to the operculum and/or isthmus is another type of head injury that could indicate exposure to shear stress during turbine passage. This type of injury was clearly detected in turbine tests at Wanapum Dam, although the injuries were not differentiated between treatments. To date, we have not acquired sufficient samples from other passage routes to examine for differences in frequencies of types of injuries.

Injury rates based on visual inspection may not be very high. In studies examining injuries in turbine-passed fish, sample sizes of 1,830, 1,209, and 1,194 treatment fish yielded visible injuries in 3.7\% 
(Normandeau et al. 1995), 3.9\% (Normandeau 1999), and 0.7\% (Normandeau et al. 2001) of tested fish respectively. Therefore, the higher detection rates of the dye-assisted method here will improve the statistical power of detection, i.e., by having a higher number of samples collected per fish. Through the use of image analysis software, qualitative observations were converted to quantitative data sets needed for developing more fish-friendly passage routes and turbine designs. The reduction of the variability of subjective injury determinations further increases the statistical power of detection for the dye technique.

Interpretation of the data requires a re-visit to the $2 \times 2 \times 3$ factorial treatment design. This design is a very useful and exploratory configuration of treatments because all treatments and interactions can be tested. However, the presence of interaction terms makes the interpretation of main effects complicated. For this small feasibility-scale experiment, we found differences in the eye injury rate of various treatments but are only able to show that there is an interaction among the main effects of discharge, unit type, and slot. The trend observed was lower injury rates at higher discharges and at the advanced unit.

Overall, this study successfully demonstrated the feasibility of the dye injury assessment technique as a new tool in fish passage research with the potential to increase the statistical sensitivity of current direct fish survival methods. The procedure was demonstrated to be rapid and portable enough to be incorporated into standard examination and observation techniques. This technique does not have any more of an adverse effect than normal handling of fish under anesthesia and a permanent archive is generated as a byproduct. These trials at Wanapum Dam documented several types of injuries occurring during turbine passage that were not detectable with conventional means. 


\subsection{Conclusions}

The new advanced design turbine (Unit 8) had slightly higher modeled injury rates than the conventional turbine design; however, there was no statistically significant difference in blade-strike probabilities. Overall injury rates predicted by the deterministic model were higher than experimental rates of injury while those predicted by the stochastic model were in close agreement. Fish orientation at the time of entry into the plane of the leading edges of the turbine runner blades is one factor contributing to uncertainty in modeled results.

The majority (80\%) of severe acceleration events were believed to be due to collision. Of the 891 total Sensor Fish releases, there were 185 severe collision events compared to 18 severe shear events, based on our categorization scheme. We found no correlation between Sensor Fish strike events in the runner blade region and the recorded pressure nadir. The predicted rate of shear injury was lower in Unit 8 than Unit 9. Most of the predicted shear injury occurred in the stay-vane/wicket-gate and runner regions with 30-ft releases showing the highest rates. Overall, the Sensor Fish events and live fish survival results showed similar patterns for each turbine unit.

The dye injury study demonstrated the feasibility of a new technique for quantifying fish injury during dam passage with the potential to increase statistical sensitivity of injury assessments. Several types of injuries were found to occur during turbine passage that were not detectable with traditional techniques. The dye technique was rapid and portable enough to be incorporated into standard examination and observational methods. There were no adverse effects to fish other than handling associated with anesthesia. Having photographic records for archiving and additional quantitative analysis was another benefit.

The Wanapum, and previously the Bonneville minimum gap runner (MGR) biological assessment data showed that the route a fish takes through a turbine is a factor in risk of injury. Risk of injury typically increases significantly with radial distance from the runner hub. As discharge increases, in turbines, there is a constriction of flow lines. In the case of the fixed elevation injection points for the Wanapum test, the likely vertical entry point of test fish through the test turbines' distributors increased as discharge increased. The net result of this condition was that passage routes through the test turbines' runners were a function of discharge. This effect was evidenced by Sensor Fish and inertial particle tracking results. A consequence is that direct comparison of findings between discharges for individual turbines or between different turbines are likely confounded in an unknown way. However, it is also likely that comparison between turbines at the same discharges are not confounded because the dynamics of flow constriction remained the same.

Overall, these studies demonstrated the importance of having a suite of tools available for assessing the response of fish to turbine passage. Our approach involved mathematical models and simulation, in situ measurements of hydraulic conditions, and biological response. Each study provided a different view of the biological performance of the advanced and an existing turbine at Wanapum Dam and contributed to the goal of achieving increased power output without incremental adverse effects to downstream 
migrating salmonids. Additional research directed at improving the understanding of collision mechanisms for different hydraulic structures associated with turbine passage and consequent fish injury seems warranted. 


\subsection{References}

Bell, M.C. 1991. Revised Compendium of the Success of Passage of Small Fish through Turbines. Technical report, U.S. Army Corps of Engineers, North Pacific Division, Portland, Oregon.

Brege, DA, RF Absolon, BP Sandford, and DB Dey. 1997. Studies to Evaluate the Effectiveness of Extended-Length Screens at John Day Dam, 1996. Report of Research to U.S. Army Corps of Engineers, Portland District, Oregon, and Coastal Zone and Estuarine Studies Division, Northwest Fisheries Science Center, NMFS/NOAA, Seattle, Washington.

Cada, G.F. 2001. The development of advanced hydroelectric turbines to improve fish passage survival. Fisheries, 26(9):14-23.

Cada, G.F., M.G. Ryon, J.G. Smith, and C.A. Luckett. 2006a. The Effects of Turbine Passage on C-Start Behavior of Salmon at the Wanapum Dam, Washington. ORNL/Tm-2006/88. Oak Ridge National Laboratory, Oak Ridge, Tennessee .

Cada GF, J. Loar, L. Garrison, R. Fisher, Jr., and D. A. Neitzel. 2006b. Efforts to reduce mortality to hydroelectric turbine-passed fish: locating and quantifying damaging shear stresses. Env. Man., 37 (6):898-906.

Carlson, T.J., J.P. Duncan, and T.L. Gilbride. 2003. The Sensor Fish: Measuring fish passage in severe hydraulic conditions. Hydro Review 22 (3), 62-69.

Carlson TJ, JP Duncan, Z Deng. 2006. Use of the Sensor Fish Device to Evaluate the Biological Performance of an Advanced Turbine Design at Wanapum Dam in 2005, PNWD-3743, Prepared for Grant County PUD, Battelle-Pacific Northwest Division, Richland, Washington.

CD-Adapco (1999). User Guide, STAR-CD Version 3.10. CD-Adapco, Limited.

Coutant, C.C. and R. R. Whitney. 2000. Fish behavior in relation to passage through hydropower turbines: A review. Transactions of the American Fisheries Society, 129(2):351-380.

Deng, Z., M.C. Richmond, C. Simmons, and T.J. Carlson. 2004. Six Degrees of Freedom Sensor Fish Design: Governing Equations and Motion Modeling. PNNL-14779, Pacific Northwest National Laboratory, Richland, WA.

Deng Z, T.J. Carlson, G.R. Ploskey, and M.C. Richmond. 2005a. Evaluation of Blade-Strike Models for Estimating the Biological Performance of Large Kaplan Hydro Turbines. PNNL-15370, Pacific Northwest National Laboratory, Richland, WA.

Deng Z, G.R. Guensch, C.A. McKinstry, R.P. Mueller, D.D. Dauble, and M.C. Richmond. 2005b. Evaluation of fish-injury mechanisms during exposure to turbulent shear flow. Canadian Journal of Fisheries and Aquatic Sciences, 62(7):1513-1522.

Deng Z, T.J. Carlson, G.R. Ploskey, M.C. Richmond, and D.D. Dauble. 2007. "Evaluation of BladeStrike Models for Estimating the Biological Performance of Kaplan Turbines." Ecological Modelling. doi:10.1016/j.ecolmodel.2007.05.019 
Dresser TJ, Dotson CL, Fisher RK, Graf MJ, Richmond MC, Rakowski CL, Carslon TJ, Mathur D, and P. Heisey. 2006. "Wanapum Dam Advanced Hydro Turbine Upgrade Project: Part 2 - Evaluation of Fish Passage Test Results Using Computational Fluid Dynamics." Proceedings of HydroVision 2006, Portland, OR

Duncan, J.P., T.J. Carlson, and Z.D. Deng. 2005. Characterization of Passage Conditions for Test Fish at Priest Rapids Dam Passing through Turbine Unit No. 8 at 15 kcfs Discharge, 2005. PNWD-3629. Pacific Northwest National Laboratory, Richland, Washington.

Efron, B. and R.J. Tibshirani. 1993. An Introduction to the Bootstrap, Chapman \& Hall, New York.

Grant County Public Utility District. 2003. “Application submitted in response to request for Applications DE-RP07-02ID14268 Manufacture, Installation, and Testing of New EnvironmentallyFriendly Hydropower Turbine Designs," Ephrata, Washington.

Hecker GE and T. C. Cook. 2005. Development and evaluation of a new helical fish-friendly hydroturbine. J. Hydr. Engr., 131(10):835-844.

Johnson G.E., B.D. Ebberts, D.D. Dauble, A.E. Giorgi, P.G. Heisey, R.P. Mueller, and D.A. Neitzel. Effects of jet entry at high-flow outfalls on juvenile Pacific salmon. North American Journal of Fisheries Management, 23(2):441-449.

Mathur D., P.G. Heisey, J.R. Skalski, and D.R. Kenney. 2000. Salmonid smolt survival relative to turbine efficiency and entrainment depth in hydroelectric power generation. Journal of the American Water Resources Association, 36(4):737-747.

Mathur D, P.G. Heisey, E.T. Euston, J.R. Skalski, and S. Hays. 1996. Turbine passage survival estimation for Chinook salmon smolts (Oncorhynchus tshawytscha) at a large dam on the Columbia River. Canadian Journal of Fisheries and Aquatic Sciences, 53(3):542-549.

Moursund R.A., and M.D. Bleich. 2004. "Non-Visible External Fish Injury Detection and Quantification in Dam Passage Research.” PNWD-SA-6379. Hydrovision 2004, August 16-20, Montreal, Canada.

Neitzel, D.A., M.C. Richmond, D.D. Dauble, R.P. Mueller, R.A. Moursund, C.S. Abernethy, G.R. Guensch, and G.F. Cada. 2000. Laboratory Studies of the Effects of Shear on Fish. PNNL-13323. Prepared for U.S. Department of Energy, Energy Efficiency and Renewable Energy, by Pacific Northwest National Laboratory, Richland, Washington.

Neitzel, D., D.D. Dauble, G.F. Cada, M.C. Richmond, G.R. Guensch, R.P. Mueller, C.S. Abernethy, and B. Amidan. 2004. "Survival estimates for juvenile fish subjected to a laboratory-generated shear environment." Transactions of the American Fisheries Society, Vol. 133, pp. 447-454.

Neter, J., W. Wassermann, and M.H. Kutner. 1990. Applied Linear Statistical Models, ${ }^{\text {rd }}{ }^{\text {Ed. Richard D. }}$ Irwin, Inc. Moston, MA. (Ridge regression section on pp. 412-418.)

Noga E.J., and P. Udomkusonsri. 2002. Fluorescein: a rapid, sensitive, nonlethal method for detecting skin ulceration in fish. Vet Pathol. 39:726-731.

Normandeau Associates Inc. 1999. Relative Passage Survival and Injury Mechanisms for Chinook Salmon Smolts within the Turbine Environment at McNary Lock and Dam, Columbia River. Report 
prepared for U.S. Army Corps of Engineers, Walla Walla District, Washington, by Normandeau Associates.

Normandeau Associates Inc., J.R. Skalski, and Mid Columbia Consulting Inc. 1995. Turbine Passage Survival of Juvenile Spring Chinook Salmon (Oncorhynchus tshawytscha) at Lower Granite Dam, Snake River, Washington. Prepared for U.S. Army Corps of Engineers, Walla Walla District, Washington, by Normandeau Associates.

Normandeau Associates, Inc., JR Skalski, and Mid-Columbia Consulting, Inc. 2000. Direct Survival and Condition of Juvenile Chinook Salmon Passed through an Existing and New Minimum Gap Runner Turbines at Bonneville Dam First Powerhouse, Columbia River. Report to U.S. Army Corps of Engineers, Portland District, Portland, Oregon.

Normandeau Associates Inc., J.R. Skalski, and Mid Columbia Consulting Inc. 2001. Passage Survival Investigation of Juvenile Salmon through Bonneville Powerhouse II Bypass Sluice at Two Tailwater Conditions, Columbia River, Washington. Prepared for U.S. Army Corps of Engineers, Portland District, Portland, Oregon.

Normandeau Associates, Inc., John R. Skalski, Rich Townsend. 2005. Performance Evaluation of the New Advanced Hydro Turbine (AHTS) at Wanapum Dam, Columbia River, Washington. Prepared for Grant County PUD, by Normandeau Associates, Drumore, Pennsylania.

Odeh M and G. Sommers. 2000. New design concepts for fish friendly turbines. Int. J. Hydropower and Dams, 73(3):64-71.

Ploskey, G.R., and T.J. Carlson. 2004. Comparison of Blade-Strike Modeling Results with Empirical Data. PNNL-14603. Prepared for U.S. Department of Energy, Energy Efficiency and Renewable Energy, by Pacific Northwest National Laboratory, Richland, Washington.

Pointwise. 1998. Gridgen User Manual, Version 13. Pointwise, Inc.

Pouliquen H, and M Algoet. 1995. Acute toxicity of fluorescein to turbot (Scophthalmus maximus). Vet Human Toxicol. 37 (6): 527-529.

Rakowski CL, L.L. Ebner, and M. C. Richmond. 2005. Juvenile Salmon Bypass and CFD Tools for Bonneville Dam on the Columbia River. HydroReview XXIV(1):56-65.

Sale, M.J., G.F. Cada, T.L. Acker, T.J. Carlson, D.D. Dauble, and D.G. Hall. 2006. DOE Hydropower Program Annual Report for FY 2005-2006. ORNL/TM-2006/97, Prepared for U.S. Department of Energy, Office of Energy Efficiency and Renewable Energy, Wind and Hydropower Technologies, Washington D.C., by Oak Ridge National Laoboratory, Oak Ridge, Tennessee.

Skalski, J.R., R.L. Townsend, and Normandeau Associates, Inc. 2005. Quantitative Evaluation of the Performance of the New Advanced Hydro Turbine System (AHTS) at Wanapum Dam, Columbia River, Washington. Prepared for Public Utility District No. 2 of Grant County, Ephrata, Washington.

Turnpenny, A.W.H. Mechanisms of fish damage in low-head turbines: An experimental appraisal. In M. Jungwirth, S. Schmutz, and S. Weiss, editors, Fish Migration and Fish Bypasses, pages 300-314. Blackwell Publishing, Oxford, United Kingdom, 1998. 
Turnpenny, A.W.H, S. Clough, K.P. Hanson, R. Ramsay, and D. McEwan. 2000. Risk Assessment for Fish Passage through Small, Low-Head Turbines. Technical Report ETSUH/06/00054/REP, Energy Technology Support Unit, Harwell, United Kingdom.

USACE. 2004. Turbine Survival Program Phase 1 Report, 1997-2002. Technical report, U.S. Army Corps of Engineers, Portland, Oregon.

Von Raben K. 1957. Regarding the problem of mutilations of fishes by hydraulic turbines. Die Wasserwirtschaft, 4:97-100. 


\section{Appendix A}

Tabulated Results of Sensor Fish Studies at Wanapum Dam 2005 



\section{Appendix A}

\section{Tabulated Results of Sensor Fish Studies at Wanapum Dam 2005}

Table A.1. Summary of Collision and Shear Sensor Fish Events in Wicket Gate / Stay Vane Region

\begin{tabular}{|c|c|c|c|c|c|c|c|c|c|c|}
\hline Unit & $\begin{array}{c}\mathrm{Q} \\
(\mathrm{kcfs})\end{array}$ & Pipe & $\begin{array}{c}\text { \# of } \\
\text { samples }\end{array}$ & $\begin{array}{l}\text { Severe } \\
\text { collision }\end{array}$ & $\begin{array}{l}\text { Std dev } \\
\text { severe } \\
\text { collision }\end{array}$ & $\begin{array}{l}\text { Medium } \\
\text { collision }\end{array}$ & $\begin{array}{l}\text { Slight } \\
\text { collision }\end{array}$ & $\begin{array}{l}\text { Severe } \\
\text { Shear }\end{array}$ & $\begin{array}{l}\text { Medium } \\
\text { Shear }\end{array}$ & $\begin{array}{l}\text { Slight } \\
\text { Shear }\end{array}$ \\
\hline 8 & 9 & 10 & 46 & $10.9 \%$ & $4.6 \%$ & $4.3 \%$ & $6.5 \%$ & $0.0 \%$ & $0.0 \%$ & $4.3 \%$ \\
\hline 8 & 9 & 30 & 52 & $17.3 \%$ & $5.1 \%$ & $9.6 \%$ & $17.3 \%$ & $0.0 \%$ & $0.0 \%$ & $5.8 \%$ \\
\hline 8 & 11 & 10 & 44 & $13.6 \%$ & $5.1 \%$ & $6.8 \%$ & $0.0 \%$ & $0.0 \%$ & $0.0 \%$ & $4.5 \%$ \\
\hline 8 & 11 & 30 & 56 & $17.9 \%$ & $5.0 \%$ & $5.4 \%$ & $3.6 \%$ & $0.0 \%$ & $0.0 \%$ & $17.9 \%$ \\
\hline 8 & 15 & 10 & 44 & $13.6 \%$ & $5.1 \%$ & $4.5 \%$ & $9.1 \%$ & $0.0 \%$ & $0.0 \%$ & $0.0 \%$ \\
\hline 8 & 15 & 30 & 56 & $10.7 \%$ & $4.2 \%$ & $3.6 \%$ & $1.8 \%$ & $0.0 \%$ & $12.5 \%$ & $26.8 \%$ \\
\hline 8 & 17 & 10 & 44 & $13.6 \%$ & $5.2 \%$ & $0.0 \%$ & $2.3 \%$ & $0.0 \%$ & $0.0 \%$ & $4.5 \%$ \\
\hline 8 & 17 & 30 & 97 & $15.5 \%$ & $3.7 \%$ & $1.0 \%$ & $5.2 \%$ & $1.0 \%$ & $8.2 \%$ & $21.6 \%$ \\
\hline 8 & 18 & 10 & 45 & $6.7 \%$ & $3.6 \%$ & $0.0 \%$ & $6.7 \%$ & $0.0 \%$ & $0.0 \%$ & $11.1 \%$ \\
\hline \multirow[t]{2}{*}{8} & 18 & 30 & 52 & $13.5 \%$ & $4.8 \%$ & $5.8 \%$ & $1.9 \%$ & $1.9 \%$ & $5.8 \%$ & $30.8 \%$ \\
\hline & All & & 536 & $13.6 \%$ & $1.5 \%$ & $3.9 \%$ & $5.4 \%$ & $0.4 \%$ & $3.4 \%$ & $14.2 \%$ \\
\hline 9 & 9 & 10 & 45 & $8.9 \%$ & $4.3 \%$ & $2.2 \%$ & $4.4 \%$ & $0.0 \%$ & $0.0 \%$ & $2.2 \%$ \\
\hline 9 & 9 & 30 & 43 & $16.3 \%$ & $5.6 \%$ & $2.3 \%$ & $7.0 \%$ & $0.0 \%$ & $0.0 \%$ & $7.0 \%$ \\
\hline 9 & 11 & 10 & 47 & $8.5 \%$ & $4.1 \%$ & $2.1 \%$ & $0.0 \%$ & $2.1 \%$ & $0.0 \%$ & $2.1 \%$ \\
\hline 9 & 11 & 30 & 44 & $11.4 \%$ & $4.9 \%$ & $2.3 \%$ & $6.8 \%$ & $0.0 \%$ & $4.5 \%$ & $13.6 \%$ \\
\hline 9 & 15 & 10 & 45 & $4.4 \%$ & $3.1 \%$ & $4.4 \%$ & $2.2 \%$ & $2.2 \%$ & $0.0 \%$ & $0.0 \%$ \\
\hline 9 & 15 & 30 & 43 & $25.6 \%$ & $6.6 \%$ & $4.7 \%$ & $4.7 \%$ & $0.0 \%$ & $7.0 \%$ & $18.6 \%$ \\
\hline 9 & 17 & 10 & 44 & $6.8 \%$ & $3.8 \%$ & $4.5 \%$ & $2.3 \%$ & $2.3 \%$ & $0.0 \%$ & $0.0 \%$ \\
\hline \multirow[t]{2}{*}{9} & 17 & 30 & 44 & $4.5 \%$ & $3.2 \%$ & $4.5 \%$ & $0.0 \%$ & $0.0 \%$ & $6.8 \%$ & $6.8 \%$ \\
\hline & All & & 355 & $10.7 \%$ & $1.7 \%$ & $3.4 \%$ & $3.4 \%$ & $0.8 \%$ & $2.3 \%$ & $6.2 \%$ \\
\hline
\end{tabular}


Table A.2. Summary of Collision and Shear Sensor Fish Events in Runner Region

\begin{tabular}{|c|c|c|c|c|c|c|c|c|c|c|}
\hline Unit & $\begin{array}{c}\mathrm{Q} \\
(\mathrm{kcfs})\end{array}$ & Pipe & $\begin{array}{c}\text { \# of } \\
\text { samples }\end{array}$ & $\begin{array}{l}\text { Severe } \\
\text { collision }\end{array}$ & $\begin{array}{l}\text { Std dev } \\
\text { severe } \\
\text { collision }\end{array}$ & $\begin{array}{l}\text { Medium } \\
\text { collision }\end{array}$ & $\begin{array}{c}\text { Slight } \\
\text { collision }\end{array}$ & $\begin{array}{l}\text { Severe } \\
\text { Shear }\end{array}$ & $\begin{array}{l}\text { Medium } \\
\text { Shear }\end{array}$ & $\begin{array}{l}\text { Slight } \\
\text { Shear }\end{array}$ \\
\hline 8 & 9 & 10 & 46 & $2.2 \%$ & $2.2 \%$ & $2.2 \%$ & $2.2 \%$ & $0.0 \%$ & $6.5 \%$ & $32.6 \%$ \\
\hline 8 & 9 & 30 & 52 & $9.6 \%$ & $4.1 \%$ & $11.5 \%$ & $1.9 \%$ & $1.9 \%$ & $5.8 \%$ & $34.6 \%$ \\
\hline 8 & 11 & 10 & 44 & $4.5 \%$ & $3.2 \%$ & $0.0 \%$ & $0.0 \%$ & $0.0 \%$ & $6.8 \%$ & $9.1 \%$ \\
\hline 8 & 11 & 30 & 56 & $12.5 \%$ & $4.4 \%$ & $8.9 \%$ & $3.6 \%$ & $1.8 \%$ & $0.0 \%$ & $17.9 \%$ \\
\hline 8 & 15 & 10 & 44 & $0.0 \%$ & $0.0 \%$ & $0.0 \%$ & $2.3 \%$ & $0.0 \%$ & $0.0 \%$ & $25.0 \%$ \\
\hline 8 & 15 & 30 & 56 & $3.6 \%$ & $2.5 \%$ & $3.6 \%$ & $5.4 \%$ & $0.0 \%$ & $1.8 \%$ & $5.4 \%$ \\
\hline 8 & 17 & 10 & 44 & $2.3 \%$ & $2.2 \%$ & $6.8 \%$ & $4.5 \%$ & $0.0 \%$ & $4.5 \%$ & $13.6 \%$ \\
\hline 8 & 17 & 30 & 97 & $5.2 \%$ & $2.2 \%$ & $4.1 \%$ & $1.0 \%$ & $0.0 \%$ & $3.1 \%$ & $12.4 \%$ \\
\hline 8 & 18 & 10 & 45 & $0.0 \%$ & $0.0 \%$ & $2.2 \%$ & $2.2 \%$ & $0.0 \%$ & $0.0 \%$ & $17.8 \%$ \\
\hline \multirow[t]{2}{*}{8} & 18 & 30 & 52 & $5.8 \%$ & $3.2 \%$ & $7.7 \%$ & $3.8 \%$ & $3.8 \%$ & $1.9 \%$ & $7.7 \%$ \\
\hline & All & & 536 & $4.9 \%$ & $0.9 \%$ & $4.9 \%$ & $2.6 \%$ & $0.7 \%$ & $3.0 \%$ & $17.0 \%$ \\
\hline 9 & 9 & 10 & 45 & $15.6 \%$ & $5.4 \%$ & $4.4 \%$ & $4.4 \%$ & $0.0 \%$ & $0.0 \%$ & $15.6 \%$ \\
\hline 9 & 9 & 30 & 43 & $11.6 \%$ & $4.9 \%$ & $7.0 \%$ & $7.0 \%$ & $9.3 \%$ & $4.7 \%$ & $20.9 \%$ \\
\hline 9 & 11 & 10 & 47 & $6.4 \%$ & $3.5 \%$ & $2.1 \%$ & $4.3 \%$ & $0.0 \%$ & $2.1 \%$ & $17.0 \%$ \\
\hline 9 & 11 & 30 & 44 & $15.9 \%$ & $5.4 \%$ & $2.3 \%$ & $2.3 \%$ & $2.3 \%$ & $9.1 \%$ & $11.4 \%$ \\
\hline 9 & 15 & 10 & 45 & $0.0 \%$ & $0.0 \%$ & $0.0 \%$ & $2.2 \%$ & $0.0 \%$ & $4.4 \%$ & $8.9 \%$ \\
\hline 9 & 15 & 30 & 43 & $7.0 \%$ & $3.8 \%$ & $4.7 \%$ & $4.7 \%$ & $2.3 \%$ & $0.0 \%$ & $16.3 \%$ \\
\hline 9 & 17 & 10 & 44 & $9.1 \%$ & $4.4 \%$ & $0.0 \%$ & $4.5 \%$ & $4.5 \%$ & $2.3 \%$ & $13.6 \%$ \\
\hline \multirow[t]{2}{*}{9} & 17 & 30 & 44 & $11.4 \%$ & $4.8 \%$ & $6.8 \%$ & $2.3 \%$ & $2.3 \%$ & $6.8 \%$ & $25.0 \%$ \\
\hline & All & & 355 & $9.6 \%$ & $1.6 \%$ & $3.4 \%$ & $3.9 \%$ & $2.5 \%$ & $3.7 \%$ & $16.1 \%$ \\
\hline
\end{tabular}

Table A.3. Summary of Collision and Shear Sensor Fish Events in Draft Tube Region

\begin{tabular}{|c|c|c|c|c|c|c|c|c|c|c|}
\hline Unit & $\begin{array}{c}\mathrm{Q} \\
(\mathrm{kcfs})\end{array}$ & Pipe & $\begin{array}{c}\text { \# of } \\
\text { samples }\end{array}$ & $\begin{array}{c}\text { Severe } \\
\text { collision }\end{array}$ & $\begin{array}{l}\text { Std dev } \\
\text { severe } \\
\text { collision }\end{array}$ & $\begin{array}{l}\text { Medium } \\
\text { collision }\end{array}$ & $\begin{array}{c}\text { Slight } \\
\text { collision }\end{array}$ & $\begin{array}{c}\text { Severe } \\
\text { Shear }\end{array}$ & $\begin{array}{l}\text { Medium } \\
\text { Shear }\end{array}$ & $\begin{array}{l}\text { Slight } \\
\text { Shear }\end{array}$ \\
\hline 8 & 9 & 10 & 46 & $2.2 \%$ & $2.1 \%$ & $2.2 \%$ & $4.3 \%$ & $0.0 \%$ & $0.0 \%$ & $0.0 \%$ \\
\hline 8 & 9 & 30 & 52 & $0.0 \%$ & $0.0 \%$ & $9.6 \%$ & $19.2 \%$ & $0.0 \%$ & $0.0 \%$ & $0.0 \%$ \\
\hline 8 & 11 & 10 & 44 & $0.0 \%$ & $0.0 \%$ & $2.3 \%$ & $6.8 \%$ & $0.0 \%$ & $0.0 \%$ & $0.0 \%$ \\
\hline 8 & 11 & 30 & 56 & $5.4 \%$ & $3.0 \%$ & $7.1 \%$ & $8.9 \%$ & $0.0 \%$ & $0.0 \%$ & $0.0 \%$ \\
\hline 8 & 15 & 10 & 44 & $2.3 \%$ & $2.2 \%$ & $0.0 \%$ & $2.3 \%$ & $0.0 \%$ & $0.0 \%$ & $0.0 \%$ \\
\hline 8 & 15 & 30 & 56 & $3.6 \%$ & $2.5 \%$ & $7.1 \%$ & $7.1 \%$ & $0.0 \%$ & $0.0 \%$ & $0.0 \%$ \\
\hline 8 & 17 & 10 & 44 & $0.0 \%$ & $0.0 \%$ & $4.5 \%$ & $2.3 \%$ & $0.0 \%$ & $0.0 \%$ & $2.3 \%$ \\
\hline 8 & 17 & 30 & 97 & $6.2 \%$ & $2.5 \%$ & $8.2 \%$ & $7.2 \%$ & $0.0 \%$ & $0.0 \%$ & $0.0 \%$ \\
\hline 8 & 18 & 10 & 45 & $2.2 \%$ & $2.2 \%$ & $4.4 \%$ & $4.4 \%$ & $0.0 \%$ & $0.0 \%$ & $2.2 \%$ \\
\hline \multirow[t]{2}{*}{8} & 18 & 30 & 52 & $7.7 \%$ & $3.6 \%$ & $7.7 \%$ & $9.6 \%$ & $0.0 \%$ & $0.0 \%$ & $1.9 \%$ \\
\hline & All & & 536 & $3.4 \%$ & $0.8 \%$ & $5.8 \%$ & $7.5 \%$ & $0.0 \%$ & $0.0 \%$ & $0.6 \%$ \\
\hline 9 & 9 & 10 & 45 & $2.2 \%$ & $2.2 \%$ & $2.2 \%$ & $8.9 \%$ & $0.0 \%$ & $0.0 \%$ & $0.0 \%$ \\
\hline 9 & 9 & 30 & 43 & $2.3 \%$ & $2.3 \%$ & $0.0 \%$ & $7.0 \%$ & $0.0 \%$ & $0.0 \%$ & $0.0 \%$ \\
\hline 9 & 11 & 10 & 47 & $4.3 \%$ & $2.9 \%$ & $0.0 \%$ & $4.3 \%$ & $0.0 \%$ & $0.0 \%$ & $0.0 \%$ \\
\hline 9 & 11 & 30 & 44 & $4.5 \%$ & $3.2 \%$ & $4.5 \%$ & $13.6 \%$ & $0.0 \%$ & $0.0 \%$ & $0.0 \%$ \\
\hline 9 & 15 & 10 & 45 & $0.0 \%$ & $0.0 \%$ & $6.7 \%$ & $4.4 \%$ & $0.0 \%$ & $0.0 \%$ & $2.2 \%$ \\
\hline 9 & 15 & 30 & 43 & $7.0 \%$ & $3.8 \%$ & $0.0 \%$ & $0.0 \%$ & $0.0 \%$ & $0.0 \%$ & $0.0 \%$ \\
\hline 9 & 17 & 10 & 44 & $2.3 \%$ & $2.2 \%$ & $4.5 \%$ & $2.3 \%$ & $0.0 \%$ & $0.0 \%$ & $0.0 \%$ \\
\hline \multirow[t]{2}{*}{9} & 17 & 30 & 44 & $4.5 \%$ & $3.1 \%$ & $2.3 \%$ & $6.8 \%$ & $0.0 \%$ & $0.0 \%$ & $0.0 \%$ \\
\hline & All & & 355 & $3.4 \%$ & $1.0 \%$ & $2.5 \%$ & $5.9 \%$ & $0.0 \%$ & $0.0 \%$ & $0.3 \%$ \\
\hline
\end{tabular}


Table A.4. Summary of Collision and Shear Sensor Fish Events, All Regions Combined

\begin{tabular}{|c|c|c|c|c|c|c|c|c|c|c|}
\hline Unit & $\begin{array}{c}\mathrm{Q} \\
(\mathrm{kcfs})\end{array}$ & Pipe & $\begin{array}{c}\text { \# of } \\
\text { samples }\end{array}$ & $\begin{array}{c}\text { Severe } \\
\text { collision }\end{array}$ & $\begin{array}{l}\text { Std dev } \\
\text { for } \\
\text { severe } \\
\text { collision }\end{array}$ & $\begin{array}{l}\text { Medium } \\
\text { collision }\end{array}$ & $\begin{array}{c}\text { Slight } \\
\text { collision }\end{array}$ & $\begin{array}{c}\text { Severe } \\
\text { Shear }\end{array}$ & $\begin{array}{l}\text { Medium } \\
\text { Shear }\end{array}$ & $\begin{array}{l}\text { Slight } \\
\text { Shear }\end{array}$ \\
\hline 8 & 9 & 10 & 46 & $15.2 \%$ & $5.3 \%$ & $6.5 \%$ & $10.9 \%$ & $0.0 \%$ & $6.5 \%$ & $34.8 \%$ \\
\hline 8 & 9 & 30 & 52 & $26.9 \%$ & $6.1 \%$ & $19.2 \%$ & $21.2 \%$ & $1.9 \%$ & $5.8 \%$ & $36.5 \%$ \\
\hline 8 & 11 & 10 & 44 & $18.2 \%$ & $5.8 \%$ & $9.1 \%$ & $6.8 \%$ & $0.0 \%$ & $6.8 \%$ & $11.4 \%$ \\
\hline 8 & 11 & 30 & 56 & $32.1 \%$ & $6.2 \%$ & $12.5 \%$ & $7.1 \%$ & $1.8 \%$ & $0.0 \%$ & $33.9 \%$ \\
\hline 8 & 15 & 10 & 44 & $13.6 \%$ & $5.1 \%$ & $4.5 \%$ & $13.6 \%$ & $0.0 \%$ & $0.0 \%$ & $27.3 \%$ \\
\hline 8 & 15 & 30 & 56 & $17.9 \%$ & $5.2 \%$ & $10.7 \%$ & $12.5 \%$ & $0.0 \%$ & $14.3 \%$ & $30.4 \%$ \\
\hline 8 & 17 & 10 & 44 & $15.9 \%$ & $5.5 \%$ & $9.1 \%$ & $4.5 \%$ & $0.0 \%$ & $4.5 \%$ & $20.5 \%$ \\
\hline 8 & 17 & 30 & 97 & $24.7 \%$ & $4.4 \%$ & $8.2 \%$ & $8.2 \%$ & $1.0 \%$ & $11.3 \%$ & $30.9 \%$ \\
\hline 8 & 18 & 10 & 45 & $8.9 \%$ & $4.1 \%$ & $4.4 \%$ & $6.7 \%$ & $0.0 \%$ & $0.0 \%$ & $24.4 \%$ \\
\hline \multirow[t]{2}{*}{8} & 18 & 30 & 52 & $23.1 \%$ & $5.7 \%$ & $11.5 \%$ & $9.6 \%$ & $5.8 \%$ & $7.7 \%$ & $36.5 \%$ \\
\hline & All & & 536 & $20.5 \%$ & $1.8 \%$ & $9.7 \%$ & $10.1 \%$ & $1.1 \%$ & $6.3 \%$ & $29.3 \%$ \\
\hline 9 & 9 & 10 & 45 & $24.4 \%$ & $6.7 \%$ & $8.9 \%$ & $11.1 \%$ & $0.0 \%$ & $0.0 \%$ & $17.8 \%$ \\
\hline 9 & 9 & 30 & 43 & $25.6 \%$ & $6.7 \%$ & $4.7 \%$ & $11.6 \%$ & $9.3 \%$ & $4.7 \%$ & $20.9 \%$ \\
\hline 9 & 11 & 10 & 47 & $14.9 \%$ & $5.2 \%$ & $4.3 \%$ & $4.3 \%$ & $2.1 \%$ & $2.1 \%$ & $19.1 \%$ \\
\hline 9 & 11 & 30 & 44 & $27.3 \%$ & $6.8 \%$ & $6.8 \%$ & $15.9 \%$ & $2.3 \%$ & $13.6 \%$ & $18.2 \%$ \\
\hline 9 & 15 & 10 & 45 & $4.4 \%$ & $3.1 \%$ & $11.1 \%$ & $8.9 \%$ & $2.2 \%$ & $4.4 \%$ & $8.9 \%$ \\
\hline 9 & 15 & 30 & 43 & $37.2 \%$ & $7.2 \%$ & $7.0 \%$ & $4.7 \%$ & $2.3 \%$ & $7.0 \%$ & $30.2 \%$ \\
\hline 9 & 17 & 10 & 44 & $18.2 \%$ & $5.9 \%$ & $9.1 \%$ & $6.8 \%$ & $6.8 \%$ & $2.3 \%$ & $13.6 \%$ \\
\hline \multirow[t]{2}{*}{9} & 17 & 30 & 44 & $18.2 \%$ & $5.8 \%$ & $11.4 \%$ & $6.8 \%$ & $2.3 \%$ & $13.6 \%$ & $29.5 \%$ \\
\hline & All & & 355 & $21.1 \%$ & $2.2 \%$ & $7.9 \%$ & $8.7 \%$ & $3.4 \%$ & $5.9 \%$ & $19.7 \%$ \\
\hline
\end{tabular}

Table A.5. Summary of Significant Sensor Fish Events (shear or collision), All Regions Combined

\begin{tabular}{cccc|cccc}
\hline & & & & \multicolumn{4}{|c}{ Std dev } \\
Unit & $\begin{array}{c}\text { Q } \\
\text { (kcfs) }\end{array}$ & Pipe & $\begin{array}{c}\text { \# of } \\
\text { samples }\end{array}$ & $\begin{array}{c}\text { Severe } \\
\text { events }\end{array}$ & $\begin{array}{c}\text { Medium } \\
\text { events }\end{array}$ & $\begin{array}{c}\text { Slight } \\
\text { events }\end{array}$ & events \\
\hline 8 & 9 & 10 & 46 & $15.2 \%$ & $5.2 \%$ & $10.9 \%$ & $41.3 \%$ \\
8 & 9 & 30 & 52 & $28.8 \%$ & $6.3 \%$ & $23.1 \%$ & $32.7 \%$ \\
8 & 11 & 10 & 44 & $18.2 \%$ & $5.8 \%$ & $15.9 \%$ & $18.2 \%$ \\
8 & 11 & 30 & 56 & $32.1 \%$ & $6.0 \%$ & $12.5 \%$ & $26.8 \%$ \\
8 & 15 & 10 & 44 & $13.6 \%$ & $5.2 \%$ & $4.5 \%$ & $27.3 \%$ \\
8 & 15 & 30 & 56 & $17.9 \%$ & $5.3 \%$ & $19.6 \%$ & $30.4 \%$ \\
8 & 17 & 10 & 44 & $15.9 \%$ & $5.7 \%$ & $13.6 \%$ & $18.2 \%$ \\
8 & 17 & 30 & 97 & $25.8 \%$ & $4.3 \%$ & $17.5 \%$ & $28.9 \%$ \\
8 & 18 & 10 & 45 & $8.9 \%$ & $4.3 \%$ & $4.4 \%$ & $31.1 \%$ \\
8 & 18 & 30 & 52 & $26.9 \%$ & $6.3 \%$ & $19.2 \%$ & $30.8 \%$ \\
& All & & 536 & $21.3 \%$ & $1.8 \%$ & $14.7 \%$ & $28.7 \%$ \\
\hline 9 & 9 & 10 & 45 & $24.4 \%$ & $6.4 \%$ & $8.9 \%$ & $22.2 \%$ \\
9 & 9 & 30 & 43 & $34.9 \%$ & $7.1 \%$ & $9.3 \%$ & $27.9 \%$ \\
9 & 11 & 10 & 47 & $14.9 \%$ & $5.2 \%$ & $6.4 \%$ & $19.1 \%$ \\
9 & 11 & 30 & 44 & $29.5 \%$ & $6.7 \%$ & $18.2 \%$ & $27.3 \%$ \\
9 & 15 & 10 & 45 & $6.7 \%$ & $3.7 \%$ & $15.6 \%$ & $13.3 \%$ \\
9 & 15 & 30 & 43 & $39.5 \%$ & $7.2 \%$ & $14.0 \%$ & $27.9 \%$ \\
9 & 17 & 10 & 44 & $20.5 \%$ & $6.2 \%$ & $9.1 \%$ & $13.6 \%$ \\
9 & 17 & 30 & 44 & $20.5 \%$ & $5.9 \%$ & $20.5 \%$ & $25.0 \%$ \\
& All & & 355 & $23.7 \%$ & $2.2 \%$ & $12.7 \%$ & $22.0 \%$ \\
\hline & & & & & & &
\end{tabular}


Table A.6. Comparison of Unit 8 (AHT) Injury-Free Rate from Balloon Tag Tests (Normandeau et al. 2005) with the No Severe Event Rate from Sensor Fish. The lowest rate for each discharge is highlighted. The double asterisk (**) indicates the difference between Unit 8 and 9 release pipe balloon tag data where a P-value of less than 0.05 occurred.

\begin{tabular}{|c|c|c|c|c|c|}
\hline & & & \multicolumn{3}{|c|}{ Unit 8 (AHT) } \\
\hline & & & $\begin{array}{l}\text { Injury Free } \\
\text { Rate }\end{array}$ & Std. Error & $\begin{array}{l}\text { Sensor Fish } \\
\text { No Severe Event }\end{array}$ \\
\hline \multirow[t]{6}{*}{9} & 10 & $\mathrm{~A}$ & 0.992 & 0.010 & 0.800 \\
\hline & & B & 0.995 & 0.009 & 0.813 \\
\hline & & $\mathrm{C}$ & 0.994 & 0.006 & 0.933 \\
\hline & $30^{* *}$ & A & 0.978 & 0.014 & 0.684 \\
\hline & & $\mathrm{B}$ & 0.954 & 0.019 & 0.684 \\
\hline & & $\mathrm{C}$ & 0.981 & 0.012 & 0.786 \\
\hline \multirow[t]{6}{*}{11} & 10 & $\mathrm{~A}$ & 0.995 & 0.017 & 0.857 \\
\hline & & B & 0.995 & 0.054 & 0.765 \\
\hline & & $\mathrm{C}$ & 0.985 & 0.010 & 0.846 \\
\hline & 30 & A & 0.992 & 0.010 & 0.722 \\
\hline & & $\mathrm{B}$ & 0.957 & 0.017 & 0.727 \\
\hline & & $\mathrm{C}$ & 0.956 & 0.019 & 0.563 \\
\hline \multirow[t]{6}{*}{15} & 10 & $\mathrm{~A}$ & 0.995 & 0.009 & 0.667 \\
\hline & & B & 0.994 & 0.006 & 0.933 \\
\hline & & $\mathrm{C}$ & 0.984 & 0.011 & 1.000 \\
\hline & $30^{* *}$ & A & 0.975 & 0.014 & 0.833 \\
\hline & & B & 0.930 & 0.023 & 0.850 \\
\hline & & $\mathrm{C}$ & 0.962 & 0.017 & 0.778 \\
\hline \multirow[t]{6}{*}{17} & 10 & $\mathrm{~A}$ & 0.956 & 0.018 & 0.786 \\
\hline & & $\mathrm{B}$ & 0.989 & 0.013 & 0.800 \\
\hline & & $\mathrm{C}$ & 0.984 & 0.013 & 0.933 \\
\hline & 30 ** & A & 0.976 & 0.013 & 0.750 \\
\hline & & B & 0.941 & 0.021 & 0.700 \\
\hline & & $\mathrm{C}$ & 0.974 & 0.014 & 0.882 \\
\hline
\end{tabular}


Table A.7. Comparison of Unit 9 (existing) Injury-Free Rate from Balloon Tag Tests (Normandeau et al. 2005) with the No-Severe Event Rate from Sensor Fish. The lowest rate for each discharge is highlighted.

\begin{tabular}{|c|c|c|c|c|c|}
\hline & & & \multicolumn{3}{|c|}{ Unit 9 (existing) } \\
\hline & & & \multirow[b]{2}{*}{$\begin{array}{l}\text { Injury Free } \\
\text { Rate }\end{array}$} & \multicolumn{2}{|r|}{ Sensor Fish } \\
\hline & & & & Std Error & No Severe Event \\
\hline \multirow[t]{6}{*}{9} & 10 & A & 0.979 & 0.013 & 0.733 \\
\hline & & B & 0.982 & 0.013 & 0.733 \\
\hline & & $\mathrm{C}$ & 0.983 & 0.012 & 0.800 \\
\hline & 30 & A & 0.989 & 0.010 & 0.714 \\
\hline & & B & 0.984 & 0.012 & 0.643 \\
\hline & & $\mathrm{C}$ & 0.975 & 0.015 & 0.600 \\
\hline \multirow[t]{6}{*}{11} & 10 & A & 0.984 & 0.012 & 0.786 \\
\hline & & B & 0.971 & 0.015 & 0.944 \\
\hline & & $\mathrm{C}$ & 0.995 & 0.012 & 0.800 \\
\hline & 30 & A & 0.945 & 0.020 & 0.833 \\
\hline & & B & 0.995 & 0.008 & 0.722 \\
\hline & & $\mathrm{C}$ & 0.978 & 0.014 & 0.571 \\
\hline \multirow[t]{6}{*}{15} & 10 & A & 0.981 & 0.012 & 0.933 \\
\hline & & B & 0.984 & 0.011 & 0.933 \\
\hline & & $\mathrm{C}$ & 0.995 & 0.008 & 0.933 \\
\hline & 30 & A & 0.964 & 0.017 & 0.500 \\
\hline & & B & 0.976 & 0.014 & 0.643 \\
\hline & & $\mathrm{C}$ & 0.973 & 0.014 & 0.667 \\
\hline \multirow[t]{6}{*}{17} & 10 & A & 0.980 & 0.012 & 0.733 \\
\hline & & B & 0.992 & 0.010 & 0.786 \\
\hline & & $\mathrm{C}$ & 0.961 & 0.018 & 0.867 \\
\hline & 30 & A & 0.975 & 0.013 & 0.800 \\
\hline & & B & 0.980 & 0.012 & 0.786 \\
\hline & & $\mathrm{C}$ & 0.985 & 0.010 & 0.800 \\
\hline
\end{tabular}


Table A.8. Predicted Shear Injury Rates Using Sensor Fish Correlation Relationship for a Fast Fish to Slow Water Exposure. Live fish shear injury rates are from Normandeau et al. (2005).

\begin{tabular}{|c|c|c|c|c|c|c|c|c|c|c|c|c|c|c|c|}
\hline \multicolumn{5}{|c|}{ Fast fish to slow water } & \multicolumn{2}{|c|}{ Intake } & \multicolumn{2}{|c|}{$\begin{array}{l}\text { Stay vane / Wicket } \\
\text { gate }\end{array}$} & \multicolumn{2}{|c|}{ Runner region } & \multicolumn{2}{|c|}{ Draft tube } & \multicolumn{2}{|c|}{$\begin{array}{c}\text { Total predited shear } \\
\text { injury }\end{array}$} & \multirow{2}{*}{$\begin{array}{l}\text { Live fish* } \\
\begin{array}{l}\text { Shear } \\
\text { injury* }\end{array}\end{array}$} \\
\hline Cases & Unit & $\mathrm{Q}(\mathrm{kcfs})$ & Pipe & $\begin{array}{c}\text { total } \\
\text { releases }\end{array}$ & $\begin{array}{l}\text { Minor } \\
\text { injury }\end{array}$ & $\begin{array}{l}\text { Major } \\
\text { injury }\end{array}$ & $\begin{array}{l}\text { Minor } \\
\text { injury }\end{array}$ & $\begin{array}{l}\text { Major } \\
\text { injury }\end{array}$ & $\begin{array}{l}\text { Minor } \\
\text { injury }\end{array}$ & $\begin{array}{l}\text { Major } \\
\text { injury }\end{array}$ & $\begin{array}{l}\text { Minor } \\
\text { injury }\end{array}$ & $\begin{array}{l}\text { Major } \\
\text { injury }\end{array}$ & $\begin{array}{l}\text { Minor } \\
\text { injury }\end{array}$ & $\begin{array}{l}\text { Major } \\
\text { injury }\end{array}$ & \\
\hline 1 & 8 & 9 & 10 & 46 & $0.0 \%$ & $0.0 \%$ & $0.2 \%$ & $0.1 \%$ & $7.3 \%$ & $2.8 \%$ & $0.0 \%$ & $0.0 \%$ & $7.6 \%$ & $2.9 \%$ & $1.10 \%$ \\
\hline 2 & 8 & 9 & 30 & 52 & $0.0 \%$ & $0.0 \%$ & $0.5 \%$ & $0.2 \%$ & $8.0 \%$ & $3.2 \%$ & $0.0 \%$ & $0.0 \%$ & $8.5 \%$ & $3.3 \%$ & $1.60 \%$ \\
\hline 3 & 8 & 11 & 10 & 44 & $0.0 \%$ & $0.0 \%$ & $0.4 \%$ & $0.1 \%$ & $4.6 \%$ & $2.0 \%$ & $0.0 \%$ & $0.0 \%$ & $5.0 \%$ & $2.1 \%$ & $1.10 \%$ \\
\hline 4 & 8 & 11 & 30 & 56 & $0.0 \%$ & $0.0 \%$ & $1.8 \%$ & $0.6 \%$ & $3.1 \%$ & $2.0 \%$ & $0.0 \%$ & $0.0 \%$ & $4.9 \%$ & $2.7 \%$ & $1.70 \%$ \\
\hline 5 & 8 & 15 & 10 & 44 & $0.4 \%$ & $0.1 \%$ & $0.0 \%$ & $0.0 \%$ & $2.4 \%$ & $0.8 \%$ & $0.0 \%$ & $0.0 \%$ & $2.8 \%$ & $0.9 \%$ & $0.50 \%$ \\
\hline 6 & 8 & 15 & 30 & 56 & $0.0 \%$ & $0.0 \%$ & $8.4 \%$ & $3.1 \%$ & $1.2 \%$ & $0.4 \%$ & $0.0 \%$ & $0.0 \%$ & $9.6 \%$ & $3.5 \%$ & $0.70 \%$ \\
\hline 7 & 8 & 17 & 10 & 44 & $0.0 \%$ & $0.0 \%$ & $0.3 \%$ & $0.1 \%$ & $3.9 \%$ & $1.3 \%$ & $0.3 \%$ & $0.3 \%$ & $4.5 \%$ & $1.6 \%$ & $1.10 \%$ \\
\hline 8 & 8 & 17 & 30 & 97 & $0.0 \%$ & $0.0 \%$ & $7.4 \%$ & $3.2 \%$ & $3.1 \%$ & $1.0 \%$ & $0.0 \%$ & $0.0 \%$ & $10.5 \%$ & $4.2 \%$ & $0.70 \%$ \\
\hline 9 & 8 & 18 & 10 & 45 & $0.0 \%$ & $0.0 \%$ & $0.9 \%$ & $0.3 \%$ & $2.1 \%$ & $0.7 \%$ & $0.3 \%$ & $0.3 \%$ & $3.3 \%$ & $1.1 \%$ & \\
\hline \multirow[t]{2}{*}{10} & 8 & 18 & 30 & 52 & $0.0 \%$ & $0.0 \%$ & $8.2 \%$ & $3.2 \%$ & $5.3 \%$ & $3.6 \%$ & $0.1 \%$ & $0.1 \%$ & $13.5 \%$ & $6.9 \%$ & \\
\hline & & All & & 536 & $0.0 \%$ & $0.0 \%$ & $3.4 \%$ & $1.4 \%$ & $4.0 \%$ & $1.7 \%$ & $0.1 \%$ & $0.1 \%$ & $7.5 \%$ & $3.1 \%$ & $1.06 \%$ \\
\hline 11 & 9 & 9 & 10 & 45 & $0.0 \%$ & $0.0 \%$ & $0.2 \%$ & $0.1 \%$ & $1.6 \%$ & $0.5 \%$ & $0.0 \%$ & $0.0 \%$ & $1.8 \%$ & $0.6 \%$ & $0.50 \%$ \\
\hline 12 & 9 & 9 & 30 & 43 & $0.0 \%$ & $0.0 \%$ & $0.4 \%$ & $0.2 \%$ & $12.9 \%$ & $7.7 \%$ & $0.0 \%$ & $0.0 \%$ & $13.3 \%$ & $7.9 \%$ & $0.90 \%$ \\
\hline 13 & 9 & 11 & 10 & 47 & $0.0 \%$ & $0.0 \%$ & $2.1 \%$ & $1.7 \%$ & $3.1 \%$ & $1.1 \%$ & $0.0 \%$ & $0.0 \%$ & $5.3 \%$ & $2.7 \%$ & $0.40 \%$ \\
\hline 14 & 9 & 11 & 30 & 44 & $0.0 \%$ & $0.0 \%$ & $3.4 \%$ & $1.1 \%$ & $8.0 \%$ & $4.1 \%$ & $0.0 \%$ & $0.0 \%$ & $11.4 \%$ & $5.2 \%$ & $1.10 \%$ \\
\hline 15 & 9 & 15 & 10 & 45 & $0.0 \%$ & $0.0 \%$ & $1.9 \%$ & $1.1 \%$ & $3.4 \%$ & $1.3 \%$ & $0.3 \%$ & $0.3 \%$ & $5.6 \%$ & $2.6 \%$ & $0.50 \%$ \\
\hline 16 & 9 & 15 & 30 & 43 & $0.0 \%$ & $0.0 \%$ & $7.6 \%$ & $3.2 \%$ & $3.2 \%$ & $1.7 \%$ & $0.0 \%$ & $0.0 \%$ & $10.8 \%$ & $4.9 \%$ & $1.30 \%$ \\
\hline 17 & 9 & 17 & 10 & 44 & $0.0 \%$ & $0.0 \%$ & $2.2 \%$ & $2.0 \%$ & $6.8 \%$ & $4.0 \%$ & $0.0 \%$ & $0.0 \%$ & $9.0 \%$ & $6.0 \%$ & $1.60 \%$ \\
\hline \multirow[t]{2}{*}{18} & 9 & 17 & 30 & 44 & $0.0 \%$ & $0.0 \%$ & $4.2 \%$ & $1.5 \%$ & $9.3 \%$ & $3.9 \%$ & $0.0 \%$ & $0.0 \%$ & $13.6 \%$ & $5.4 \%$ & $1.10 \%$ \\
\hline & & All & & 355 & $0.0 \%$ & $0.0 \%$ & $2.7 \%$ & $1.4 \%$ & $6.0 \%$ & $3.0 \%$ & $0.0 \%$ & $0.0 \%$ & $8.8 \%$ & $4.4 \%$ & $0.93 \%$ \\
\hline
\end{tabular}

